\title{
Cognitive Psychology in the Seminar Room
}

Helen Abadzi 
The following EDI Seminar Papers currently in print are available from the Economic Development Institute of the World Bank, $1818 \mathrm{H} \mathrm{St}$., N.W., Washington, D.C. 20433, attention: Ms. Edith Pena.

9 Sterility of Equilibrium Economics: An Aspect of Sociology of Science. V. Bhatt. 1974.

11 Some Aspects of Financial Policies and Central Banking in Developing Coun. tries. V. Bhatt. 1981.

16 Industrial Development Banks and Social Benefit-Cost Analysis. F. Helmers. 1979.

17 Decision Structure, Technological SelfReliance, and Public Enterprise Performance. V. Bhatt. 1980.

18 Cost-Benefit Analysis and Decision Making. F. Helmers. 1980.

19 Choice of Technology: The Case of the Indonesian Rice Mills. F. Helmers. 1980.

20 Some Aspects of Development Strategy and Policies. V. Bhatt. 1974.

21 Development Problem, Strategy, and Technology Choice: Sarvodaya and Socialist Approaches in India. V. Bhatt. 1979.

22 Project Evaluation Criteria and Technology Choice. V. Bhatt. 1981.

23 Theories of Development and Development Strategy. V. Bhatt. 1981.

.25 Price Distortions in Market Economies and Critical Comments. F. Helmers and A. Harberger. 1982.

27 What is the Value of a Lake? F. Helmers. 1984.

28 Institutional Framework and Public Enterprise Performance. V. Bhatt. 1984.
29 Asset Financing: Capital Equipment Leasing. J. Upper. 1984.

30 Investing in Education: A Quarter Century of World Bank Experience. S. Heyneman. 1985.

32 An Approach to Development Policy Analysis. Henry J. Bruton and Paul G. Clark. 1986.

33 The Search for School Effects in Developing Countries. 1966-1986. S. Heyneman.

35 Economies in the Provision of Facilities for Teaching Secondary School Science. R. Mundangepfupfu. 1986.

36 Uses of Examinations in Developing Countries: Selection, Research, and Education Sector Management.

S. Heyneman. 1987.

The following titles may be purchased from local distributors of World Bank publications (listed in the back of the book) or, if there is no distributor, from the Publication Sales Unit, World Bank, 1818 H Street, N.W., Washington, D.C. 20433.

37 User Charges for Health Care in Principle and Practice. Charles C. Griffin. 1988.

38 Rural Reform, Nonfarm Development and Rural Modernization in China. Dong Fureng. 1988.

39 Technological Development: The Historical Experience. Raymond Vernon. 1989.

40 Microeconomic Issues of Labor Markets in Developing Countries: Analysis and Policy Implications. Dipak Mazumdar. 1989.

41 Applications of Cognitive Science for Seminar Managers. Helen Abadzi. 1989. 
An EDI Seminar Paper No. $\bullet 41$

\title{
Coginitive Psychology in the Seminar Room
}

\author{
Helen Abadzi
}

The World Bank

Washington, D.C. 
Copyright $\odot 1990$

The International Bank for Reconstruction and Development / THE WORLD BANK

1818 H Street, N.W.

Washington, D.C. 20433, U.S.A.

All rights reserved

Manufactured in the United States of America

First printing February 1990

The Economic Development Institute (EDI) was established by the World Bank in 1955 to train officials concerned with development planning, policymaking, investment analysis, and project implementation in member developing countries. At present the substance of theEDI's work emphasizes macroeconomic and sectoral economic policy analysis. Through a variety of courses, seminars, and workshops, most of which are given overseas in cooperation with local institutions, the EDI seeks to sharpen analytical skills used in policy analysis and to broaden understanding of the experience of individual countries with economic development. Although the EDI's publications are designed to support its training activities, many are of interest to a much broader audience. EDI materials, including any findings, interpretations, and conclusions, are entirely those of the authors and should not be attributed in any manner to the World Bank, to its affiliated organizations, or to members of its Board of Executive Directors or the countries they represent.

Because of the informality of this series and to make the publication available with the least possible delay, the typescript has not been prepared and edited as fully as would be the case with a more formal document, and the World Bank accepts no responsibility for errors.

The material in this publication is capyrighted. Requests for permission to reproduce portions of it should be sent to Director, Publications Department, at the address shown in the copyright notice above. The World Bank encourages dissemination of its work and will normally give permission promptly and, when the reproduction is for noncommercial purposes, without asking a fee. Permission to photocopy portions for classroom use is not required, though notification of such use having been made will be appreciated.

The backlist of publications by the World Bank is shown in the annual Index of Publications, which is available from Publications Sales Unit, The World Bank, 1818 H Street, N.W., Washington, D.C. 20433, U.S.A., or from Publications, Banque mondiale, 66, avenue d'Iéna, 75116 Paris, France.

At the time of writing Helen Abadzi was an educational psychologist in the Studies and Training Design Division, Economic Development Institute, the World Bank.

\section{Library of Congress Cataloging-in-Publication Data}

Abadzi, Helen, 1951-

Cognitive psychology in the seminar room / Helen Abadzi.

p. cm. -- (An EDI seminar paper; no. 41)

Includes bibliographical references.

ISBN 0-8213-1333-9

1. Learning, Psychology of. 2. Knowledge, Theory of. 3. Memory.

4. Cognition--Study and teaching. I. Title. II. Series: EDI

seminar paper (Washington, D.C. : 1988) ; no. 41.

LB1060.A23 1990

$370.152--\mathrm{dc} 20$

$89-24782$

CIP 


\section{Contents}

Abstract 1

Seminar Adventures 3

1. In the Beginning Was the Brain 5

2. How Knowledge Is Represented in the Human Mind

How People Learn, Remember, and Forget 6

Sensory Memory for Initial Information Screening 6

Attention: Focusing on the Important 9

What Factors Influence the Ability to Pay Attention? 12

Back to the Seminar Room 13

Storage: Turning Sensations into Memories 13

The Structure of Memory: Boxes in the Head 13

Short-Term Memory for Temporary Use 14

Long-Term Memory: The Largest File Cabinet of Unknown Location in the World 14

How Memories Are Retrieved 18

Levels of Processing: Shallow and Deep Memories $\quad 18$

Distinctiveness of Memories Helps Later Recall 20

How to Present Information So That People Will Remember It

\section{From Memories to Thoughts 27}

The Reconstructive Work of Memory 27

Forgetting: Where Have All the Memories Gone?

Transferring Seminar Knowledge the Real World

27

Blind Training Begets Inert Knowledge 30

Problem Solving, Reasoning, and Decisionmaking $\quad 31$

How Does Culture Influence Cognition? 32

A Look at the Field of Adult Education $\quad 32$

\section{Beyond Individual Cognition 33}

People in a Group $\quad 33$

Participants are Not Always of Like Minds $\quad 33$

5. Back to the Seminar Room: Applying the Rules of Cognition

Seminar Objectives: For What Purposes? 34

Open Sesame: Advance Organizers to Open Schemata 34

Cognitive Strategies: Tools for Etching Meaning in Memory

Common Seminar Presentation Methods and Their Cognitive Eef

6. In a Nutshell: What Improvements Are Feasible? $\quad 37$

Is Material Presented in a Memorable Way? 37

Is Material Packaged for Transfer to the Work Environment? 38

Do Participants Support Seminar Planning and Execution? 


\section{Annexes}

A. Cognitive Psychology Research Techniques 40

B. Physiological Bases of Learning 44

C. Differences between Younger and Older Adults Which Affect Learning

D. Cognitive Structure of Learning 52

E. Methods of Facilitating Learning 61

F. Deep and Shallow Elaboration: Back to Bloom's Taxonomy 68

G. Higher Cognitive Processes 70

H. How Adults Learn 76

I. Social Factors That Influence Seminar Participants 81

J. People's Beliefs and Attitude Change 83

Glossary $\quad 88$

References 90 


\begin{abstract}
How can a trainer organize a seminar to increase the chances that participants will retain the material presented and use it in their work?

Cognitive research provides some answers. All long-term knowledge is sorted into lengthy, intricate networks on the basis of its meaning. Information coming in must be analyzed and inserted in new slots under multiple existing categories. If the information is meaningless (for example, a discussion in an unknown foreign language), it is unlikely that it will find slots and, therefore, be remembered. Knowledge classified under a particular section of the mind's networks is not readily accessible from other sections. A person looking for answers to problems, therefore, may not use information she or he has. To be accessible, information must be learned along with its potential uses so that connections between different sections of networks can be established.

What techniques make information memorable and accessible in the long run? Since participants must restructure the information and attach it to many sections of their networks in order to retain it, the most memorable information is (a) welloutlined; (b) in plain language; (c) connected with as many concepts as possible through comparison, contrast, applications, analogies, and so on; (d) elaborated, that is, taken apart and put together by the participants themselves through analysis, synthesis, and evaluation; and (e) connected explicitly with reasons why and occasions when it should be used. To achieve the above, trainers should

- respect the limitations of human attention and present varied stimuli of intermediate complexity to educated adults;

- use outlines during presentations to facilitate organization of knowledge;

- create specific occasions to allow participants to elaborate the information;

- determine which information should be remembered in the long run (that is, in two years) and provide activities to make it memorable;

- spend as much time developing why and when to use certain procedures as they spend on how to use them;

- avoid extensive readings that will interfere with top priority information and thus make it less memorable;

- avoid one-shot sessions on important topics, which do not elaborate information sufficiently.
\end{abstract}





\section{Seminar Adventures}

As manager of a week-long seminar to stress the importance of educational planning, you have invited 25 senior-level officials from Middle Eastern countries to Athens. The contents of the seminar have been planned in detail, lengthy materials have been produced, and well-known consultants have been hired to conduct sessions that will include lectures, group discussion, and a case study. As usual, the backgrounds and objectives of the participants vary. Some are specialists who could direct sessions themselves; others are political appointees with little knowledge of the subject. While many are interested in the topics presented, others are more interested in the Acropolis. During the seminar, you wonder whether participants are absorbing everything you want them to aborb. As each session unfolds and lectures or group presentations start, participants face the speakers attentively. Twenty minutes later, half of them fidget, doodle, read materials, or look out the window. Attention perks up again during discussion time, before people trot off to the coffee service. Night outings in Plaka successfully compete with the recommended study of volumes of carefully prepared, scholarly materials. By the end of the US $\$ 100,000$ seminar, participants have become acquainted with each other, have exchanged views on important problems, have listened to experts, have evaluated the seminar positively, and have accumulated seminar materials for future reference. But have they acquired information or made decisions that will change their professional behavior? How will they synthesize two years from now the words of wisdom they heard in the seminar?

People presumably attend because they feel to some extent deficient in an area of knowledge or in its applications. Accordingly, your task is to organize a seminar that will (a) give participants knowledge that will stay with them in the long run and (b) motivate them to use that knowledge in their work. But, like many managers, you are dissatisfied with the educational methodology available to disseminate the necessary information and its applicability. The wisdom that should flow through participants to their work environments appears blocked to a considerable extent, partly because

- seminar participants are adults, often highly placed, who are free to learn or not to learn; indeed, some may believe they have nothing more to learn;

- a large volume of important information is presented either in some form of a lecture or in recommended after-hours readings (Farrell 1986), and much of that is soon forgotten; unless recalled frequently, memories of that information are probably vague two years later;

- mere information is usually not enough to change well-entrenched professional behaviors; people may find what they hear interesting but do not modify their work accordingly.

You may have given considerable thought to making seminars meet development objectives. You may have used case studies, policy discussions, country presentations, and variously encouraged participation to make seminars more interesting, creative, and relevant. To motivate adults to participate, however, is a complex process in which you control very few variables. Which method(s) will best suit your purposes?

Several publications exist that give good advice on what to do and which methods to use (for example, Youker and Dowsett 1983). But many of us who have read lists 
of dos and don'ts find it difficult to use them because we do not know when they should be used or why they should be useful in the first place. As you will see further on, the fact that dos and don'ts are often disjointed items makes us likely to forget them.

This work aims to strengthen the considerable practical wisdom of trainers by offering insight on how the mind handles knowledge (as understood in 1988) and on why particular methods affect the thinking of participants differently. This insight should help the reader prepare seminars that pay attention to the rules of human cognition and increase the amount of information that will be integrated in the participants' minds for long-term use. To suit various interests, a brief text is supplemented by a series of detailed annexes. As you read, reflect on the extent to which research findings are verified by your own experience. 


\section{In the Beginning Was the Brain}

The learning readiness of the brain can be illustrated as an empty document created by a very sophisticated word processor of the 21st century. Heredity hardwires many brain functions, possibly creating before birth fixed pathways that carry messages from one part to another (Squire 1986). Hard-wired functions include easy language acquisition for children, depth perception, distinction between figures and background, and the attention process. Heredity also gives the brain exceedingly plastic architecture; to a considerable extent, it can change and adapt on demand. Nerve pathways can be formed to detour damaged areas, enabling determined 60-year-olds to recover from strokes (Chall and Peterson 1986).

New nerve pathways are also formed in response to enriching environmental experiences. The consequences of learning make an impact on the weight of the brain and on the anatomy of rats that are experimentally raised in "rich," stimulating environments of treadmills and mazes. These rats develop longer and multiply connected nerves in the cerebral cortex, where most thinking is presumed to take place, in comparison with "poor" rats who are brought up in small cages (Rosenzweig 1970). In the final analysis, learning might constitute development of longer nerves with more connections to other nerves. Furthermore, specific learning may form characteristic patterns of brain pathways (Campbell and Spear 1972); as a result, the brain of an economist may become structurally somewhat different from the brain of a neurosurgeon. All in all, the consequences of learning are apparently cumulative and anatomically identifiable on the brain (see more in annex 1).

For the moment, we only know some commands of the brain word processor and very little of the structure of the word-processing program itself or of the machine language it uses. Unable to experiment with human brains as is possible with rats, psychologists can infer the commands and the structure of the word processor only by studying the layout of the document it creates, the thinking mind. This study is the object of cognitive psychology. 


\section{How Knowledge Is Represented in the Human Mind}

Cognitive psychology investigates how we organize in our minds information about the world and how we use it to think, usually through hundreds of complicated and often ingenious experiments (annex A). Cognitive psychology is searching for answers, among other topics, on

- how knowledge is registered in the mind: how people perceive, learn, remember, and forget;

- how people use the knowledge they have acquired: to what extent the learning of one skill transfers to another; how people think, reason, and solve problems.

As a result of work that has been carried out for the last 100 years, a significant body of evolving but educationally useful knowledge exists, whose essentials will be explained below. Cognitive research findings have confirmed many insights of good teachers. But even the best have generally underestimated two very important conclusions of cognitive research:

- meaningfulness to the receiver and organization in the person's mind are indispensable for the retention and recall of knowledge;

- if, along with the knowledge, people learn what it can be used for, they are much more likely to use it in "real life."

Before you continue, take a few minutes to study the two concept maps that outline the functions of memory (figures 1 and 2).

\section{How People Learn, Remember, and Forget}

Memory makes people who they are. Without memories no one would have the continuity that is necessary to the concept of self. Even though many memories become inaccessible, enough remain throughout our lives so that we continue to identify with our younger selves of 10 or 70 years ago.

As learning takes place, information from eyes, ears, and other sensory organs is screened by the brain. If accepted, information is encoded in a way that the brain understands. It may then be stored in memory for later retrieval, during which it is brought out of storage for use. The processing of information involves several transformations, and the end result (for example, an event recalled 20 years after it happened) may have little resemblance to objective data.

In order for the learning process to occur, a person must first perceive (sounds, pictures, smells) and then pay attention to what is perceived. To import information, the brain uses the following techniques: sensory memory for initial information screening and attention.

\section{Sensory Memory for Initial Information Screening}

We think that the world flows smoothly around us, but in the split-second timespan, this is an illusion. The brain registers in small bursts what our senses perceive, in order to examine the vitility of the percepts somewhat coherently. A 
Figure 1: A concept map outlining the basics of cognitive psychology

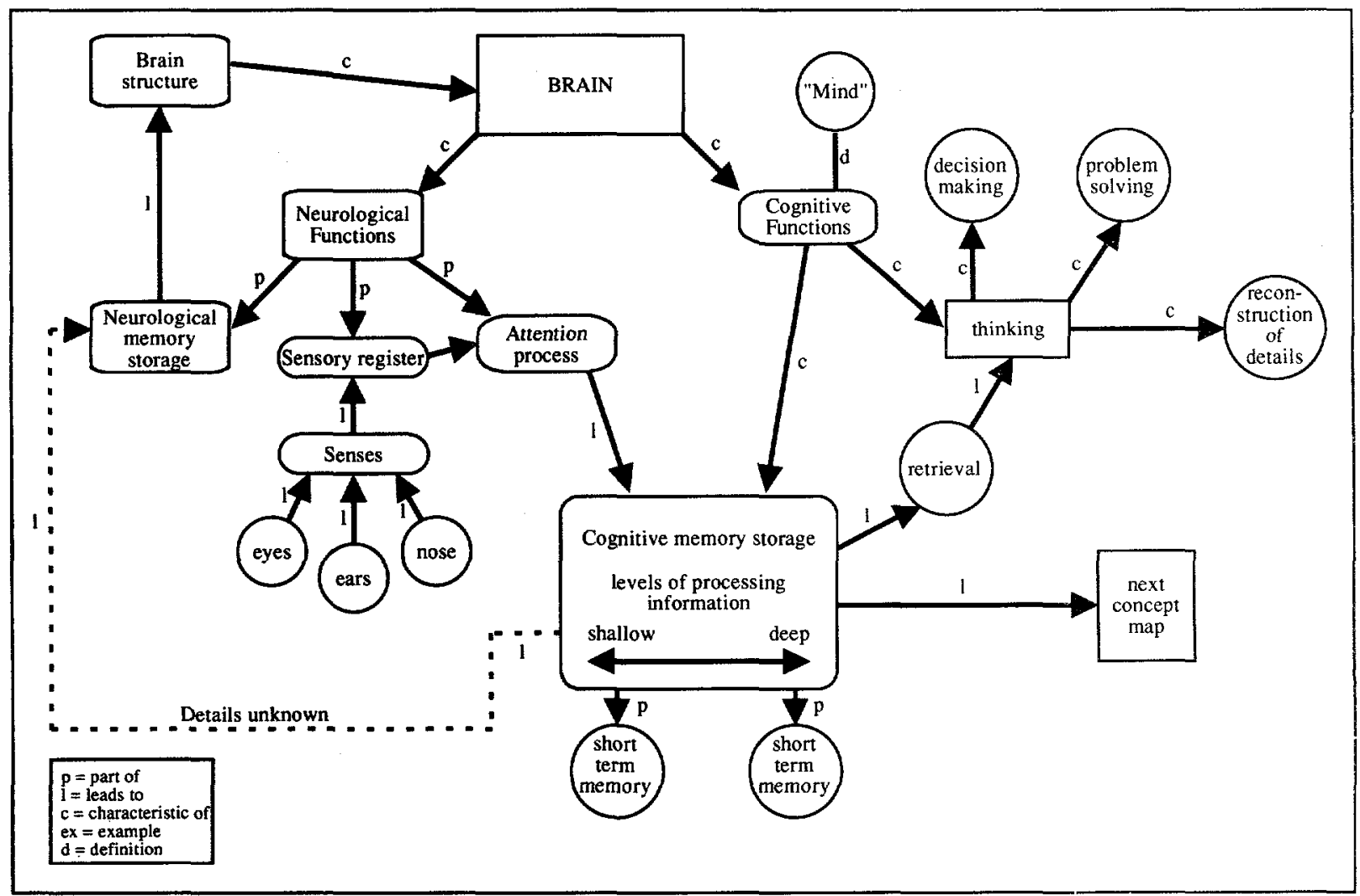

$\mathrm{kst} / \mathrm{w} 45818 \mathrm{a}$ 
Figure 2: Concept map outlining how the memory works

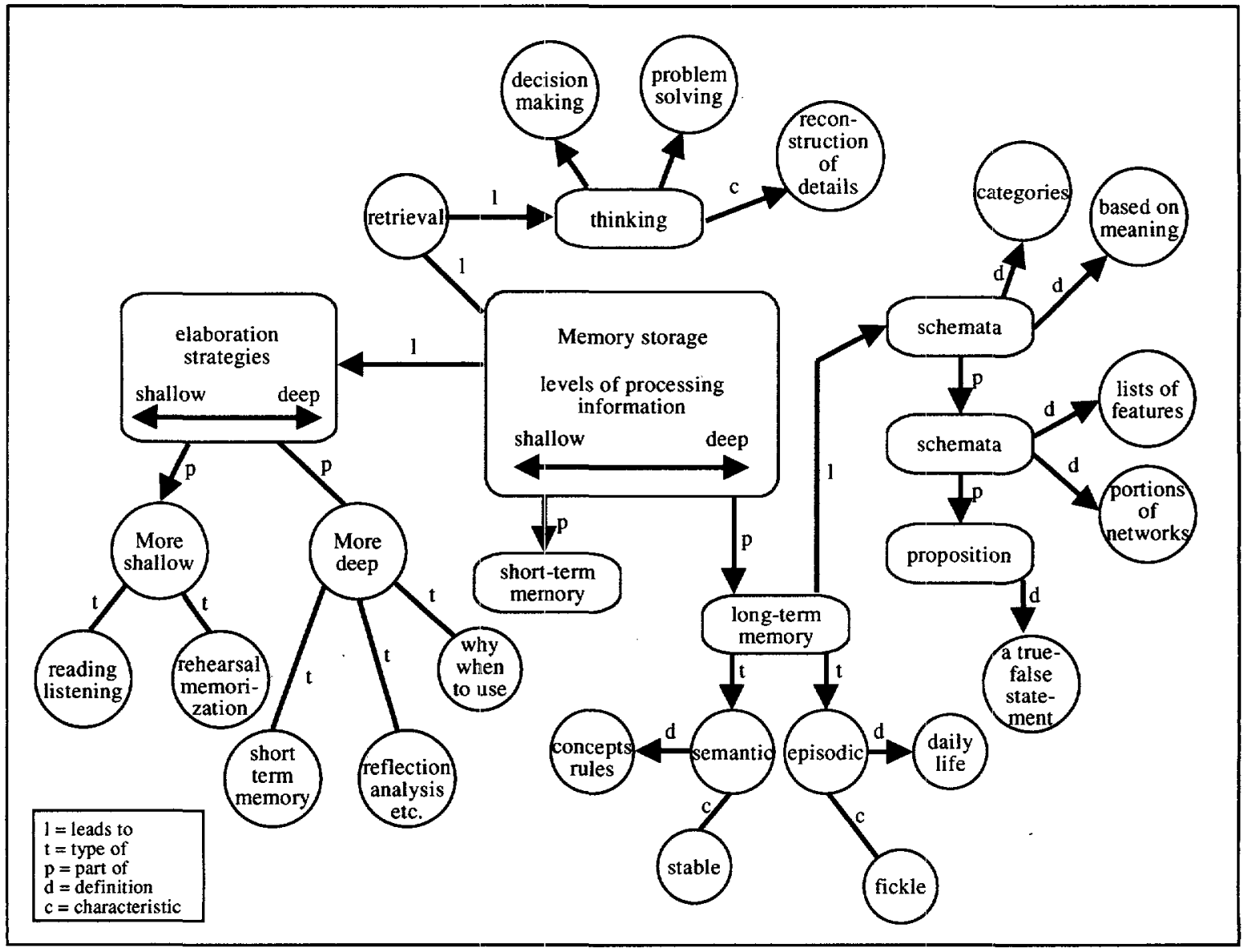

$\mathrm{ksr} / \mathrm{w} 45818 \mathrm{~b}$ 
sensory register briefly stores the material. Therefore, if we close our eyes for a split second we continue to see the world (Solso 1988). Memories stored in the register (whether visual, auditory, gustatory, tactile, or olfactory) are perfect but remain perfect for only 250 milliseconds to 4 seconds (annex A). If the information does not receive attention at that moment, it is lost because another small chunk takes its place. If attention is given, the brain extracts cogent features (for example, words of a book) from the stimulus and discards the unimportant information (for example, the color of the paper). The sensory register can only take in a finite number of stimuli per unit of time, and thereby limits the amount and speed of information that can be processed. If we find ourselves in a situation where things happen too fast, we may see everything but have the time to make sense out of very little. The development of this very brief memory store, however, may have been an essential component in man's evolution; it allows us to perceive everything coherently and yet attend to only the essential components of our percepts, making for the most economical system evolved (Solso 1988). Our ability to read may be based on this mechanism.

\section{Attention: Focusing on the Important}

You are at a cocktail party. You are listening to your boss, who is telling you a story about his children, when you suddenly hear your name mentioned in a nearby conversation. While you are smiling and nodding at your boss, you are listening attentively over the din to the other conversation, which interests you greatly although you mostly hear disjointed words. At the end of the party, you have a vague idea of what your boss was talking about but you can recall quite well what was being said about you across the room (Cherry 1953). Why? Because

- The brain focuses on the most striking stimulus. Attention has been studied widely in people and animals because the electricity it generates in the brain can be measured, though roughly, through psychophysiological instruments using an electroencephalograph (EEG) (Thompson, 1975; Picton and others 1986). When a person connected to an EEG machine first pays attention to a light or a click, the machine orients itself towards that light or click, and the EEG registers a large electrical spike (figure 3). It is difficult, however, to continue getting a large spike to the same light or sound; only Zen monks in meditation have been found to do it (Kasamatsu and Hirai 1966). Subsequent spikes get smaller and smaller as the person's attention begins to wander off to other noises or sounds. The brain, which receives a myriad of potentially important stimuli, must pay attention only to the most pressing ones and shut out the rest. (For example, what is your left big toe feeling now?) Similarly, the monotonous voice of lecturers is a stimulus that eventually gets left unattended as other matters (hunger, personal worries, muscle fatigue) are judged more important by the organism. Novel and changing stimuli on the other hand, such as audiovisual presentations, repeatedly trigger the brain's attention mechanism (Thompson 1975). An observer, therefore, can reasonably infer which listeners are inattentive from blank stares, doodling, looking out of the window, fidgeting, and a general lack of orientation towards the direction of the stimulus (Farrell 1986).

- The brain maintains attention when stimuli have meaning. The distinctness of stimuli attracts attention but does not maintain it for long. Studies of people listening through earphones to two different messages 
Important messages do attract our attention even in the din of a party.

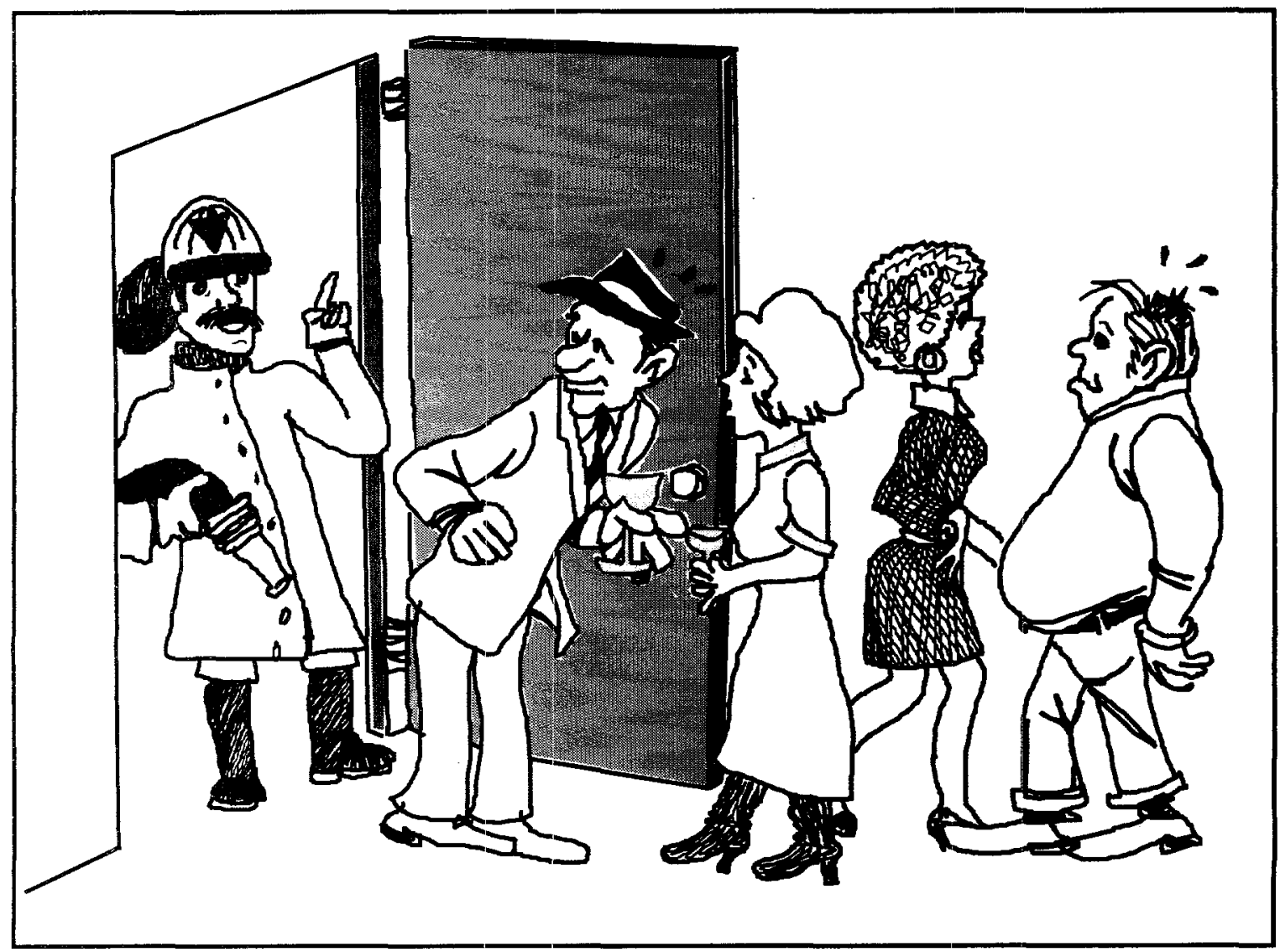

Adapted from Wingfield (1981)

kst/w44303e 
Figure 3: Evoked potentials: Voltage spikes in the brain when attention is attracted

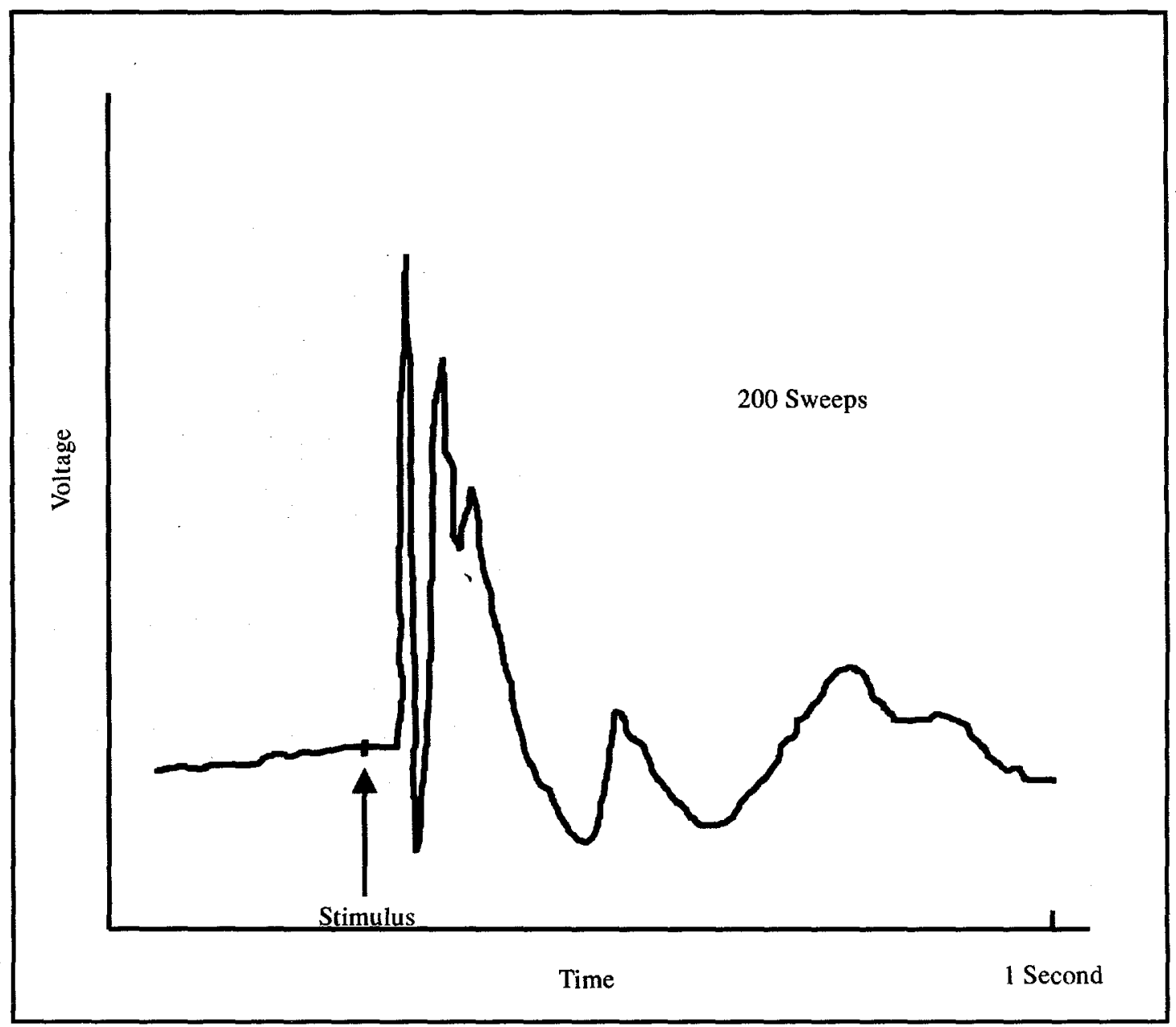

Adapted from Fox and O'Brien (1965)

kss/w44303L 
showed that the brain preliminarily evaluates the meaning of input and determines what is worthy of attention. If a seminar participant stops paying attention for a while, she or he may lose the speaker's train of reasoning. When she or he starts paying attention again, the message may not make sense any longer and will be more likely to get left unattended again unless the speaker does something unusual. Attention often wanders momentarily, but people can make sense out of a message if they have not missed a great deal. One reason is that the brain can tune out one message in order to listen to another but it can also retain information coming through an unattended channel if it is important enough (Treisman 1964). By switching attention between channels of information, people can extract meaning and make some sense out of simultaneous events in the environment. Moreover, adults, infants, and rats will give their most persistent attention to stimuli of average complexity for them (Simon 1986). If stimuli are too simple, they are considered inconsequential and are ignored; if they are too complex, they are found incomprehensible and are again ignored.

- There is limited attention to go around at any given moment. Except for a few very unusual people, most of us cannot do a number of mental tasks in parallel (for example, repeat a poem while counting backwards; Solso 1988). Specific brain mechanisms make it nearly impossible. Since organisms can react to only a few stimuli at a time, they limit the amount of sensory input they can process at a given moment in order to carry out what they must (Thompson 1975). As a result, people have a finite capacity to pay attention (Wingfield and Byrnes 1981), and, like mainframe computers, they timeshare it, allocating most resources to the most significant stimuli but also some to secondary inputs. Simple or well-learned tasks require few resources and allow other tasks to take place simultaneously (for example, driving and chatting). Complex calculations take up all attentional resources and if attention is divided to a child making noise, errors result (Eagle and Ortoff 1967). All in all, limited resources create major bottlenecks in our acquisition and maintenance of information.

\section{What Factors Influence the Ability to Pay Attention?}

Biochemical factors, like the presence of certain substances in the brain, influence attention (annex B), as do malnutrition and certain drugs (Klein and Lasky 1982). Aging somehow reduces the resources people can marshall and makes them less able to switch rapidly from one information channel to another (annex C). Anxiety is detrimental to learning because it diverts people's attention from external stimuli to their own thoughts (Smith and others 1982; Snow 1986). The amount of time one can pay attention is trainable to some extent (Posner and Friedrich 1986), as research on meditators shows (Kasamatsu and Hirai 1966), but this area has not been studied extensively. It is not certain that education actually trains attention. Educated people seem to remain attentive longer, but this may be partly a result of their accumulated knowledge, which makes many stimuli meaningful and, therefore, worthy of attention. Moreover, the people most likely to benefit from education may be the people with the largest attentional resources in the first place; children with learning difficulties are less able to focus attention than others (Simon 1986). 


\section{Back to the Seminar Room}

The brain allocates resources for paying attention after it determines how significant a stimulus is. The importance of attracting and keeping attention through interesting and varied materials has been empirically understood by teachers of children, and the use of such materials is widespread (Slavin 1986). But the tolerance of educated adults for monotony is probably overestimated. Data (Farrell 1986) show that 77 percent and 33 percent of participants were, on the average, attentive in two World Bank Economic Development Institute (EDI) seminars, one considered successful and another not as much. Attention wandered after 20 to 30 minutes of lecturing, but rose again after discussions started. Up to 75 percent seemed to tune out if the presentation involved well-known material. On another occasion, empirical data recorded by two World Bank staff members showed that their own attention wandered briefly every 10 to 20 seconds during a particularly boring lecture!

Maintaining attention-since no learning takes place without it-is the first of many reasons why training effectiveness increases through use of the following techniques:

- questions to the audience (either rhetorical to evoke an unspoken answer or actual, where a respondent is identified after the question is asked);

- examples, stories, personal references;

- some movement in the room, audiovisual aids;

- displayed outlines to direct participants' attention and to orient late comers;

- presentation speed that does not overload the screening of information by the memory buffer;

- avoidance of well known material that tunes people out, except as a brief lead-in to new material.

These well-understood principles are not always applied. Extensive lecturing takes place even in high-level conferences (such as the senior policy seminars of EDI) (Farrell 1986). It appears that seminar managers need to turn their own attention to keeping participants attentive during presentations.

\section{Storage: Turning Sensations into Memories}

Many pieces are still missing from the puzzle of how knowledge is prepared for storage. Existing data support two partly overlapping theories: (a) memory consists of two "boxes" for short- and long-term storage (duplex theory by Atkinson and Schiffrin 1968), and (b) the boxes are really stages of a continuum that can process information from a superficial, easily forgotten level to a very deep, meaningful, and never-forgotten level (levels-of-processing theory, Craik and Lockhart 1972). Both theories are useful in predicting and explaining learning processes, and will be discussed below.

\section{The Structure of Memory: Boxes in the Head}

Our daily lives are carried out in our short-term memory, but the repository of knowledge that gives meaning to our immediate existence resides in the long-term memory (Solso 1988). 


\section{Short-Term Memory for Temporary Use}

This is one more sifting mechanism (after the sensory register and the attention process) designed to cut down on the amount of information stored. Short-term memory gives people a chance to use small bits of information so that they can decide if they want to keep it. Short-term memory is very brief, lasting 3 to 20 seconds, for example, long enough to look up a phone number and dial it (Krech and others 1982). After that, the information is either deemed important and transferred into long-term memory or is forgotten (figure 4). Candidates for short-term oblivion are unrelated items such as digits of a phone number, the contents of a grocery list, thoughts, and small events of no long-term significance (for example, the amount of change when buying something). This memory store has slots for about seven items or categories of similar items, usually remembered by their sound. When people want to remember this information longer than the 20 seconds, they repeat it until they either no longer need it or have processed it into long-term memory. If this repetition is interrupted before the long-term memory takes it in, the information is lost (Solso 1988; see annex B for neurological evidence). According to the duplex theory, therefore, rehearsal is all that is needed to remember information permanently.

Most, if not all information that has been attended to is thought to pass through short-term memory on its way to permanence or oblivion. This mechanism is the most important system for doing the work of memory (Krech and others 1982). Limitations on how much the short-term memory can retain affect performance in

a wide variety of tasks, many of which are used to measure intelligence. To make sense out of information, one must be able to remember facts, statistics, or relationships long enough to put them together.

\section{Long-Term Memory: The Largest File Cabinet of Unknown Location in the World}

Even though we do not know where in the brain the depository of memories is located, its capacity appears to be almost infinite. To keep track of this volume, nature has chosen to encode and store information according to its meaning. Possibly, the brain comes into the world hard-wired for categorization and meaningful organization of the information it receives; preschoolers and even very young infants have been found to sort new information into categories (Denney 1972). At this last stage, information is pared down further and its meaning rather than the redundant, exact wording is preserved. Therefore, if you memorize a list of words containing "bough" and make an error in recalling that word several days later, you are more likely to report "branch" (a semantic error) rather than "plow" (an acoustic error) or "rough" (a visual error) (Krech and others 1982).

Cognitive networks: drawers of long-term storage. Everything a person knows is classified into intricate, interconnected networks that form superordinate and subordinate categories (see figure 5) (Collins and Quillian 1969). Categories end in lists of features for objects and concepts. Sections of networks are called schemata, a frequently used term (annex D). If a person is an expert in economics, schemata for that domain are very detailed and have a lot of ramifications. They are also structured differently from the sketchier, less detailed schemata of a layman 
Short-term memory has very limited capacity.

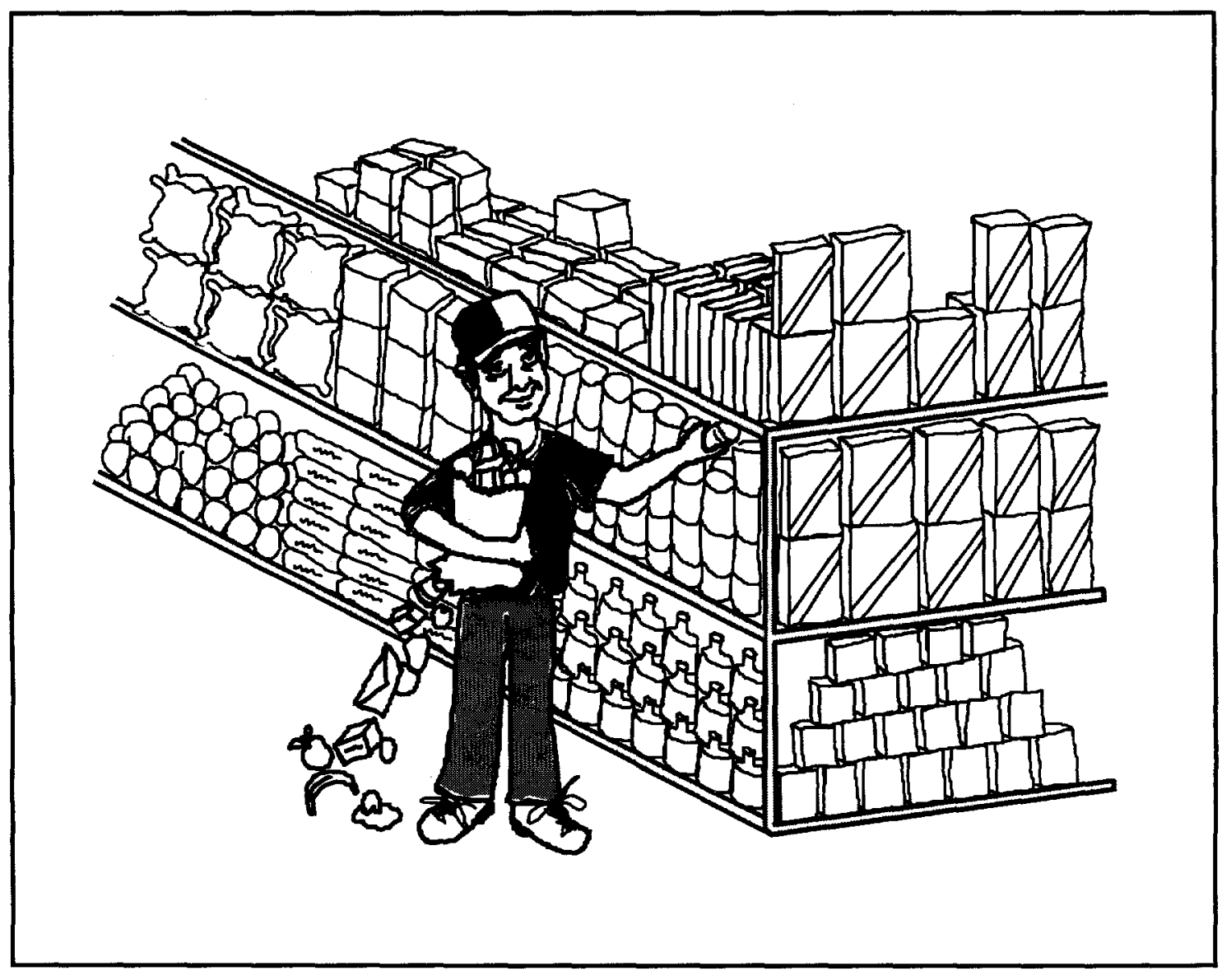

Adapted from Wingfield (1981)

ksr'w44303c 
Figure 4: A hypothesis of how short-term memory works

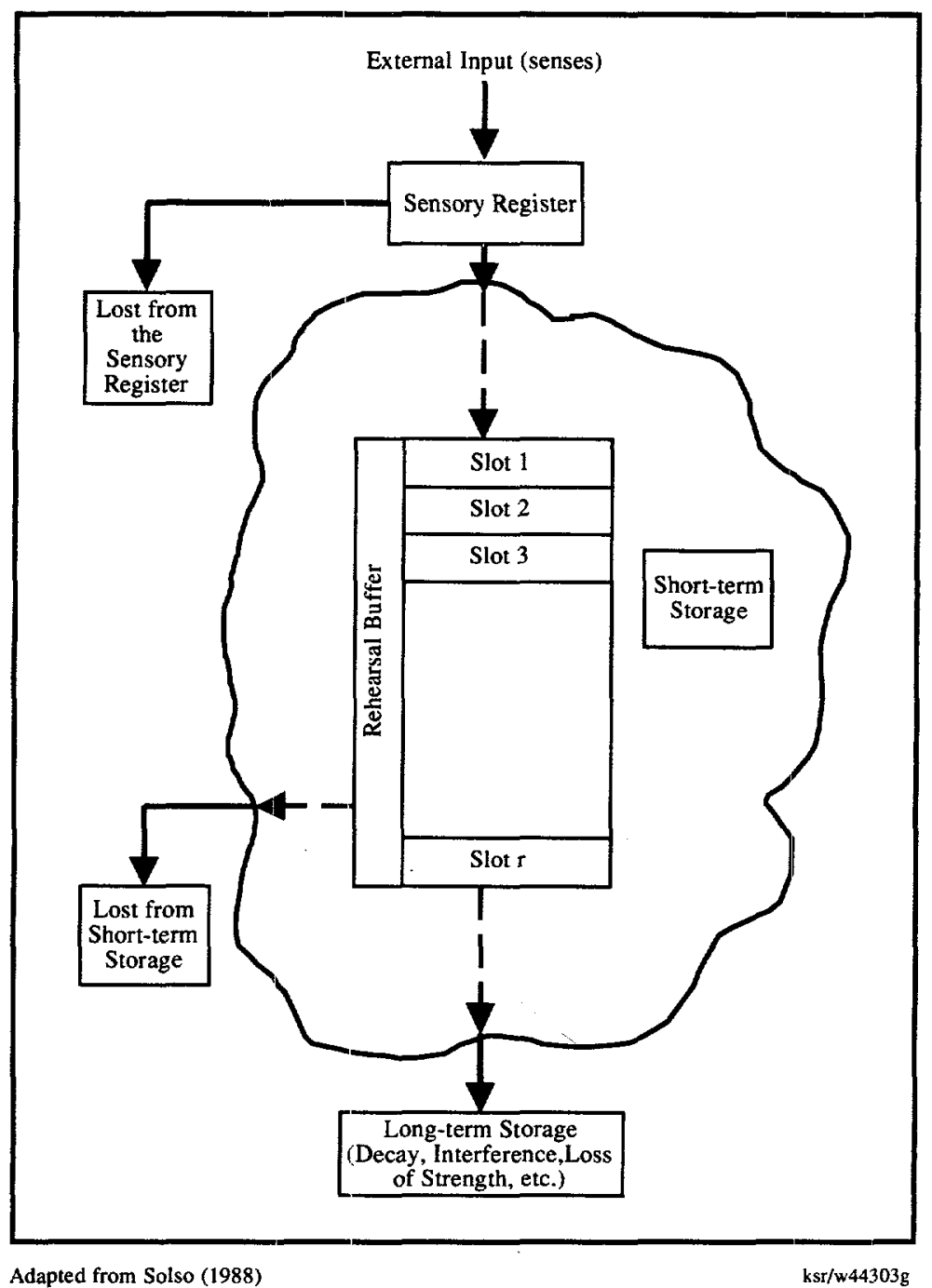


Figure 5: Categories in long-term memory

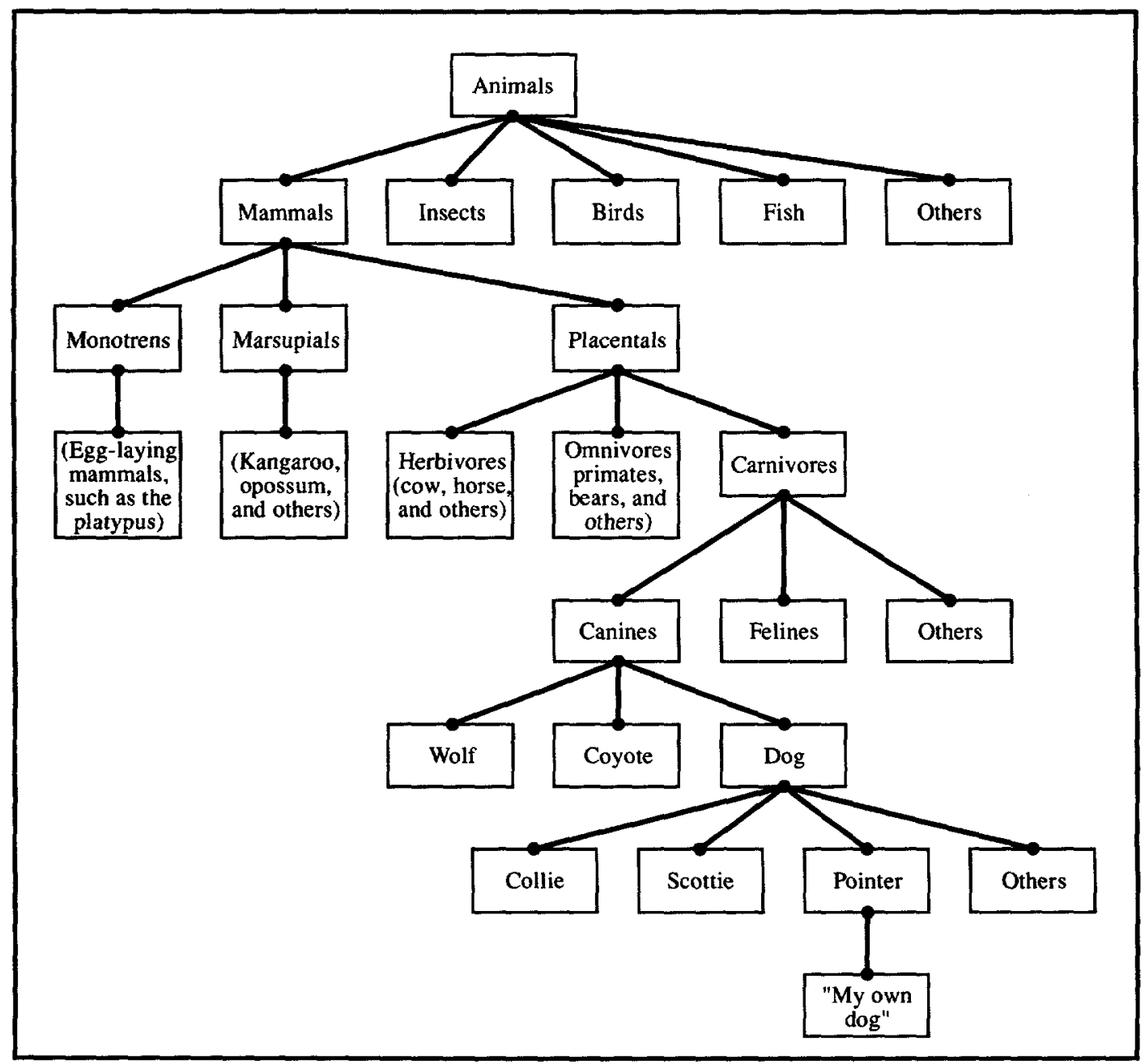


(Dansereau 1987; Carey 1986). The structure of networks can be changed. When a person learns more about a topic, previous knowledge is rearranged to accommodate new information and insights (Bransford and others 1986). When an item finds a category to get attached to, people "understand." When a person knows a lot about a domain, incoming items may fill in slots already created but empty, and are "interesting." But when material cannot find intricately structured categories to fit into, it is "boring" or "incomprehensible." The cumulative effect of many networks interconnected produces "insight" and "wisdom."

\section{How Memories Are Retrieved}

To store an item of information, the mind attaches it to one or more of the schemata with similar content. To retrieve an item, the mind searches through likely networks to find a category that has that item attached to it, somewhat like searching for a piece of paper in a huge file cabinet. Effective retrieval, therefore, is only as good as initial classification. If an item is stored in schemata that are not directly connected with the schemata of a problem a person is trying to solve, that item will not be easily retrievable when a solution is sought, and the knowledge will remain inert.

Information is usually stored under multiple headings that also include images (Paivio 1971; figure 6). People may be unable to retrieve a name, for example, but may remember quite a bit about it: that it is long, Polish, starts with an $M$, and is connected to a certain face (tip-of-the-tongue phenomenon). It is possible that information once stored is rarely forgotten (Smith and others 1982). Instead, its traces somehow decay, and its location in the networks is lost. During brain surgery on conscious patients, electrical stimulation may bring up misplaced, long-lost memories (annex B).

Memory for events (episodic memory) works somewhat differently than memory for concepts and rules (semantic memory). Events are stored in longterm memory on the basis of their relationships to each other in time and space. Similar, repeated events such as the contents of your lunch two weeks ago, are easily forgotten (Tulving 1972), but unique events, such as the contents of a lunch that caused food poisoning, are much more durable. Concepts, on the other hand, are organized in the abstract intricate relationships described above and are less easily forgotten once formed, but individual information items are prone to oblivion. Seminar participants will easily remember episodes of the seminar days but remember less easily the information that is synthesized into new or changed concepts. The challenge of successful seminars is to overcome this difficulty and to bring about durable changes in the participants' knowledge about certain concepts and rules.

\section{Levels of Processing: Shallow and Deep Memories}

The workings of short- and long-term memory are well established. But contrary to postulates of the duplex theory, mere rehearsal of material without analysis and rearrangement has been found insufficient for committing material to long-term memory (Craik and Watkins 1973). A complementary theory posits that short- and long-term memory are not isolated boxes. They are, instead, stages in a continuum, and what we remember depends on how thoroughly we analyze the 
Figure 6: An item is stored in many schemata

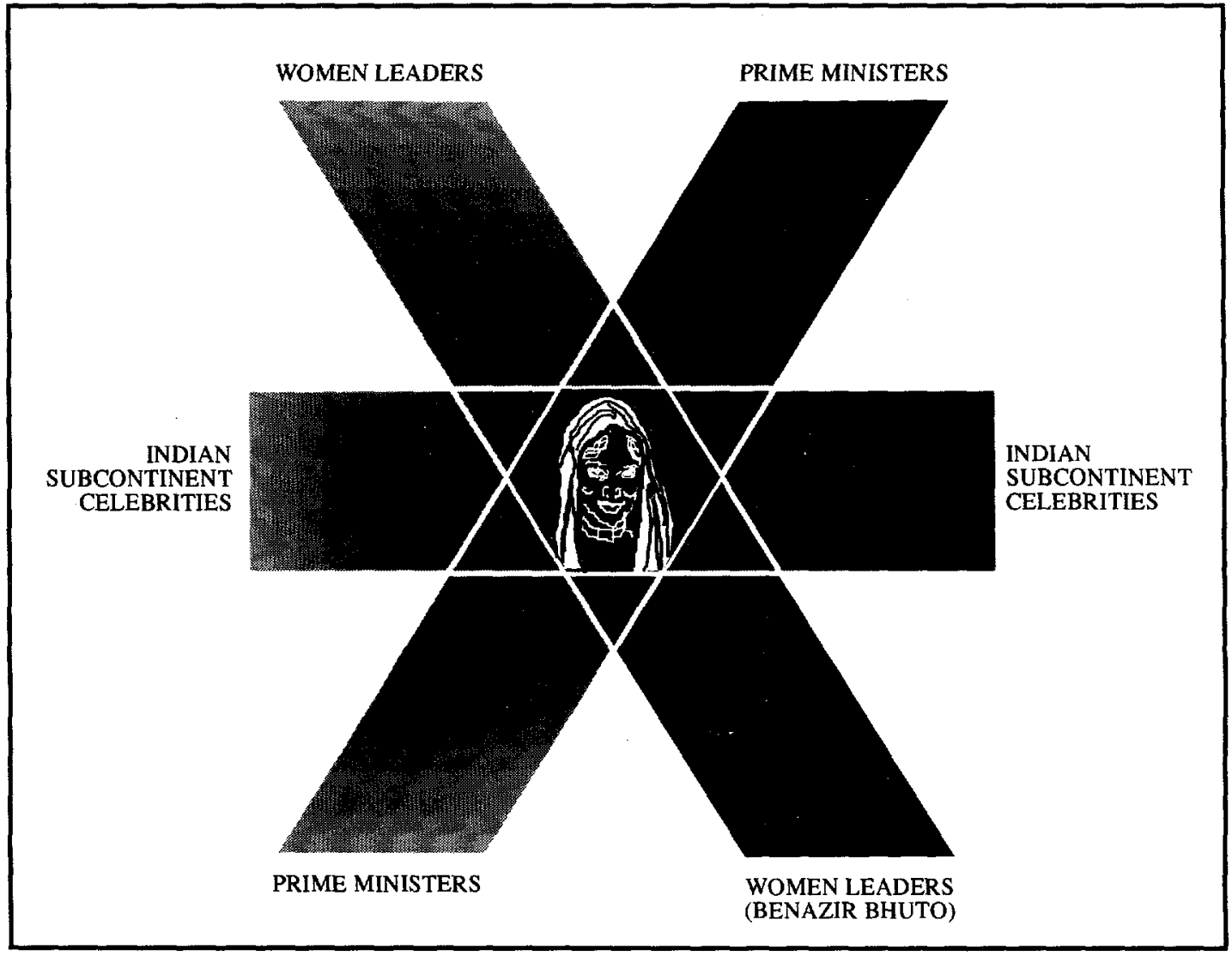


information we receive from the environment (Wingfield and Byrnes 1981; figures 7 and 8). Therefore, merely repeated information is superficially processed and easily forgotten (like telephone numbers) because no meaningful connections are made with preexisting knowledge. But information whose meaning has been extensively and "deeply" analyzed and connected to many existing schemata, is virtually guaranteed to be remembered. The more elaborate and analytical the processing, the stronger are the traces etched when a memory is attached to the cognitive networks of long-term memory (Wingfield and Byrnes 1981). Depth is still ambiguously defined, but the following levels have been identified for learning unknown words (Craik and Tulving 1975; Rogers and others 1977; figure 7) and can serve as a guideline:

- Structural features: size of letters on a page, what word comes before and after. This is the level of the most superficial processing.

- Phonemic features: verbatim memorization, what a word rhymes with. This level is still superficial. Meaningful prose is retained better than rhyming poetry (Guilford 1939; Morris, Bransford, and Franks 1977; figure 9).

- Semantic features: synonyms, antonyms, analogies, similes, meaning of a word in a sentence. This is a level of deep processing, attaching the meaning of the word to many schemata.

- Self-reference: whether a word has a relationship to the individual. This is the deepest level of processing and produces best recall, possibly because the schemata about oneself are the most detailed and extensive of all (Slavin 1986).

\section{Distinctiveness of Memories Helps Later Recall}

In general, material stored under categories having to do with superficial characteristics (such as what comes before and after it, as in memorization) is recalled much less accurately than material stored on the basis of meaningbearing characteristics. Pegging material to the schemata of self produces the best recall rates. But the picture is complex and still being researched. In order to be remembered, a memory must leave a trace behind it that distinguishes it from similar memories. Superficial features that attract attention (for example, big blue letters) also contribute to making material memorable by helping create a unique trace (Stein 1978). By the same token, most daily episodes (for example, what you wore last Monday) do not leave behind a distinct trace and are lost in the routine of life. A strong mood or emotion at the time material is learned (including humor) helps create a distinct trace that later facilitates retrieval (Bower 1981); people who are sad or depressed are more likely to remember unpleasant past experiences than people who are in a good mood (Smith and others 1982). Memory for pictures is often superior to memory for words becaluse pictures point out relationships among items (figure 10) and because much of the right cerebral hemisphere processes spatial information (annex B).

When people are exposed to material they do not understand well, they may miss its meaning but still remember striking, salient details, which have somehow succeeded in creating a distinctive memory trace (Peper and Mayer 1978). A person with a facility for remembering relatively unconnected material can sound very erudite. 
Figure 7: Levels of processing for learning unknown words

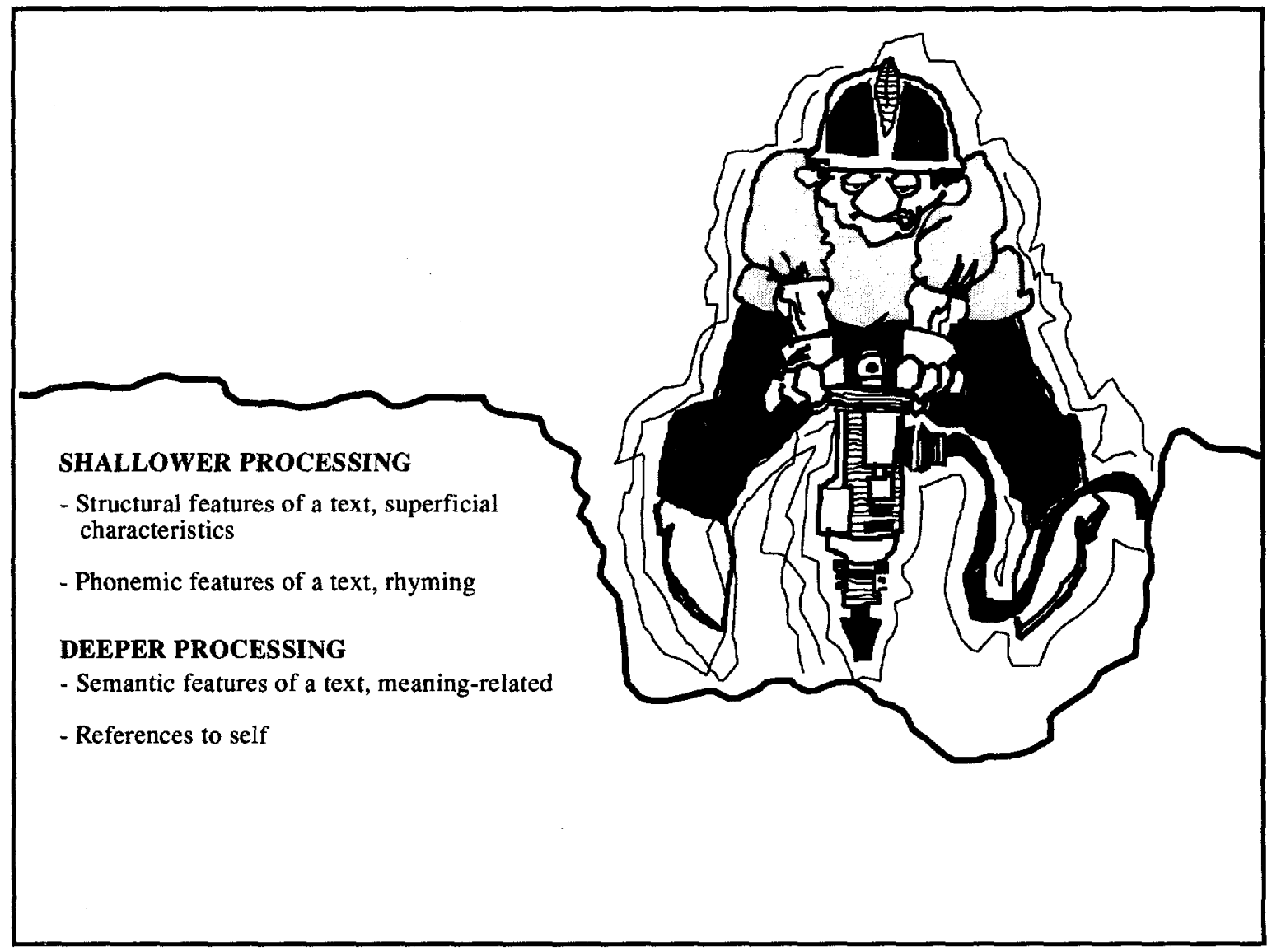

$\mathrm{ksr} / \mathbf{w 4 4 3 0 3 j}$ 
Figure 8: The duplex theory and the levels of processing theory contrasted

(A) DUPLEX THEORY

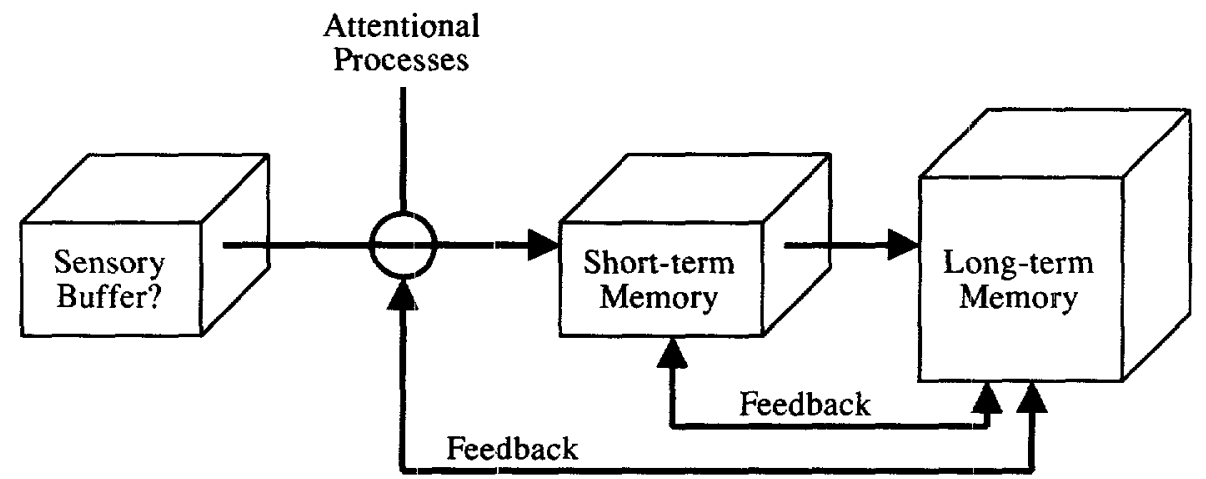

(B) LEVELS-OF-PROCESSING THEORY
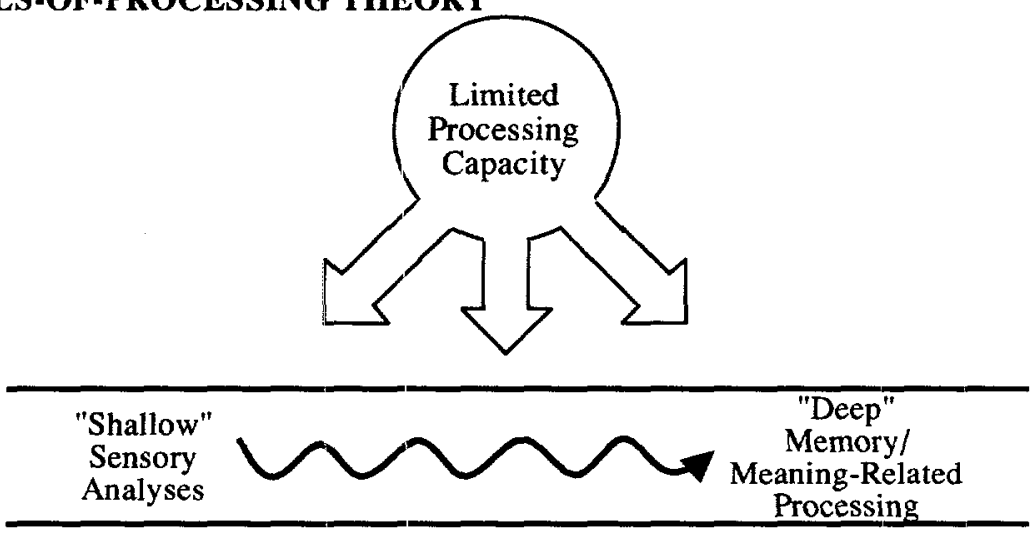

Time $\longrightarrow$ 
Figure 9: Rates of forgetting meaningful and meaningless materials

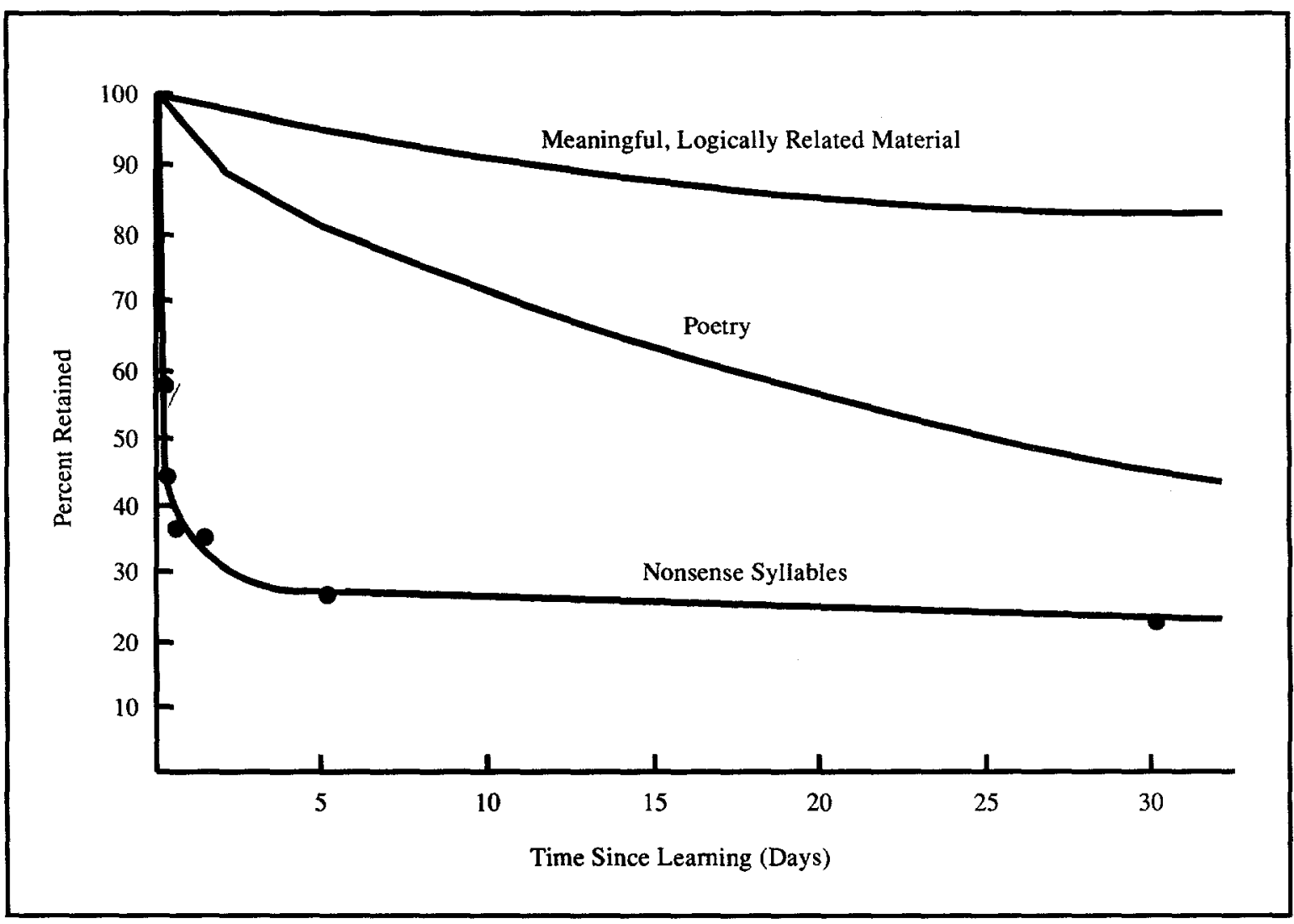

Adapted from Guilford (1939)

$k s t / w 44303 p$ 
Figure 10: Bizarre images may be remembered better than ordinary ones, but interactive imagery facilitates retention even if the images are not bizarre

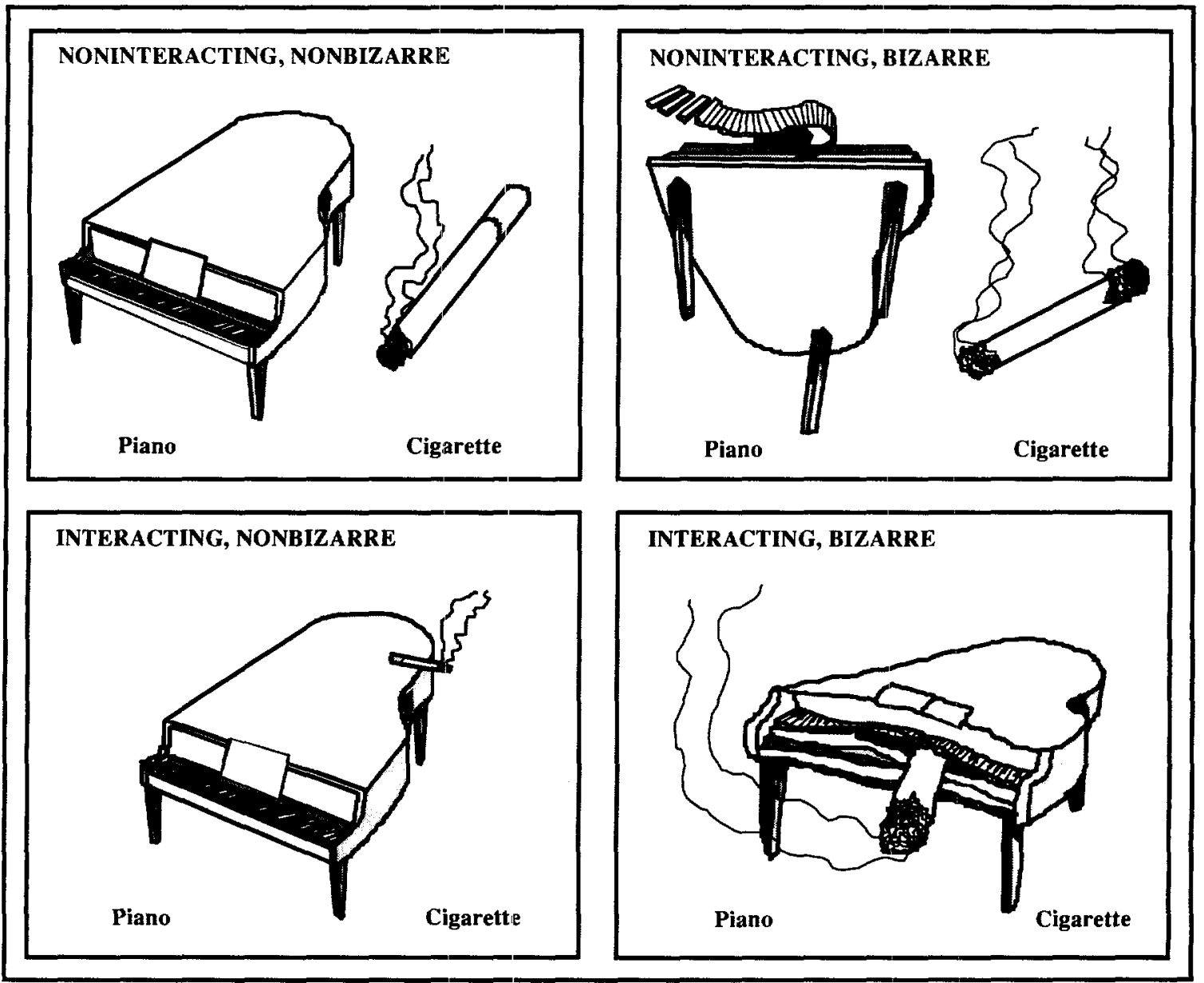

Adapted from Wollen, Weber \& Lowry (1972)

ksr $/$ w44303f 


\section{How to Present Information So That People Will Remember It}

A presenter has to weave before the participants, slowly and systematically, a web of knowledge that attaches reasonably well to schemata they have in their minds about the topic. The theories of memory storage propose the following:

- Go slow with material that is not immediately meaningful. Whether it is a separate "box" or a shallow processing stage, short-term memory needs time to process information for long-term memory; when there is not enough time to process, most information that does not make immediate sense, for example, unknown economics terms, gets lost when the next concept comes.

- Dwell on meaning. When learners attempt to retain the superficial characteristics of the material, that is, what comes before and after, as in memorization and lesson recitation used extensively in many countries, information is much more likely to be forgotten. Material connected to oneself is processed "deeply" and acquires a lot of meaning. For example, if an extension agent presents lists of cow diseases to peasants, they will remember much less than if the extention agent started by making references to their cows and building their schemata from there. Since the cognitive networks of an expert differ from those of a layman, a teacher must acquire insight on how material is classified in students' minds and make connections to that inexpert classification rather than to his or her own.

- Rearrange unstructured material and impose classifications on it. The meaning-based operation of the mind implies that information presented in categories will be learned more easily and later recalled more accurately. Recall scores are better for lists of clustered objects than for lists without order (Smith and others 1982). For this reason, outlines mapping the information facilitate retention significantly (Brooks and Dansereau 1987). Summarizing, explaining material orally or in writing, also helps impose order, and is one reason why peer tutoring is so beneficial to the tutor (Slavin 1986). In contrast, loose definitions of terms, often emphasized in learning institutions of many countries, are just the semantic memory items likely to be forgotten. Not only do they have a low probability of being retained, they have an even lower probability of being used to build further on a cognitive network.

- Bridge new material with material existing in as many schemata as possible. Point out similarities, differences, and analogies with other concepts. But passive listening is not enough. Participants must have the chance to manipulate and elaborate the material, actually or figuratively, by answering analysis, synthesis, and evaluation questions on it (annexes $\mathbf{E}$ and $F$ ). In addition to giving participants optional readings, therefore, include a list of analytical and synthetic questions.

- First build the general categories of a domain, then fill in the details. Presentation of a topic with its details in one shot may hinder subsequent recall of both main and secondary points (Dansereau 1987). As people store information, they rearrange their cognitive networks to accommodate new connections. Superordinate categories may become subordinate, others may be fused or acquire more classes. Schemata attached to them acquire more 
detail. Rearrangement takes some time, and reflection between learning sessions contributes to it. Therefore, to present details that should be tacked on the ends of currently forming networks may (a) confuse people about what is important and what is detail and create "wrong" networks; (b) result in loss of the detail, since for the moment it is meaningless; (c) clutter the short-term memory with both main and secondary points and result in losing both.

- Present information in actual or figurative pictures. Create imagery, if possible with meaningfully interacting items (figure 10). It facilitates the development of cognitive networks, creates distinct memory traces, and greatly improves the probability of retention (Wollen, Weber, and Lowry 1972). One picture is worth a thousand words, but it has to be a picture of relationships.

- Make information more memorable by selectively adding unusual superficial characteristics to the material (for example, colorful, beautifully illustrated texts, humor, and so on). Attention to the superficial characteristics of material is an inefficient way to retain it, but addition of unusual superficial characteristics makes memories distinct (Wingfield and Byrnes 1981).

The bottom line of this section is that information by itself has no meaning without cognitive networks ready to tack it on. But to fit in various places of the networks, the information has to be taken apart and rearranged by the learners themselves. 


\section{From Memories to Thoughts}

\section{The Reconstructive Work of Memory}

A man goes into a building. He picks up a loaf. He walks to the counter. He picks up his change.

The meaning of this passage (Slavin 1986) is easily understood by the city dweller, and demonstrates the ability of the meaning-oriented memory to use the contents of its schemata to make sense out of disjointed material. People routinely use their store of information about the world, that is, the semantic memory, to interpret what they learn and to rationalize what does not make sense to them (Sulin and Dooling 1974; Smith and others 1982). Readers of an advertisement saying "Lavium Pills may help relieve tension" are later likely to remember that Lavium pills do relieve tension (Leahey and Harris 1985). In a similar vein, people fill in the blanks and invent likely outcomes when they forget. (This is the cognitive mechanism that gives rise to distorted rumors and unreliable court witnesses-Loftus 1979). This reconstructive process underlines the fact that cognitive networks do not accept information "as is." Instead, they accommodate a new item under a category that may differ from person to person and in doing so, they reinterpret it. As a result, a presentation and its subsequent reconstruction by seminar participants will probably have different structures and may emphasize different issues.

\section{Forgetting: Where Have All the Memories Gone?}

Knowledge that gets encoded in the long-term memory of seminar participants may never really get lost. The trace it leaves behind, however, may either decay somehow or become similar to other traces that may then turn up in the search for the lost item. The latter reason sounds especially true for small events in daily life, and for this reason, episodic memory-the memory of events-is generally weak. Information may also be mixed with other items during learning and get misfiled. Cues to retrieve it then come back empty-handed, even though that item has been retained somewhere (for example, student protests: “ I didn't know that was what you wanted on the test").

Superficially elaborated information is particularly vulnerable to interference from other items. Experiments that involved learning of nonsense syllables showed 70 percent loss within two days (Ebbinghaus 1885; figure 9). Previously learned information may interfere with subsequent items and vice versa. Information imparted in the middle of a learning event (for example, on the Wednesday of a Monday-through-Friday seminar) is least likely to be remembered in the long run because previous as well as subsequent topics interfere with it (figure 11). In the short run, the last items in a series are remembered best, but in the long run, the first items are retained (Smith and others 1982). Therefore, important information should be presented on a Monday to increase the probability 
Figure 11: The first and the last items learned in a series interfere with items learned in the middle

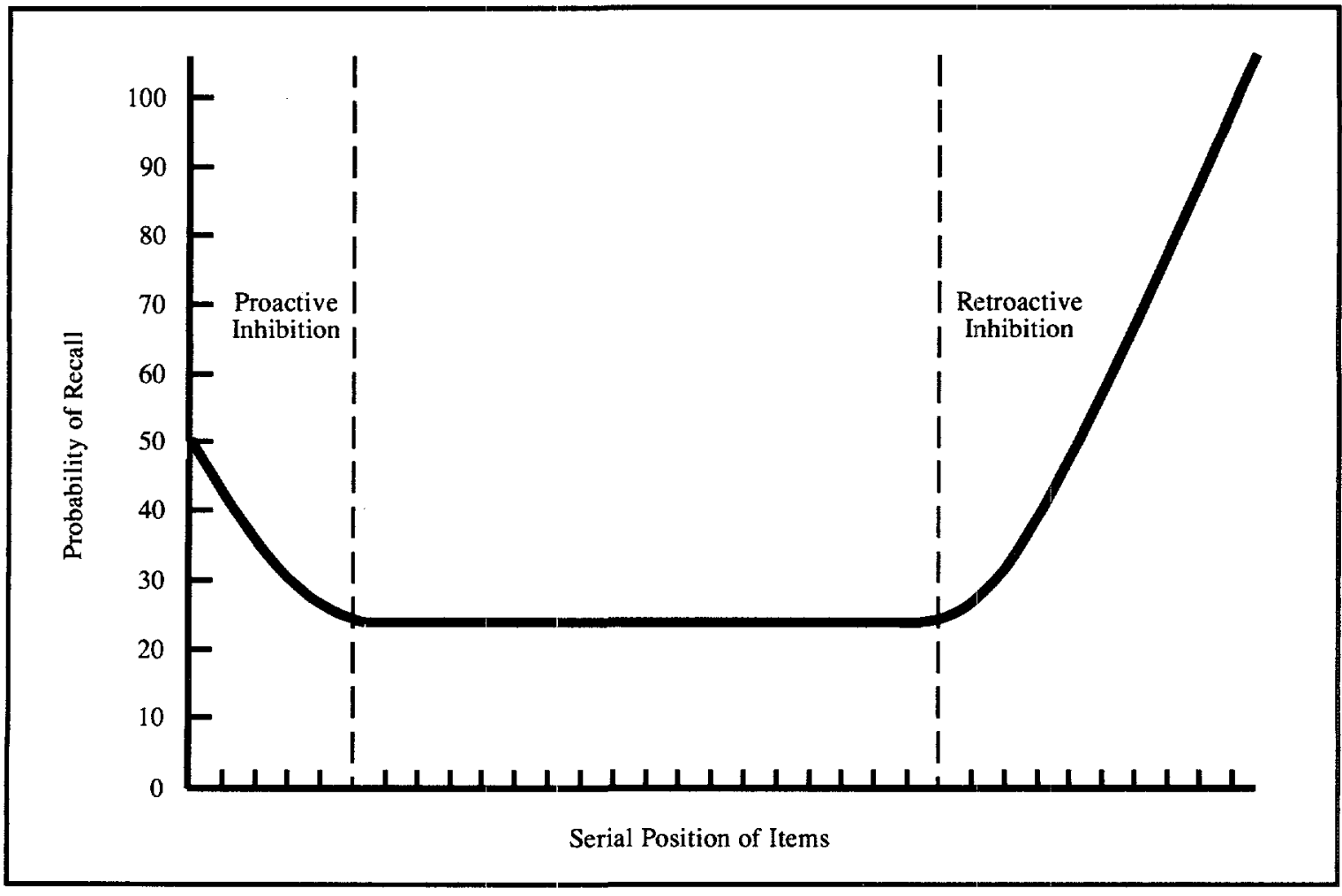

Adapted from Solso (1988)

ksriw44303i 
Memory organization must reflect relationships between events and the context in which they occured.

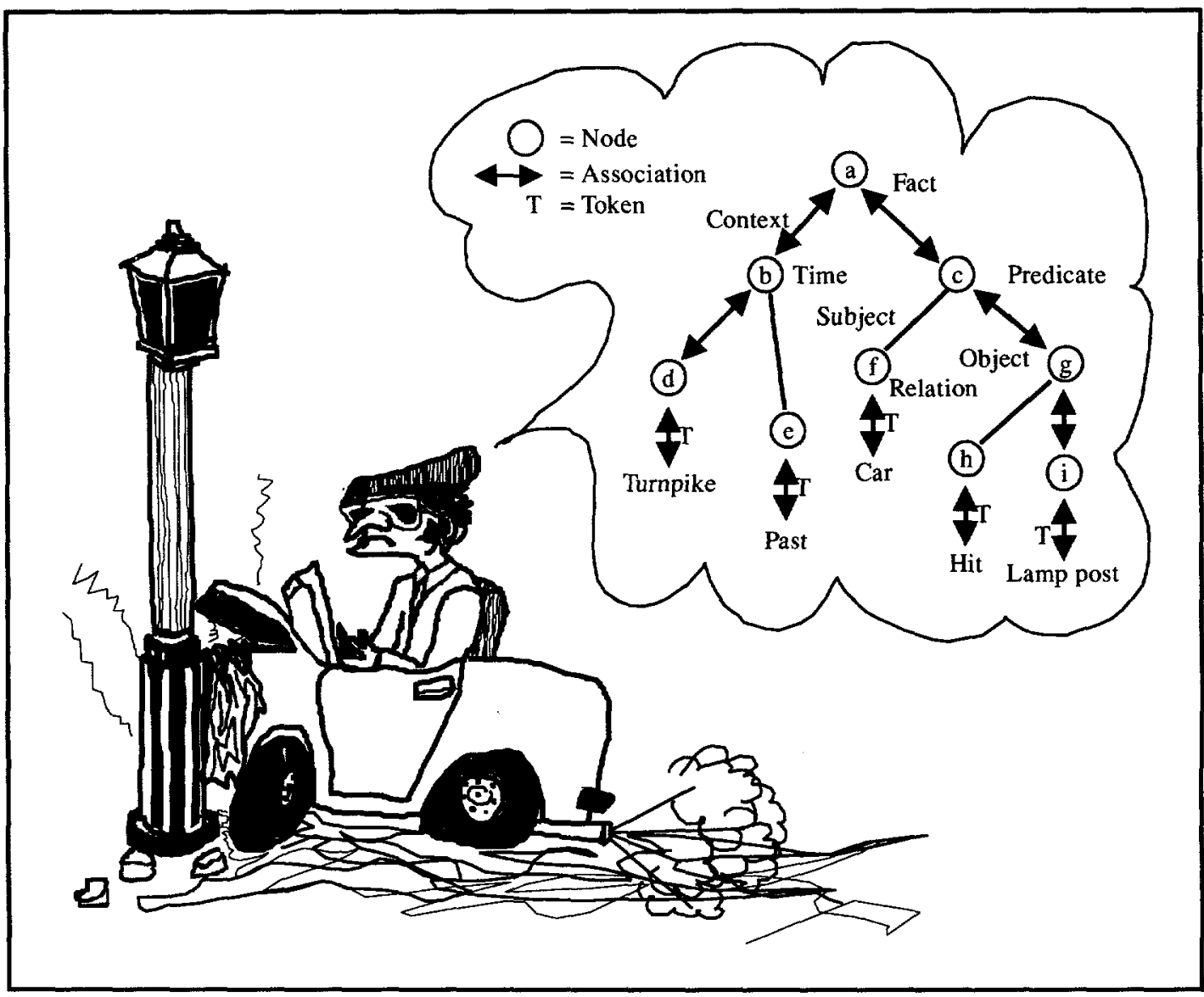

Adapted from Wingfield (1981)

ksriw44303b 
that it will be remembered in the long run. Wednesday would be a better day for reviews, reflection-type sessions, and free afternoons.

As a result of all the factors presented thus far, the inevitable fate of seminar information is as follows:

- a portion is lost through inattention and high speed of presentation, which prevents material from being elaborated or passed into long-term memory;

- a portion makes it to long-term memory but is eventually forgotten, presumably through interference, the bane of poor elaboration (particularly orphan items, such as terms);

- the rest is reconstructed by memory and subjected to transformations and creative filling of blanks.

Nothing remains the same (see annex D for an illustration of how a topic presented in a seminar will be remembered two years later). A trainer who respects the rules of human cognition can significantly cut down the first two items above. But the third is a legitimate mechanism that gives us a glimpse of how the mind assembles events and known concepts to create new concepts and rules. When important concepts in a topic have been singled out for extensive elaboration, then the reconstructive memory can rely on them later and reconstruct the whole presentation around them if needed.

\section{Transferring Seminar Knowledge to the Real World}

The ultimate goal of all seminars is to improve participants' work performance. How should information be imparted to achieve that goal? At the beginning of this century, it was widely believed that training in mathematics and Latin would transfer to all domains of knowledge so that a disciplined mind would show superior performance in fields not previously studied. Acquisition of categorization skills may make this belief partly correct, but the sum total of considerable investigation since the beginning of the century shows the key for transfer is similarity; the more similar two tasks or domains are, the more likely it is that skills will be transferred from one to the other (Thorndike and Woodworth 1901; Cormier and Hagman 1987).

\section{Blind Training Begets Inert Knowledge}

The culprit is called encoding specificity. As mentioned earlier, the ease with which an item is retrieved from memory depends on the circumstances under which it was encoded during learning (see more in annex E). The cues encoded with the information guide its placement in particular schemata and make its later retrieval possible. For instance, a child who has filed the multiplication tables under "rhymes recited in school" is not likely to use them to figure out how much seven bananas cost in the market. To achieve transfer from a theoretical setting to "real life," cues about "real life" must be encoded with an item during learning. These cues usually refer to why, when, or where a piece of information should be used.

Considerable recent research exists to show that people can access most easily the knowledge that includes information about the conditions and constraints of its use. Learning activities that let people (a) experience problems and then (b) 
experience the usefulness of information for solving those problems increase the likelihood that the information will be looked for in subsequent, similar situations (Sherwood, Kinzer, Bransford, and Franks 1985, cited in Bransford and others 1986). Blind training, on the other hand, the learning of material for the sake of learning, results in inert information that people cannot use to solve problems even though they may know it well (Brown and Campione 1986; see example in annex A).

Another reason why the uses for the knowledge are as important as the knowledge itself, is that items are rarely used by themselves in thinking. Instead, schemata become synthesized into patterns in our minds. When experts look at a problem, they use these patterns to recognize salient features that turn out to be the most relevant issues for handling a situation (Bransford and others 1986). To become an expert, one must learn to discern and interpret patterns of similarities for broad classification of a problem as well as patterns of differences for narrow diagnosis and remediation. Research on this subject has barely begun, but the future of effective instructional methodology clearly lies in pattern recognition. Participants must learn to distinguish the "real life" signs that enable experienced users to determine when and why to use one method rather than another (Bransford and others 1986). Case studies and sequences of theory-field work-discussion attempt to accomplish this. But managers frequently invest the limited time of seminars on imparting the actual information rather than on less well understood bridging activities, which are, however, crucial in promoting pattern recognition and transfer of learning.

\section{Problem Solving, Reasoning, and Decisionmaking}

When we think, knowledge stored in the past comes together with present information and allows evaluation of a situation. A working memory space is hypothesized to exist for this purpose (Reynolds and Flagg 1983). Our thoughts have the same fate as stimuli coming from the outside. Short-term memory may wipe them out or send them on to long-term storage.

The encoding specificity drama continues. If all the knowledge we keep stored in some obscure, rarely used schemata became instantly available every time we had a problem, we would all be terribly wise. But evolution has apparently decided that there is no way to keep order and priorities and have all knowledge available at the same time. Therefore, a great deal of useful knowledge often remains inert unless specific effort and use of techniques is exerted to choose it and retrieve it when needed. Problem solving is actually a jump over the encoding specificity ravine to useful information that was not learned together with the data of the problem.

Since people work mostly with immediately available knowledge, they think accordingly, and are less than rational when making decisions (Tversky and Kahneman 1974). When people think aloud while solving problems (Smith and others 1982), they reveal chaotic thinking processes, biases, and short-cuts that may or may not optimize decisionmaking. Some of the procedures that may make people reach rational and irrational decisions are listed in annex $G$. 


\section{How Does Culture Influence Cognition?}

Interpretation of events, communication habits, and expressions are to some extent culturally determined, because we interpret what we see on the basis of what we know (Casse 1981). Experienced trainers take cultural differences into account by using examples from many countries and by avoiding stereotyping and potentially offensive situations. Seminars are, however, usually conducted on Western conceptions of time and management. Simulations and games, for example, have repeatedly used inappropriate models in the past (Schoffield 1986).

Educated people may be more similar than different. Though most of the cognitive research reported here was carried out in the United States, Great Britain, and the Federal Republic of Germany, there is evidence that the minds of people from all countries basically obey the same rules (Solso 1988; Gay and Cole 1967; Gladwin 1970). The main differences in cognitive processes are found between educated and uneducated people. Illiterate adults who are "close to the land" draw their conclusions from concrete facts or from consensus and rely less on abstract reasoning than people with four years of education (Luria 1971, cited in Solso 1988). For example, an illiterate person asked the syllogism: "All women in Mexico City are beautiful. My friend is from Mexico City. Is she beautiful?" may reply: "Of course she is, because you like beautiful women." People who have gone to school for at least four years are more able to use abstract reasoning and depend less on environmental validation of their thoughts (Laboratory of Comparative Human Cognition 1986). Education, therefore, is a cognitive bridge that creates understanding among various cultures.

\section{ALook at the Field of Adult Education}

Humanistic educators relate motivation to learn with a person's identity and needs. They point out that adults, who are mature and free to attend or not to attend training sessions, should not be taught through methods developed for captive audiences of children (Rogers 1951; Knowles 1973). The resulting philosophy of andragogy (rather than pedagogy) postulates that adults cannot actually be instructed; they can only be facilitated so that they can learn on their own. They will learn what they consider useful, at their own pace, through their own cognitive styles and rules, and need no prompting; a teacher of adults can only be a facilitator. A voluminous amount of material has been written on adult education (annex H), of which very little describes experimental research or offers insight about adult learning processes. Adult education remains mainly a system of ideas that make good common sense.

Attention to the maturity of adults, who work harder for goals they themselves set (Klausmeier and others 1975), opens the way for a new seminar methodology that can integrate the expertise of high-level participants. EDI seminar evaluations have repeatedly highlighted the satisfaction produced when participants chair sessions and make presentations. Extensive consultation with potential or actual participants about planning and execution before and during the seminar may, therefore, alleviate considerably the work of trainers. Juxtaposed are financial concerns and institutional dictates for achieving specific goals through seminars; also the fact that some people may attend for reasons unrelated to training or exchange of ideas. 


\section{Beyond Individual Cognition}

\section{People in a Group}

A good set of cognitive networks and streamlined reasoning are necessary but not sufficient for maximal absorption of seminar material. Everyone has seen participants who stay behind to talk to presenters, take copious notes, and seem to study all the materials, and others who sneak out for shopping sprees. Wise trainers encourage situations that put social pressure on less interested participants and motivate them to be productive in order to save face. Some psychological research on how people's learning behavior is modified in groups is outlined in annex I.

\section{Participants Are Not Always of Like Minds}

In its efforts to promote understanding between parties sitting at opposite ends of the bargaining table, EDI often invites to a seminar participants who represent opposing interests. These participants may be employees of allocation versus sectoral ministries, trade union leaders, tribal leaders, or representatives of opposition parties; they may also represent countries whose political or social philosophy may be considered extremist by seminar managers or other participants. By allowing participants to air their views in seminars, EDI expects that opposite interest groups will modify their attitudes and narrow the gap that separates them, so that cooperation between them thereafter will be easier.

What can seminar managers do to help narrow the ideological gap between proponents of opposing interests? The considerable research on beliefs and how people can be persuaded to change them provides some answers. A brief review is given in annex $\mathrm{J}$. 


\section{Back to the Seminar Room: Applying the Rules of Cognition}

\section{Seminar Objectives: For What Purposes?}

"To understand the perspectives and approaches of economics and economists."

"To develop the ability to understand, interpret, and use the basic terminology most frequently used in macroeconomics work."

A highly regarded seminar manager has disseminated the above objectives. Are they useful in limiting seminar activities to those that will help achieve an objective? All seminars issue a list of objectives, but these are often too general and vague to guide the activities of either participants or presenters.

Since the ultimate goal of seminars is to modify thinking in the long run, seminar objectives ought to describe what a participant should be able to retain two years after the seminar. Specific cognitive objectives can then outline elaboration activities to achieve the general objectives: which concepts should be worked at through group discussions, evening reading, and so on. Developing and using cognitive objectives during the seminar would serve to focus the seminar on what participants should retain, not on what presenters should present.

\section{Open Sesame: Advance Organizers to Open Schemata}

Advance organizers are general statements given before a presentation that relate new information to existing knowledge and signal the memory to open up the appropriate schemata (Ausubel 1963; Slavin 1986). In seminars, they most frequently take the form of outlines on overhead projectors or flip-charts. Many studies have established that advance organizers increase the understanding of material, particularly when the topic has a structure that may not be apparent to learners (Hartley and Davies 1976; Lawton and Wanska 1977; Mayer 1979; Check 1984). To be effective, however, these organizers must provide a cognitive hierarchy of the topic, and presenters must refer to them as they proceed. People stay alert longer and process material more efficiently when they are shown its structure (Slavin 1986). In addition, they receive cues to "open up" new schemata for upcoming information or to find schemata that contain some of the information that will be discussed.

Concept maps (annex E; figures 1 and 2) are outlines that graphically display relationships among concepts in a topic, and have been found to be highly effective in promoting retention (Brooks and Dansereau 1987; Dansereau 1987). They are an effective tool for presenting complex procedures (for example, the project cycle of the World Bank).

Given the benefits and the few resources needed for development, a presentation without prepared, hierarchical, and consistently referenced advance organizers should not be acceptable. 


\section{Cognitive Strategies: Tools for Etching Meaning in Memory}

People, to a greater or lesser extent, monitor and correct the processes and products of their cognition, and develop insight regarding what they must do to learn something. To learn material, people use cognitive strategies, which they develop from early school years (annex E). Strategies that impose meaning and order on material (for example, mnemonics, cognitive maps, PQ4R technique: Preview, Question, Read, Reflect, Recite, Review) enable people to retain information better than mere reading, repetition, or memorization. Because meaning-based strategies were not adequately reinforced in schools of previous years, some seminar participants may still recite materials they want to learn rather than analyze their meaning. In addition, older participants process material more superficially (Craik 1977; Slaughnessy and Reif 1985) and tend to forget it more easily than younger participants. Seminar participants will probably process the material more deeply if they are asked to find answers to application, analysis, and synthesis questions that will accompany the recommended evening reading (O'Neil and Spielberger 1979). If participants are told in advance that they will give their answers the next day, they may be more likely to prepare them. Keeping a journal of important or meaningful ideas has also been found to be a good elaboration strategy (Harris 1982).

\section{Common Seminar Presentation Methods and Their Cognitive Effects}

It must be clear by now that lectures, particularly long ones, are quite ineffective in promoting long-term retention. However, lectures need relatively little time to prepare, are generally accepted by participants (Check 1984), offer control in terms of time and content, and provide ample testimony that managers and consultants have discharged their responsibilities. Lectures also seem like the most straightforward thing to do, and many presenters from developing countries have little experience with anything else.

Substitutions for lectures seem difficult and costly. Lecture format, however, can be substantially improved by (a) using ample audiovisual advance organizers, (b) lecturing nonstop for only 10 to 15 minutes, and (c) presenting hierarchically organized information that caters to participants' schemata. Elaboration of material can be achieved by requiring advance preparation from participants and posing analytical questions on the topic rather than going over the subject matter.

Participant presentations, in addition to being low-cost, benefit those participants who have to organize material in order to explain it. Presenters, however, may be chosen for their command of a specific topic, not for their ability to command attention, outline the material, and promote deep information processing. In the latter case, lecturing problems are seen at their worst. Their effectiveness could increase significantly if they received instructions on how to address their colleagues.

Case studies have been considered a very good method to achieve transfer of learning, because they allow participants to identify with the actors of the study. However, debriefing participants who may initially find the material meaningless can become tedious and time-consuming, and have the same effect as teaching little-structured material to people (Doherty 1982). 
Simulations achieve transfer of learning only to the extent that their activities have elements in common with real-life work (Cormier and Hagman 1987). Lego and tug-of-war games may be fun but have dubious value facilitating transfer (Schoffield 1986). The difficulty, expense, and situation-specificity required to develop them make them rather unwieldy tools ( 200 workdays may be required to develop a business game for $\mathbf{4 5}$ participants).

The main advantage of group discussions is their ability to reduce the social loafing of large groups. When participants are few, they are forced to interact, and may realize the need to prepare better in order to do so. An agenda-conscious moderator is necessary, since discussions can easily get off the subject.

Computer-assisted learning is now more feasible and sophisticated, and there are some excellent examples in the field (Halff; Hollan, and Hutchins 1986; Sheckley 1986; Heerman 1986). Participants in this type of learning can (a) clarify doubts they do not want to raise aloud; (b) get practice and elaboration on material presented, particularly for lower-level concepts (for example, terms) and relations among them; (c) achieve learning- rather than performance-related goals, since the computer "instructor" is not threatening and nobody is watching. The obvious problem with computer exercises is that they are often not available in sizable numbers in the field and that software is still expensive to produce.

Participants often receive writtien materials, articles, books, together with heavy evening homework assignments, which may or may not be completed. It is difficult to focus on the important aspects that should be remembered in the long run when they are hidden amidst loads of verbiage (Dansereau 1987). Thinner materials, outlining the main points, offering elaborative hints, and using simple language and syntax would be more effective in achieving seminar goals (annex D). Materials meant to serve as future reference should be so designated.

Assessments are acceptable by many adult learners (Check 1984) but are generally seen as inappropriate for seminars of high-level officials, and EDI does not use them. They can be very useful, however, because in addition to providing feedback to managers on what has been retained, examinations would also (a) increase the probability that concepts are "marked" for further elaboration when they are presented (students remember items better when told that they will be "on the test"-Slavin 1986); (b) force review and organization of the material; (c) provide, in the process of writing, elaboration of concepts that should contribute to their retention.

Given the cognitive benefits of examinations, the question seems to be not whether to give them, but how to present them to participants so that they are not seen as threatening or undignified. Alternatives include (a) asking synthesis and evaluative questions, which require use of lower-level concepts but allow participants to express professional opinions; (b) making examinations anonymous; (c) using them as a conclusion paper to be prepared the night before the closing date and issuing them to all participants (anonymously or otherwise). 


\section{In a Nutshell: What Improvements Are Feasible?}

The body of research presented above, in comparison with training practices at all levels, suggests that trainers overestimate people's capacity in some areas. We may exaggerate participants' ability to

- pay attention to monotonous presentations;

- learn from one-shot presentations (they may, but they later remember episodes, such as jokes, not concepts and rules);

- retain concepts and rules in the long term by mere listening or reading;

- use relatively academic, not specifically designated information for problem solving in daily life.

Most seminar activities (for example, senior policy seminars, worldwide, national, or regional courses, and training of trainers seminars) include a mix of information presentation and deliberation on issues. The mix varies for each type of seminar, but attention to the rules of cognition can help achieve goals for midlevel professionals and senior decisionmakers alike. How can the above misconceptions be remedied?

\section{Is Material Presented in a Memorable Way?}

Seminar managers are knowledgeable, and could monitor more closely presentation details that improve long-term retention and transfer. Presenters may be subject matter experts but usually not educators. Managers and consultants can jointly produce

- Cognitive objectives: What should participants retain two years after the seminar?

- Advance organizers in the form of outlined transparencies, flip-charts, and/or concept maps.

- Plain-language, short, meaningfully segmented presentations that respect the rules of attention process and long-term memory.

- Plain-language materials, outlining the main points and asking synthetic, problem-solving questions, prepared for a daily, two-hour study-reflection period (texts for general reference should be so labeled and set apart).

- Avoidance of one-shot sessions. Once-presented, never elaborated material is very likely to be forgotten. To build cognitive networks, the general aspects of all topics could be presented in the first two days of a week-long seminar, the specifics in the next two, and a summary-integration in the last.

- Opportunities for elaboration: Participants can be asked (a) to answer the analytic questions they should have reflected on during the previous evening; and (b) to keep a personal diary of what they find meaningful/usable and report its contents at the end.

- Assessments constructed with sensitivity for content as well as for the feelings of participants. 


\section{Is Material Packaged for Transfer to the Work Environment?}

Conventional wisdom thus far has emphasized the how at the expense of the why or when. Accordingly, educational technology is not as specific on what to do, and methods are still in the process of development. Still, seminar managers can

- Reduce transmission of potentially inert knowledge. Activities that couple theory, field visits, and discussion make knowledge immediately applicable. Not surprisingly, EDI seminar participants rate these activities very highly.

- Present participants with problems and give them important, memorable information in the form of potential solutions to problems. Case studies often operate in this manner.

- Give participants structured opportunities to consider the usefulness of information for their daily work.

The dilemma arises that if significantly more time is devoted to the promotion of why- and when- activities, less material will be covered in seminars. In weighing pros and cons, the amount of material presented versus the amount of information retained and used in the long run needs to be taken seriously into consideration. This is, however, an area for which data do not exist, and research is needed.

\section{Do Participants Support Seminar Planning and Execution?}

Given that people are much more likely to abide by the rules they set and to consent to procedures when they know their purpose, consultations with participants before and during the seminar would probably increase their involvement and long-term retention. It is true that, for many reasons, participants are often not known until a few days before the seminar. Preliminary consultation with prospective participants, however, would help make the seminars more useful.

- Prospective participants could indicate their preferences on a detailed menu of topics during planning. Preferences will probably correspond to created but empty slots in their work-related schemata. Actual participants may find the topics useful for similar reasons.

- At the beginning of the seminar, participants could be asked if they approve of the schedule and activities. Presenters should have the flexibility to change some topics and schedules, and the facility to produce elaborative materials and advance organizers in the field.

- Participant products can be given prominence in order to increase the probability that participants will reflect and elaborate on the material. If the setup permits, final papers and senior policy seminar action plans can be typed and sent to all participants after the seminar ends. This strategy will also promote transfer of learning by making participants reflect on seminar outcomes in their work environment.

- Given the high level of expertise among many participants, selected individuals can be asked to make presentations and moderate discussion sessions. This is already done to some extent, but a system for carrying it out must be developed.

Seminars will be better designed in the future if the existing knowledge about cognition is taken into account. Emphasis should shift from the actual information 
that will be presented, to the semantic memory changes participants should take home with them. The shift probably means more intensive and detailed planning on behalf of seminar managers. But if cognitive research can be generalized to seminar situations, the output of the windmills of the mind will become more visible in the work of seminar participants. 


\section{Annex A \\ Cognitive Psychology Research Techniques}

This document has concentrated on conclusions and has avoided mentioning the specific experimental procedures that made conclusions possible. In this section you will get a flavor of cognitive research.

Cognitive psychology is wedged between physiology and areas that study various types of behavior. On the physiological side, it is related to neuroscience and perception. On the behavioral side, its findings influence social psychology (notably the study of attitudes), psychotherapies, and educational research.

\section{Brief History}

Cognition, like the rest of psychology, has been an object of philosophical speculation for centuries. It started becoming a science in the 19th century. Early psychologists in the 1870s attempted to study thinking and experience, mostly through introspection, but did not have the methodology to collect objective data. Eventually, they found observable behavior much easier to study and largely abandoned cognition for about 50 years. When sizable numbers of scientists realized in the 1950 s that overt responses to stimuli could not account for all human behavior, technology and experimental methodology had progressed to the point that replicable experiments in cognition could be undertaken.

\section{Contemporary Methods}

The thus far unobservable thinking processes have challenged researchers to find equipment and experimental designs that would allow them to assess people's experience independently and to infer thinking processes from observable responses. As technology advanced, sophisticated equipment became available. Presentations of stimuli are now made through computerized tachistoscopes, which can show to subjects simple words as well as complex designs for a precise amount of time (that starts in milliseconds). Stimuli can be presented to subjects' right or left visual field in order to study the integration of images in the brain. Stereo tape recorders present precisely timed messages to different ears, a technique that has enabled researchers (for example, Treisman 1964) to study how much sense people can make out of simultaneously presented information. To study how quickly information is available to the working memory, a person's reaction time can be measured in milliseconds. Precisely timed questions are asked, and subjects press a button as soon as they know the answer. The electroencephalograph has been used to register evoked potentials that signal when people or animals pay attention. Nuclear magnetic resonance is now used to "see" in which areas of the brain metabolic activity takes place while a person thinks certain thoughts.

Subjects for contemporary experiments are often much-tested college sophomores and children in schools that collaborate with various universities. Observations of children form the basis for theories of cognitive development 
(notably Piaget and Bruner) whose hypotheses are experimentally tested and modified. People who have sustained brain damage have also been objects of careful study. Much has been learned about brain language functions from aphasia victims.

It is difficult to control the quantity or quality of information outside the laboratory, and little research has been carried in naturalistic settings. Cognitive research in seminar settings is practically nonexistent.

\section{Research Examples}

\section{Memory for Words}

Researching an abstraction is like describing an elephant from touch; the most obvious place to begin is not necessarily the most significant, and the conclusions drawn may account for only a part of the picture. For example, much of our knowledge about memory has come from learning single words. Simple research on this issue started more than 100 years ago by investigating how experimental subjects remembered lists of words. In order to diminish personal associations that would make some words more memorable than others, Ebbinghaus (1885) used nonsense words. Studying his own memory, Ebbinghaus counted the number of trials needed before he could recite the lists without error, and the percentage of words remembered as a function of list length after varying periods of time. Subsequent researchers invented a "memory drum," a machine with a slot that would enable words to be presented one at a time. Memory for single words dominated research for many years, but meaningful sentences and stories yield slightly different results. For example, the meaning of sentences is not forgotten as easily as single words, but the exact wording of sentences is very rarely remembered after a few hours (Wingfield and Byrnes 1981).

\section{The Workings of the Visual Sensory Register}

Many researchers have found that incoming information is accurately represented in the memory buffer but disappears quickly if not passed on for further processing (Solso 1988). The questions of how much the register can hold and for how long were researched through an ingenious technique (Sperling 1960).

Subjects in previous experiments had been shown a matrix of nine letters very briefly (for 50 milliseconds) and then asked to report what they saw. Under such conditions most people report only four or five letters, but it was not clear whether this is all the memory store could hold or whether only four or five items had time to reach the short-term memory. Previous experiments had also shown that a piece of information coupled with a cue (for example, a tune) is very likely to be remembered when the cue is given again. Sperling's subjects learned to associate each row of a matrix of letters with a high, medium, or low tone. Sperling then gave his subjects letters such as the following:

B G M

$A D Y$

F SL 
Right after presenting the letters, he sounded one of the tones. The tones were effective in making subjects recall that particular row nearly 100 percent of the time. Since the subjects did not know in advance which tone would sound, Sperling inferred that they had all nine letters available for recall. Therefore, the buffer could hold at least nine items. To find out how long the items stayed in the memory buffer, Sperling varied the amount of time between the display of letters and the presentation of the tone. As the time lengthened, fewer letters were remembered. When the interval between the presentation and the tone exceeded one second, subjects could only remember the four or five items they would have remembered without a tone. From these data, he deduced that the memory store holds information intact for less than a second.

\section{Do People Use All the Information They Have for Problem Solving?}

Relevant knowledge often remains inert even though it is potentially useful in problem solving. To study the conditions under which this happens, Perfetto, Bransford, and Franks (1983, in Bransford 1986) gave three groups of students problems that require a removal of functional fixedness to be solved, such as

- Uriah Fuller, the famous Israeli superpsychic, can tell you the score of any baseball game before the game starts. What is his secret?

- A man living in a small town in the United States married 20 different women in the same town. All are still living and he has never divorced any of them, yet he has broken no law. Can you explain?

Most college students cannot answer these questions unless provided with clues or hints. One group of students received no hints. Two other groups received the following statements before seeing the problems: "Before it starts, the score of any game is 0 to $0^{\prime \prime}$ and "A minister marries several people each week." Of the two groups, one received the statements before it received the problems but without any comments on how to use them. The other received the statements before the problems but with explicit instructions to use them.

\begin{tabular}{lll}
\hline \multicolumn{1}{c}{ Group 1 } & \multicolumn{1}{c}{ Group 2 } & \multicolumn{1}{c}{ Group 3 } \\
\hline $\begin{array}{l}\text { hints, instructions: } \\
\text { excellent performance }\end{array}$ & $\begin{array}{l}\text { hints, no comments: } \\
\text { bad performance }\end{array}$ & $\begin{array}{l}\text { no hints: } \\
\text { bad performance }\end{array}$ \\
\hline
\end{tabular}

The performance of the students who received instructions to use the clues was excellent. But to the researchers' surprise, students who had the information in their memory stores but without any hint on how to use it, performed as badly as students who had not received the clues at all. This experiment provided an explicit demonstration of failure to access immediately available and relevant knowledge because its purpose is not known.

\section{Why Is Cognitive Psychology Not Better Known?}

In spite of much significant research, cognitive findings still have large gaps, and theories often seem more descriptive than predictive. They have as yet little or 
no correspondence to neuroscience and are, therefore, expected to change considerably before they reach their final form. Cognitive psychology thus far has been largely an academic field, and has rarely received from educators the attention it deserves. However, its findings have now started to leave the ivory tower walls en masse. Educational psychologists find much applicability for concepts such as cognitive strategies. As more attention is paid to this field, collaborative efforts between neuroscience, cognitive psychology, and education are expected to provide important insights that will help facilitate learning at all levels. 


\section{Annex B \\ Physiological Bases of Learning}

Neuroscience and psychophysiology have generated a lot of data from animal research and brain-damaged people. But like clusters of unconnected pieces in a large puzzle, this data has not as yet developed into coherent theories with educational implications. It is premature, therefore, to use brain research to improve training methodology. The information in this section is provided as the backdrop that will enable trainers to appreciate the complexity of what we knowand what we do not know - and to be prepared for future discoveries that will enable us to develop neurologically "correct" training methods.

In general terms, the mind-brain connection is understood. In order for an organism to pay attention, register what is taught into memory, and later retrieve and synthesize it with other information, several parts of the brain interact through interconnecting pathways, that is, bundles of nerves serving as "roads." The most important part is probably the cerebral cortex, which receives information from sensory organs (eyes, ears, and so on) and integrates it with memories to carry out thinking. Research in recent years has highlighted the importance of subcortical structures in information processing. Areas below the cortex, such as the hippocampus, play very important though not yet understood roles in sorting out and consolidating what has been learned.

\section{The Search for Biochemical Thoughts}

The memory storage site is elusive. It seems reasonable that the biochemically processed memories would be coded somewhere in the cerebral cortex, the top part of the brain, which is particularly developed in humans. The place, if it exists, has not been found, in spite of intensive research during this century (Lashley 1929; Horn 1985). No specific brain cells can be associated with a specific memory. Braindamaged victims may forget specific information, but often recall it after alternative pathways are formed that somehow access that information. When certain sites (temporal lobes of the cerebral cortex) in the brains of patients undergoing surgery are electrically stimulated, they may report vivid recall of episodes, but destruction of those sites does not necessarily erase those memories. On the other hand, the larger the amount of cerebral cortex lost, the greater the permanent memory loss or reduction of the ability to learn (Thompson 1975). In the absence of a main anatomical site where learning takes place, researchers have attempted to find the location of memories in one or more of the various mechanisms that influence the responses of nerve cells. Though much is known, a coherent picture has yet to emerge. The following hypotheses exist:

- Certain substances modify brain functions. All forms of learning apparently involve changes somewhere between the input and the output of the central nervous system. Communication among nerve cells is achieved by momentary activation of chemical substances (neurotransmitters) in the minuscule spaces (synapses) that separate cells. One such neurotransmitter, acetylcholine, and the enzyme that breaks it down are, 
necessary for the formation and maintenance of memory (and are, apparently, scarce in Alzheimer's disease cases). Other substances include adrenaline, amphetamine-like substances, and certain hormones (for example, adrenocorticotropic hormone, angiotensin, and vasopressin). Their presence or absence is related to many observable signs of learning: attention, distractibility, and consolidation of new memories into durable ones (Picton, Stuss, and Marshall 1986). Is then a memory pill possible? Not yet, though claims are made for some drugs like Hydergine and pantothenic acid, which facilitate production of acetylcholine (Pearson and Shaw 1982). Neurotransmitters (a) perform multiple tasks in the body that might be dangerous to disturb, and (b) often cannot pass through the barrier that prevents most blood substances from entering the brain (Thompson 1975; Krech and others 1982).

- Information may reverberate in brain circuits (back and forth between the cortex and the limbic system) until it is consolidated, and interruption of this process may result in memory loss. This is a plausible explanation for amnesia caused by electroshocks and concussions, as well as for loss of short-term memory if a person is interrupted while repeating information (Krech and others 1982). Drugs that increase electrical activity in the brain (for example, caffeine, strychnine) improve learning in rats and offer support for this hypothesis.

- Memory may be etched in the structure of RNA (ribonucleic acid) within brain neurons. Formation of proteins in the body is controlled by RNA, and it is reasonable to assume that long-term, stable, memories would be ultimately coded as proteins. The mechanism is complex and not well understood, but apparently, a selective production of proteins that somehow carry coded messages does take place and is essential to learning (Quinton and Kramarcy 1977; Shashoua 1979), though the information is probably also coded in other ways. On the other hand, a paradox is created, because the human body is in a perpetual state of flux; individual molecules apparently live only one month (Thompson 1975). Proteins are constantly formed and dissolved, yet memories remain relatively stable and often accessible 80 years after their formation.

\section{Where in the Brain Does Learning Take Place?}

Various brain structures interact to facilitate learning (figure 12). Verbal information is processed predominantly in the left hemisphere and spatial information in the right hemisphere of the cerebral cortex, which receives signals from sensory organs. Complex thought (for example, discrimination between objects) mainly takes place in the association cortex, which is the main bulk of the cerebral cortex. The inferotemporal region of the association cortex, in particular, may be a site where past experience with a stimulus is encoded in a schema that helps interpret the meaning of new input (Wilson 1978). Feelings may be integrated from other parts of the brain. Pathways have been found to lead from the inferotemporal region to the limbic system, a group of neural structures below the cortex and very important for formation of emotions and memory. This way the cortex probably receives information regarding the motivational and emotional 
Figure 12: Brain structures important for learning

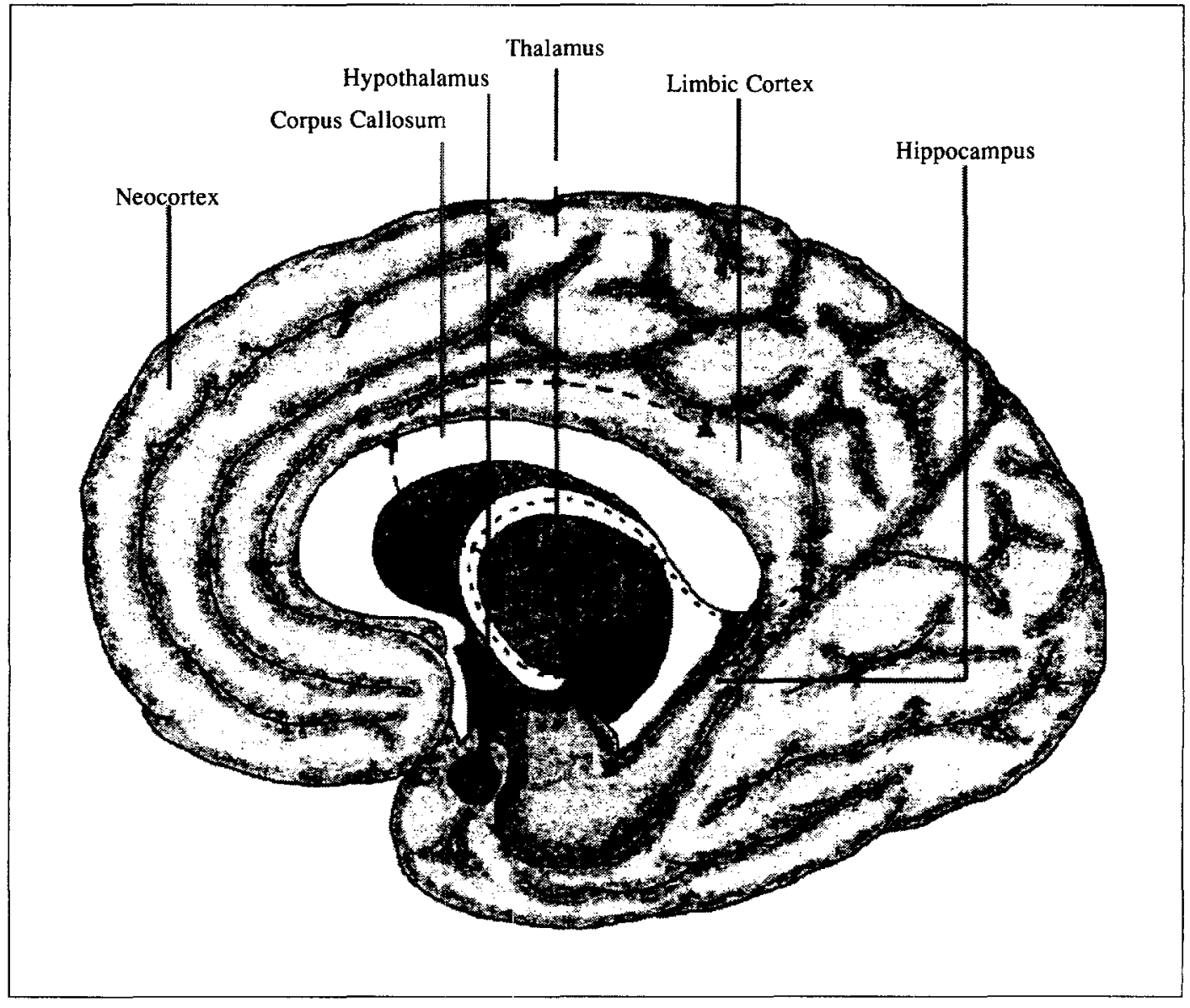

Adapted from Thompson (1975)

$\mathrm{ksr} / \mathrm{w44303k}$ 
states of the individual (Mishkin 1978), though the mechanisms that give emotional "coloring" to memories are not yet well understood. The emotions anxiety may interfere with memory formation in the limbic system.

The cerebral cortex may not be absolutely essential for learning. Neural plasticity makes it possible to redirect many cortical functions to other, unknown sites when necessary. The cortex of some hydrocephalic people can be reduced through fluid pressure to a very thin layer lining the skull, with no apparent detriment to normal functions. (One patient, with an IQ of 126 received a degree in mathematics; Chall and Peterson 1986.) It is also possible to destroy the cortex of animals, and still to condition them to respond to stimuli. Animal studies to trace how learning enters the brain through implanted electrodes show firing of nerves in the less well understood, deep, subcortical structures of the brain while information enters the cortex. The following are the most important of these structures:

- The hippocampus acts in some way to allow attention to the incoming information and, therefore, facilitates the imprinting of attended information into long-term memory (Mishkin 1982). It may also be involved in cognitive mapping, organizing memories on the basis of previous information, and remembering of significance, and of novelty. It somehow measures expectations against occurrences and registers considerable activity when there is a disparity. Its damage or loss along with the temporal lobe of the cerebral cortex or the amygdala wipes out new creation of long-term memory, and sufferers are practically unable to retain any information for more than 20 minutes (Thompson 1975). The hippocampus becomes well formed only after birth, and its development may be particularly dependent on learning and experience, as the "rich" rats experiments show (Altman 1972). Its late formation may be one reason why people do not remember events from their infancy.

- The thalamus is an area connected to many sites in the brain and possibly a region of non-specific learning. Parts of the thalamus play a role in visual discrimination (Thompson 1975). In conjunction with the frontal cortex, the thalamus may organize memories on the basis of an individual's goals and needs (Mishkin 1982).

- The brainstem reticular formation regulates the degree of arousal of an organism and, consequently, the amount of attention that it pays to a stimulus (Thompson 1975)

- The hypothalamus acts like a thermostat that controls many vital life functions, including formation of long- and short-term memory.

\section{Looking to the Future}

Advancements in neuroscience will facilitate the learning process in the long run. What is known so far has generated a great deal of enthusiasm and some premature and probably misguided speculations about educational uses. Much is heard these days about "teaching to the right hemisphere" in order to stimulate creativity, or teaching children intensively only during periods of brain growth (Rosenzweig 1986; Chall and Peterson 1986). Lack of communication between neuroscientists and educators also hampers well-conceived applications of the few currently known concepts that would be useful to educators. 
Increased understanding of what happens in humans during learning depends on the ability to monitor in detail the electrical and biochemical activity of the brain during learning without opening the skull. The technology for non-invasive study of brain activity already exists and is improving (for example, positronemission topography-PET scans, and nuclear magnetic resonance-NMR). In the next few years, it will be possible to study the activity of the human brain extensively in the process of learning, and how it reacts to various ways of presenting material. Until then, we are limited to developing training methodology by studying people's behavior. 


\section{Annex C \\ Differences between Younger and Older Adults Which Affect Learning}

The aging process affects many aspects of learning in subtle ways. Memory for pair-associate words, for instance, increases until the age of 15 , remains steady for several years, and decreases thereafter. A 50-year-old cannot learn pairs of words with the same efficiency as a 10-year-old. These differences can be due to physiological changes, education levels, social factors, medication effects, or an interaction of all these. This annex will present an outline of what is known in this area. Managers of seminars with middle-aged or older participants are likely to encounter evidence of the subtle changes brought about by age.

\section{Physiological Differences}

The vision of most people is best at 18 years. A gradual decline takes place over the next 20 years, and a sharp drop occurs between 40 and 55 years. The pupil of a 50year-old admits half as much light as the pupil of a 20-year-old (Dickinson 1973, cited in Sataka 1984). The time it takes the eye to make focal adjustments also increases with age, and middle-aged or older adults sitting at the back of a room often have difficulty shifting focus rapidly from a projection screen to their notes. Older participants have been known to complain about the dim light in rooms that were deemed adequately lit by younger managers. Seminars that include middleaged participants (for example, senior policy seminars) should, therefore, be conducted in especially well lit rooms.

Hearing is also affected by aging, and rapidly declines from 50 to 60 years; 50 percent of 60-year-olds as compared with 12 percent of 20 -year-olds have defective hearing (Dickinson 1973 in Sataka 1984). Hearing loss can cause auditory discrimination problems, which can be compounded by a reduced auditory reaction time. Older adults often have difficulty comprehending rapid speech, even when there is little or no loss of hearing. Use of desk microphones, where they are available, would therefore, ease the participation of people, who may not even be aware that they have a hearing loss.

Response speed decreases with age; older adults move and process information more slowly than children (Smith and others 1982). When there are many older participants in a seminar, they bestow a slow, deliberate, pensive tone to the proceedings.

Biochemical deficiencies are partly responsible for aging changes. As people grow older, there is a progressive reduction in the quantity, availability, or receptor sensitivity for certain brain chemicals, such as RNA (needed for memory storage), and pantothenic acid, which are needed to produce acetylcholine, a neurotransmitter necessary for attention and memory storage (see annex B; Thompson 1975). As a result, there are fewer resources with which to pay attention and less consolidation of short-term memory to long-term memory as people grow older. The uncontrolled oxidation of fatty acids in the brain is probably another cause of sensory and cognitive deficiencies of old age (Pearson and Shaw 1982). 


\section{Cognitive Differences}

The effects of physiological changes are observable in the thinking processes of adults as age advances. Though IQ declines in longitudinal studies are very slight (Krech and others 1982), older people perform more poorly in learning studies than do younger people. Some differences are even noticeable in comparisons of 40 year-olds with 20-year-olds (Slaughnessy and Reif 1985).

\section{Cognitive Functions That Are Prone to Decline}

Biochemical changes, such as diminished use or availability of acetylcholine and RNA by nerve cells, affect attention and the ability to convert short-term to longterm memories. In general, compared to 20-year-olds, 65-year-olds

- are poorer at organizing new information (Craik 1977); they may categorize it less often (Denney 1972), but they can form categories if prompted and are often able to perform at a much higher level than their initial behavior may indicate (Denney 1974);

- perform more poorly at tasks requiring divided attention, such as discriminating important information from perceptual noise. The latter impairs the performance of the elderly much more than the performance of the young (Schaie and Gribbin 1975). These effects appear to be larger when tasks are visual than when tasks are auditory;

- have difficulty retaining recent episodic memories, and do not benefit from elaboration as much as younger subjects. Shallow processing leads to less distinctive memory traces and difficulty in discrimination among various traces (Craik and Simon 1980);

- may experience difficulties in verbal-learning situations that require them to discriminate relevant from irrelevant information and process several items in quick succession (Glynn 1980); this feature is more widespread among adults over 60 ;

- need more time to respond (Kaye, Stuen, and Monk 1985).

\section{Cognitive Aspects That Are Less Prone to Decline}

There is little age decline between age groups in short-term retention (Craik 1977), in the use of thinking and problem-solving skills (Lachman and others 1979). Though older subjects have some trouble recalling recently learned and presumably not well-elaborated material, they show little if any deficiency in recognizing the material when they see it (Wingfield and Byrnes 1981). When sufficient time is provided they can perform as well as younger people.

Age-related decrements in recall can be minimized by education and previous experience. More educated people show little or no difficulty in processing new information (Glynn 1980; Owens 1987; Kaye and others 1985). This probably occurs because more educated adults have better learning strategies that compensate for age-related losses. They may also have more knowledge on which to anchor new information. Health is another significant variable: older people who function best intellectually are usually in good health (Smith and others 1982). 


\section{A caveat}

Age-related decrements are gradual when they occur at all. Research has often concentrated on postretirement age people, who may show declines because they lack environmental stimulation (Wingfield and Byrnes 1981). There is also some question whether all the differences observed are actually due to the aging process or to the fact that experimental tasks are artificial and may not be seen by older people as worthwhile occasions to exert maximal effort.

\section{Relevance to a Seminar Manager}

It takes 50- and 70-year-olds longer than 20-year-olds to respond to questions, and new information does not register in their long-term memory as easily. These phenomena may affect performance in simulations, complex case studies, and lectures with a lot of new terminology. On the other hand, highly educated people maintain their information-processing skills much better than less educated people. It is safe to assume, therefore, that older participants in high-level seminars deal with information almost as efficiently as younger participants. However, they may need more time to respond and to perform complex activities; they also have an easier time if (a) they sit close to the presenter, (b) they use microphones, and (c) the room is well lit and without visual distractions. 


\section{Annex D \\ Cognitive Structure of Learning}

\section{Pardon Me, Your Schemata Are Showing}

Spoken or written text does not in itself carry meaning. Rather, it provides directions for listeners or readers on how to use their own stored knowledge to retrieve and construct the meaning. Unless people's cognitive networks contain slots that can accept the structure, they will understand and remember very little of what was communicated. The interface between the comprehender and the text takes place in schemata.

Schemata (Bartlett 1932) are chunks of structured knowledge, sections in the networks of connected ideas, or relationships of the long-term memory. They store rules and features (for example, if something is a canary, it is a bird). New information that fits into a well-developed schema is retained far more readily than information that does not fit into a schema (that is, a mathematical formula or a highly technical discussion; Slavin 1986). Schemata related to one's person are very detailed (and probably have survival value), and this is may be one reason why references to personal experiences are so powerful in committing information to memory.

A schema is a very subjective and ill-defined concept. A chunk of structured knowledge may be big or small, and it certainly is a part or a branch of other chunks of knowledge. But it is also a most useful concept in contemporary cognitive psychology (Leahey and Harris 1985) because it allows us to refer to a module of knowledge in one word. Schemata (Rumelhart 1980) can take the form of

- plays with characters, actions, and settings (for example, what happened on a particular occasion);

- theories, which help interpret events in the world and become the basis of predictions (for example, why capitalism is beneficial);

- execution of scenarios in the mind, organization of activities with structural relationships (for example, how to behave when entering a restaurant; how to get money from an automated bank-teller);

- a parser: cutting up and pasting information, organizing and interpreting incoming data on the basis of experience (for example, classifying a person as friendly on the basis of codes on acceptable behavior in country $\mathrm{X}$ ).

How schemata are formed is not currently well understood. One hypothesis (Morton 1980) postulates a logogen. This construct is thought of as a sort of adding machine that sums information until a critical amount is tallied up and the accumulated category becomes available (Solso 1988).

\section{How Do We Know That Schemata Exist?}

It has been hypothesized that schemata are made up of propositions (Collins and Quillian 1969; figure 13). These are the smallest units of knowledge about which it 
Figure 13: Schemata and propositions

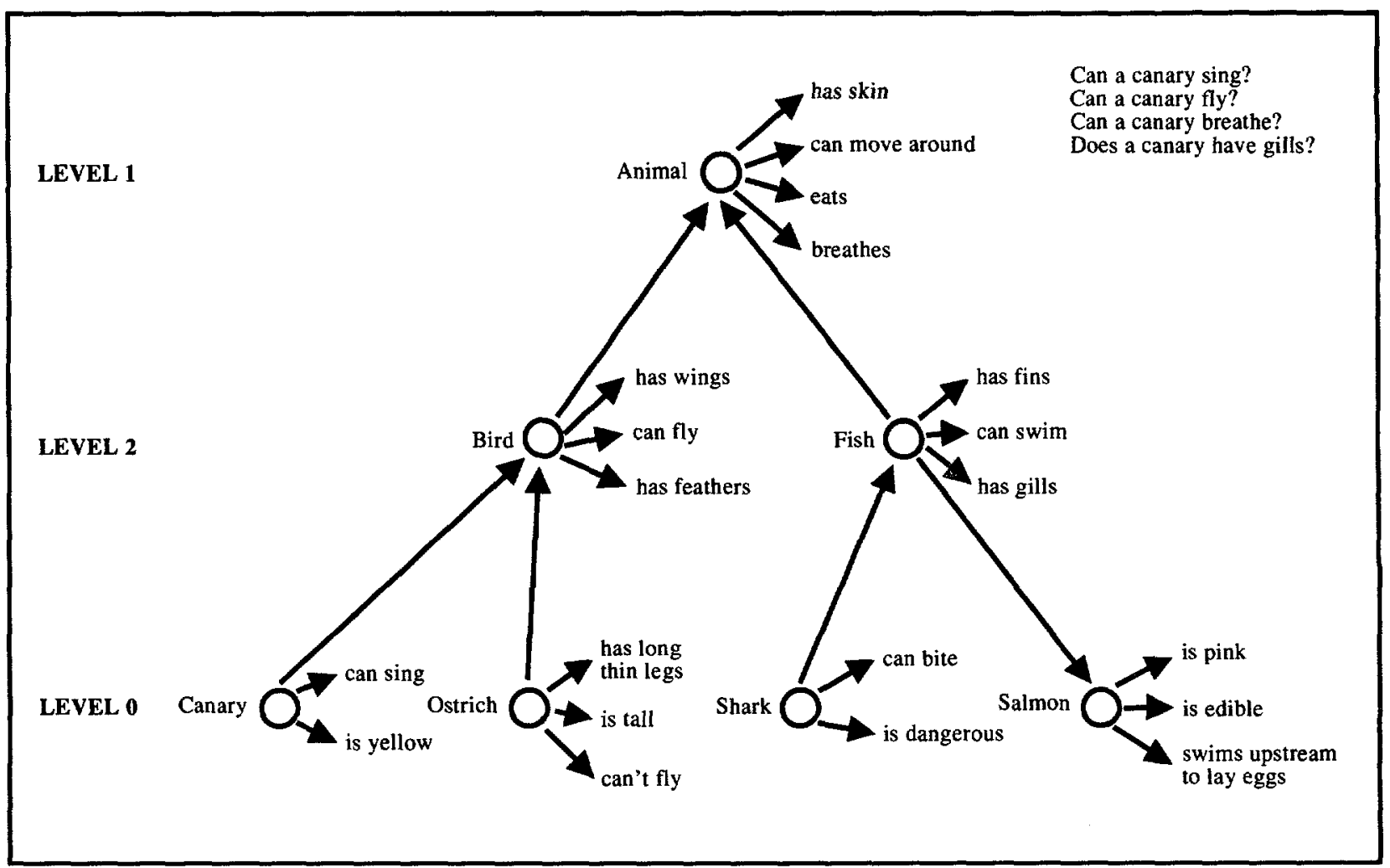

Adapted from Collins and Quillian (1969)

$\mathrm{kss} / \mathrm{w} \mathbf{4 4 3 0 3 r}$ 
makes sense to make a true or a false statement (for example, the canary is yellow). This concept has been useful in understanding how cognitive networks and schemata within them are structured. If a person has to search long before being able to answer a question, then she or he may try to put together propositions that are located in distant branches of the networks. This is indeed, the case. For example, to answer the question "does a canary eat?" takes more time (in seconds) that to answer the question "is the canary yellow?" This happens, presumably because, eating pertains to the general schema of an animal, while "yellow" pertains to the immediate schema of a canary, located further down the line from the schema "animal." Several such measurements have been made, which provide evidence for this general hypothesis (Collins and Quillian 1969; Anderson and Bower 1973). However, there is still disagreement among researchers about several aspects of cognitive structure and dynamics.

How is knowledge organized inside and across schemata? Clearly, some concepts are closer to certain others in the mind, but the exact structure has been the object of considerable theory development and research. Several tentative explanations exist of how propositions are organized to become schemata. Knowledge, apparently, is not only organized in hierarchical categories of features, but the categories are organized around "prototypes," that is, best examples of objects or situations that have all relevant features (Rosch 1978). For example, a canary is a much better example of a bird than an ostrich. Some features that define objects and their categories may have more closely related meaning than others (Collins and Loftus 1975; figure 14). Graphic representations have been made in the semantic relatedness of categories, connections, and context into account (for example, Anderson and Bower 1973; Rips, Shoben, and Smith 1973; figures 15 and 16). The issue of how concepts are organized in the semantic memory is beyond the general scope of this document.

\section{Ghosts of Knowledge in Reconstructive Memory}

Bartlett (1932) first developed the theory of schemata after researching how people transmit and remember simple stories. To do so, he asked English undergraduates to read and repeat stories at various intervals of time. Following is a repetition of one such story after 20 hours and after 2-1/2 years.

\section{The Original Story ("The War of Ghosts")}

One night two young men from Egulac went down to the river to hunt seals, and while they were there it became foggy and calm. Then they heard war-cries, and they thought, "Maybe this is a war party." They escaped to the shore and hid behind a log. Now canoes came up, and they heard the noise of paddles and saw one canoe coming up to them. There were five men in the canoe, and they said:

"What do you think? We wish to take you along. We are going up the river to make war on the people."

One of the young men said, "I have no arrows."

"Arrows are in the canoe," they said.

"I will not go along. I might be killed. My relatives do not know where I have gone. But you," he said, turning to the other, "may go down with them."

So one of the young men went, but the other returned home. 
Figure 14: Spreading activation of concepts. A schematic representation of concept relatedness. Shorter lines show greater relatedness between concepts.

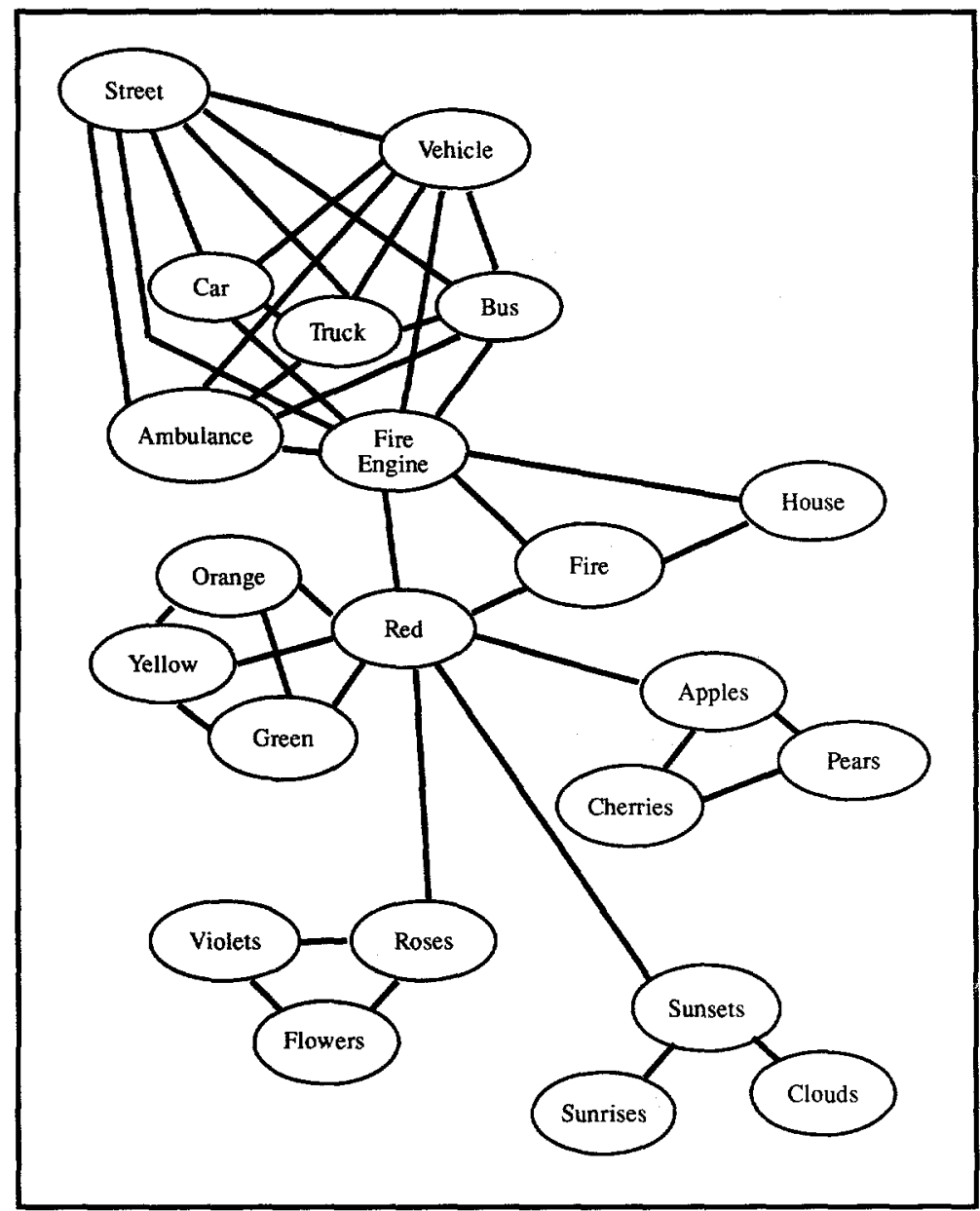

Adapted from Collins and Loftus (1975)

$\mathrm{kst} / \mathrm{w} 44303 \mathrm{~m}$ 
Figure 15: Semantic relatedness of features for birds and mammals

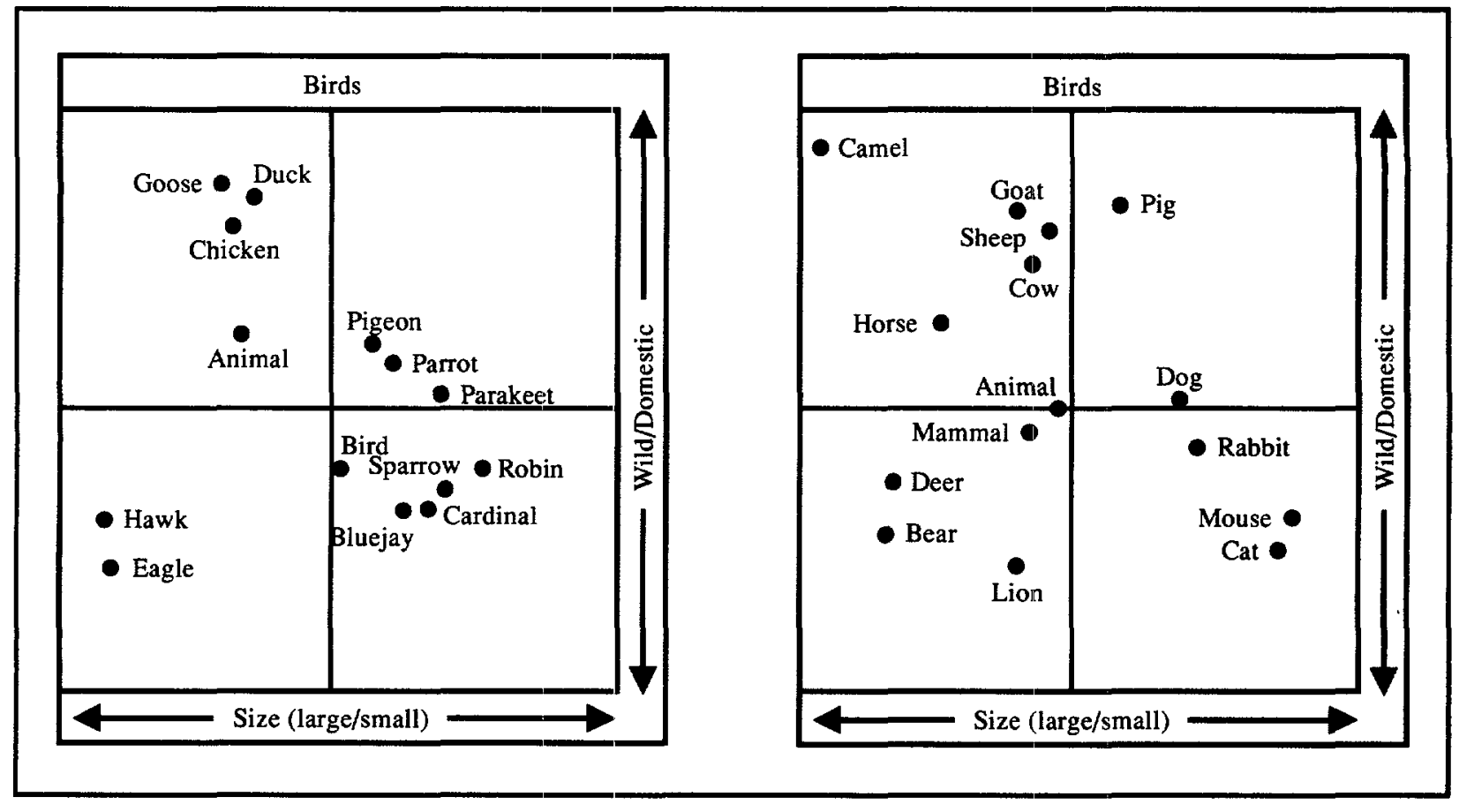

Adapted from Rips, Shoben, and Smith (1973)

ksriw44303q 
Figure 16: Context and events in Anderson's human associative memory model

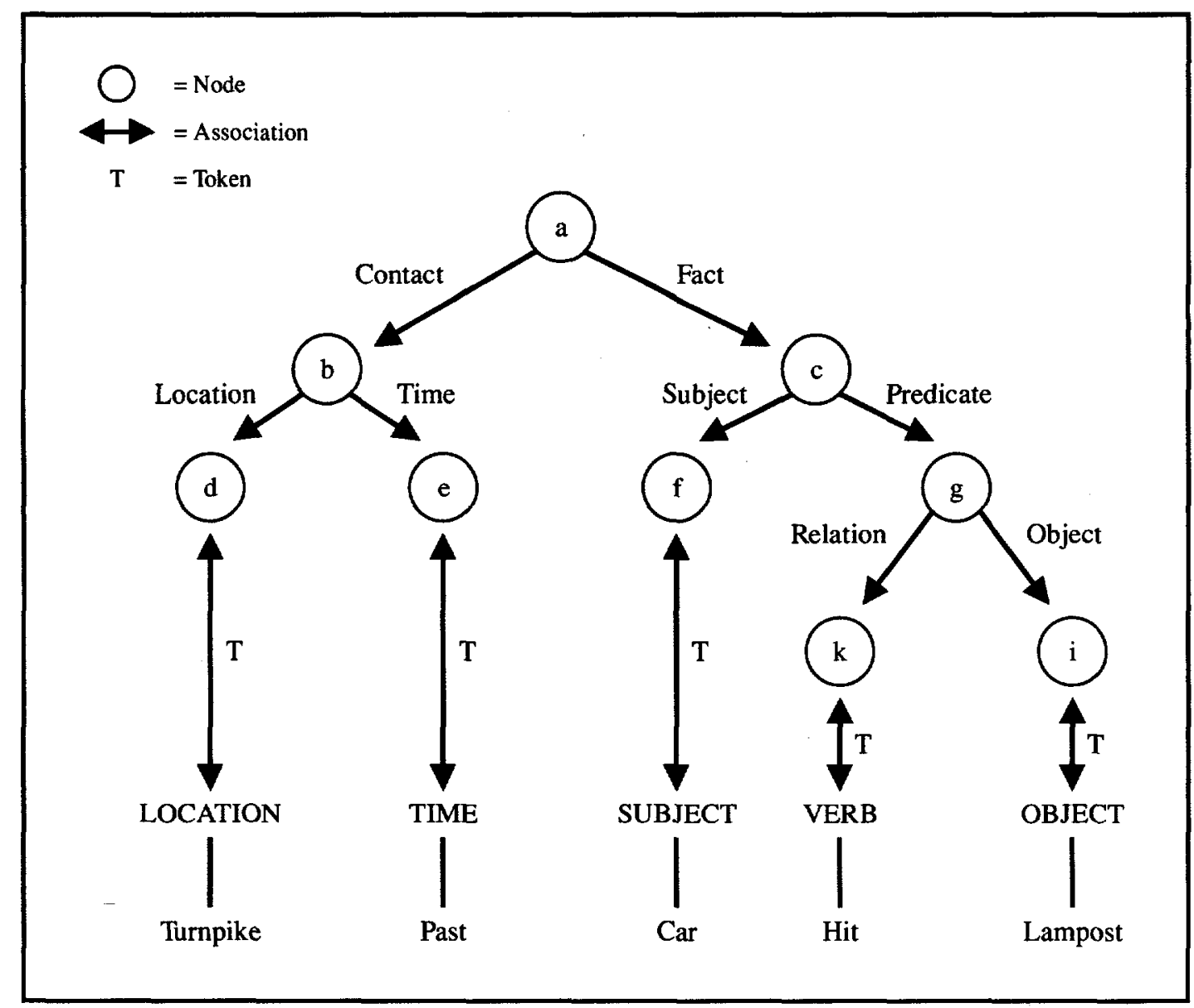

Adapted from Anderson and Bower (1973)

ksr/w44303o 
And the warriors went up the river to a town on the other side of Kalama. The people came down to the water, and they began to fight, and many were killed. But presently the young man heard one of the warriors say, "Quick, let us go home; that Indian has been hit." Now he thought, "Oh, they are ghosts." He did not feel sick, but they said he had been shot. So the canoes went back to Egulac, and the young man went ashore to his house and made a fire. And he told everybody and said, "Behold I accompanied the ghosts, and we went to fight. Many of our fellows were killed, and many of those who attacked us were killed. They said I was hit, and I did not feel sick."

He told it all, and then he became quiet. When the sun rose he fell down. Something black came out of his mouth. His face became contorted. The people jumped up and cried.

He was dead.

\section{Recall from Memory after 20 Hours}

Two men from Edulac went fishing. While thus occupied by the river they heard a noise in the distance.

"It sounds like a cry," said one, and presently there appeared some men in canoes who invited them to join the party on their adventure. One of the young men refused to go, on the grounds of family ties, but the other offered to go.

"But there are no arrows," he said.

"The arrows are in the boat," was the reply.

He thereupon took his place, while his friend returned home. The party paddled up the river to Kaloma, and began to land on the banks of the river. The enemy came rushing upon them, and some sharp fighting ensued. Presently some one was injured, and the cry was raised that the enemy were ghosts.

The party returned down the stream, and the young man arrived home feeling none the worse for his experience. The next morning at dawn he endeavoured to recount his adventures. While he was talking something black ensued from his mouth. Suddenly he uttered a cry and fell down.

But he was dead.

\section{Recall from Memory after Two Years, Six Months}

Some warriors went to wage war against the ghosts. They fought all day and one of their number was wounded.

They returned home in the evening, bearing their sick comrade. As the day drew to a close, he became rapidly worse and the villagers came round him. At sunset he sighed: something black came out of his mouth. He was dead.

Bartlett found that

- Memory for even simple stories seems to be surprisingly inaccurate. Many details are either lost or distorted, and the missing information is reconstructed to make the story consistent with the narrator's beliefs and attitudes.

- In some cases only isolated detail is remembered. Then, a reasonable narrative is created to rationalize this detail. In other cases, only the general theme or outline of the story is remembered, and then reasonable details are filled in.

- In repeated recall, proper names and titles become lost, while the outline becomes progressively more abbreviated and stereotyped. But even when 
memory is distorted, the story is always coherent, though it may require the addition of connecting information not present in the original story.

On the basis of repeated experiments, Bartlett hypothesized the existence of schemata to describe the organization of memory materials into meaningful relations. Individuals do not behave as if they store information as it comes. Rather, they seem to organize experience into their preexisting systems of knowledge and belief. Remembering, therefore, seems to be more a process of reconstruction than of reproduction (Wingfield and Byrnes 1981).

\section{Interesting Bits and Pieces of Cognitive Research}

\section{How Conducive Is Note-taking to Learning?}

Succinct note-taking can help people extract meaning and impose organization on what they hear (Slavin 1986). The fact that learners must paraphrase the material in order to take notes encourages a more elaborate and richer encoding than might be the case if a person merely listened to a lecture. Note-takers remember more ideas about the major concepts in the lectures and more often mention relevant concepts that have not been specifically mentioned by the lecturer (Peper and Mayer 1978). Without note-taking, people have a relatively literal memory for salient details of the lecture but show little assimilation and organization of the material.

Literal note-taking, however, prevents deeper processing because a participant has no time to think. Efficient, brief note-takers retain the material better than verbose note-takers (Howe 1970).

\section{How Useful is Underlining?}

Liberal highlighting or underlining of text has negligible effects on retention without further review. When subjects are limited in how much they can underline, one sentence per paragraph for example, then underlining does show positive effects on retention (Snow 1986). Limited underlining is effective because it forces learners to think about the material and to select its important points.

\section{What Features Make Texts Difficult to Comprehend?}

A linguistic study of legal documents used by juries (Charrow and Charrow 1979) has pointed out that certain "erudite" constructions hinder comprehension. Contrary to expectations, short and long sentences may be understood equally well. The problem arises with certain passive constructions and prepositional phrases, particularly those containing the stylistically awkward expression in English of "as to" (for example "as to a, the solution is b"). Sentences with two or more negations are also very confusing (for example, "it is not impossible that..."). Other constructions causing difficulties included sentences that cut a train of thought in two, such as "a proximate cause is a cause which in natural and continuous sequence produces an injury." Another type of difficult phrase was the deletion of optional relative pronouns as in "questions and facts (that were) submitted to you." 
Easily comprehended texts may be read more widely and considered more interesting, possibly because they follow the little-researched process of drawing inferences (Leahey and Harris 1985). Interesting texts are recalled much more easily (Snow 1986). As a person reads and builds up schemata abcut a topic, he or she draws inferences, and new slots may open up in the schemata, which wait for more information. If the word order of text does not give the reader the bit of information she or he expects next, the reader has to abandon the open slot and search for other points in the schemata to attach the next piece of information. That takes time. Also, an adequate slot may not be found, and a person may be motivated to skip a paragraph or to abandon the text altogether. A "however" in a sentence, for example, instructs the reader to open a slot for an opposing argument. If what follows is not an opposite of what was said, the reader has to go over the sentence, determine its meaning, abandon the "however" slot, and place the idea somewhere else on the schema. Constructions that hinder comprehension of native speakers might be particularly confusing to nonnative speakers.

Rules of good writing actually encourage the building of cognitive networks. Seminar materials may gain readability if they are written in less scholarly language and if they avoid difficult constructions.

\section{Biological Cycles: When Is the Best Time for Learning?}

The body's biological cycles influence a person's ability to allocate attention and subsequently, to learn. Attention varies according to the body's state of arousal, which is reflected by the body's temperature. The temperature reaches its lowest point $(97.6 \mathrm{~F})$, around 4:00 a.m., a high point $(98.6 \mathrm{~F})$ at 3:00 p.m., and its highest point around 8:00 pm. Other things being equal, seminar participants should be more attentive in the early afternoon and late evening rather than in the morning. This biological cycle appears to influence long-term memory. Recall of a prose passage a week after it was read was better in the afternoon than in the early morning. Short-term retention of items, however, is best in the morning and declines in the course of the day, possibly as a result of interference from other information. The effects of biological rhythms are not negligible; they can account for 10 to 20 percent of performance scores (Wingfield and Byrnes 1981). However, there are significant variations in circadian rhythms. While many people are "larks" (daytime workers), some are "owls" (night workers), and scheduling learning activities on the basis of biological cycles becomes impractical.

Travel across time zones disturbs the biological rhythms, which need more than a week to readjust completely. The result may be sleepiness and lapses of attention on the part of seminar participants. Arriving in a new time zone at night and then sleeping helps reset the biological clock (Wingfield and Byrnes 1981).

\section{An Encoding Mystery}

A person who attends for eight seconds to a chunk of information will learn that chunk and will have it stored in long-term memory (Simon 1986). If you hold your attention to an item for about eight seconds (for example, an unknown word), it will probably be stored in your memory without further elaboration. This phenomenon could be used to learn individual foreign words or terms or memorize the details of a picture. 


\section{Annex E \\ Methods of Facilitating Learning}

\section{Strategies for Retaining Information}

Why are cognitive strategies useful? We do not have all the information in our heads immediately available all of the time. How easily a piece of information is retrieved depends on the circumstances under which it was encoded in the mind and the circumstances under which retrieval is attempted. People are much more likely to remember something if many and/or unique characteristics about it are encoded together with the information at the time learning takes place. Categories, visual images, tunes, even moods (Bower 1981) can be encoded with memories, and later can serve as cues to enable retrieval. If information is not encoded along with a specific cue, it is very difficult to use that cue later to recall the information. For this reason, children who learn to recite multiplication tables actually retain information about sound patterns (Morris, Bransford, and Franks 1977). Unless they are taught the meaning and applications of multiplication tables separately, they may be able to recite them perfectly but unable to use them in the marketplace. This same principle, called the encoding specificity principle (Tulving 1972), makes much academic knowledge inert, "theoretical," and "irrelevant" because it is not coded during learning with cues that will help its later retrieval in "real" life. Learning strategies can help make knowledge more easily available by encoding it with many meaningful cues.

All learners seem to have a repertoire of strategies, though some process material more deeply and efficiently than others (Pressley, Snyder, and CarigliaBull 1987). Schools rarely, if ever, teach coding skills, which is unfortunate, because considerable evidence shows that use of meaning-promoting, elaborative strategies increases long-term retention of material (Wingfield and Byrnes 1981). But to adopt a strategy that may be laborious and time-consuming in the short run, learners must recognize that their performance improves when they use this strategy (Clifford 1984). This section will briefly present some of the issues involved.

\section{Strategies with “Shallow" Effects: Rehearsal, Memorization}

Maintenance rehearsal seems to be the most elementary learning strategy; researchers have observed that preliterate societies transmit information to their members through repetition (Gay and Cole 1967; Gladwin 1970). Four- and fiveyear-olds who are asked to learn a list of words will use some form of rehearsal (Garrity 1975). It is possible that the language acquisition mechanism of the brain makes it easy for children to retain sounds they repeat. Once children adopt this strategy, they may continue using it even after the language acquisition mechanism slows down and material is not so easy to learn through rehearsal. This hypothesis may account for the fact that many 20- and 30-year-old adults do 
not use meaning-based strategies (Rohwer and Thomas 1986; Thomas and Rohwer 1986). Verbatim repetition of material (that is, memorization) is an inefficient method to learn material, but not always so. It is useful in situations where the thinking necessary to find frequently used answers takes longer than the storing of the answers in a systematic, easily retrievable form (for example, multiplication tables).

\section{Strategies with Meaningful Organization Have "Deeper" Effects}

Mnemonic systems tie items low in meaning, such as foreign language vocabulary and terminology, with well-known and meaningful information. The best such mnemonic is the keyword method, in which a foreign word (for example, the Spanish "pato" for duck) can be transformed to a similar-sounding, interactive image, for example, "pot-o," pictured as a duck with a pot on its head (Smith and others 1982).

Strategies that elaborate material involve restructuring of the material into meaningful categories by (a) drawing implications from materials, (b) explaining differences between related and unrelated ideas, (c) speculating about how ideas in materials might be used for practical purposes, or (d) finding examples in everyday life. Systems have been developed to facilitate systematic use of these procedures by learners (Dansereau and others 1979), such as the following:

- REAP: reading, encoding, annotating, pondering;

- SQ4R: surveying, questioning, reading, reflecting, recalling, reviewing (example: The headlines of the chapter can be turned to questions before the text is read);

- MURDER: mood setting for study, read for understanding, recall without referring to the text, digest the material through amplifying and storing it, expanding knowledge by self-inquiry, and reviewing mistakes (for example, learning from texts). First degree MURDER establishes comprehension/retention of material. Second degree MURDER facilitates retrieval and utilization of learned material. Elaborative recall strategies include paraphrase, creation of imagery, or drawing of networks.

Concept maps (or knowledge maps; see figures 1-2 and 17-19) are another useful technique in facilitating elaboration. They display the structure of a topic by representing graphically the interrelationships among its key ideas and its connections with other topics. The spatial properties of the maps are used to present already classified information to the mind's cognitive networks. The reconstructive memory of the mind can then use the bare essentials of the maps to produce a narration that can be almost as complete as a text. Concept maps seem to facilitate long-term retention of material (Dansereau 1987), either as teaching devices or as summarizing devices by learners themselves. Their format is still in the process of testing and development, but they are already used in college courses (Dansereau and others 1979) and have even been tried with grade-school children (Stice and Alvarez 1986). Desktop publishing capability makes development of concept maps feasible for seminar dissemination. (Did you find the maps on cognitive functions-Figures 1 and 2-useful in structuring the material presented here?) 
Figure 17: A concept map for college biology

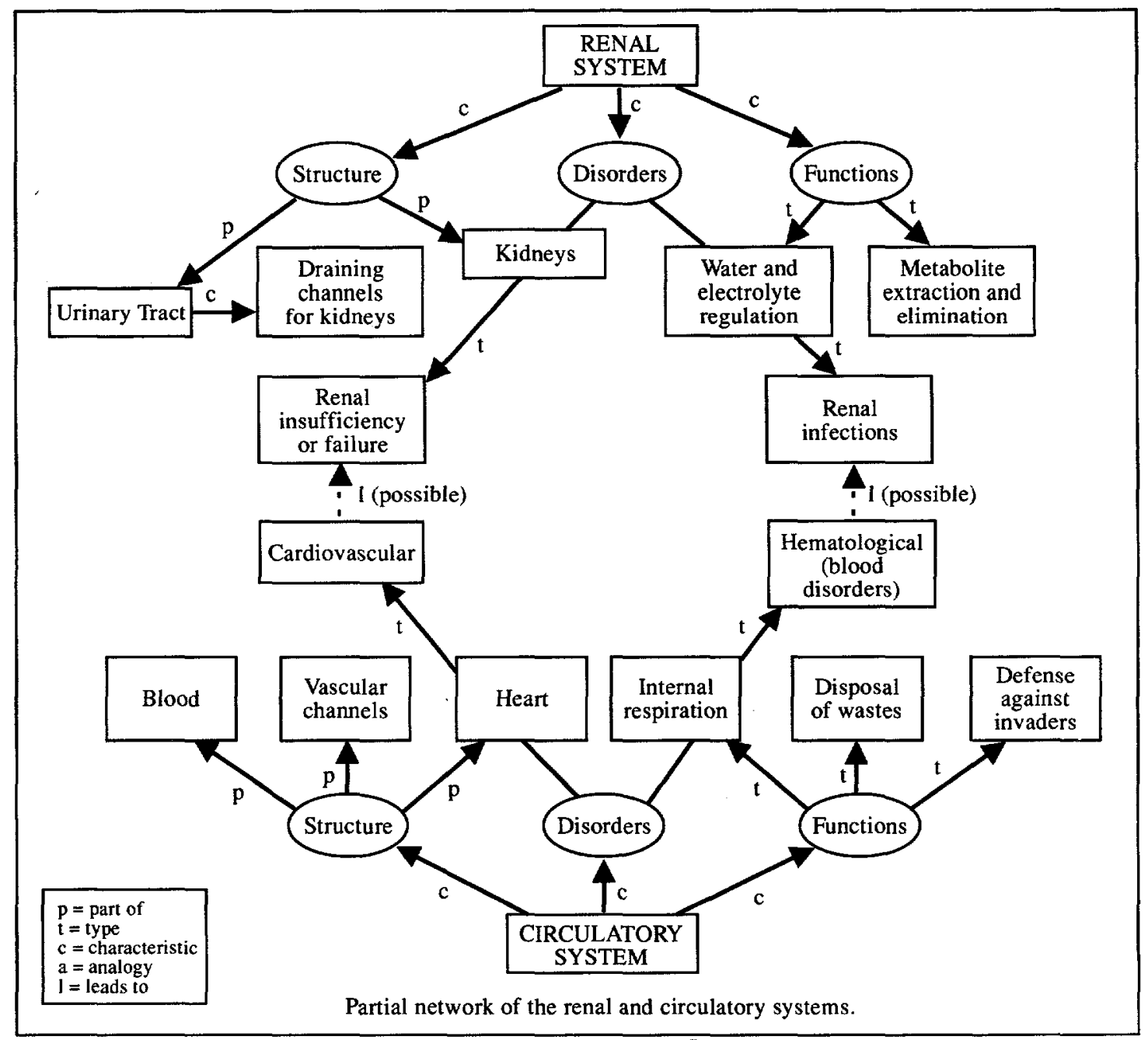

Dansereau, 1987

ksr/w45818c 
Figure 18: A concept map for introductory statistics

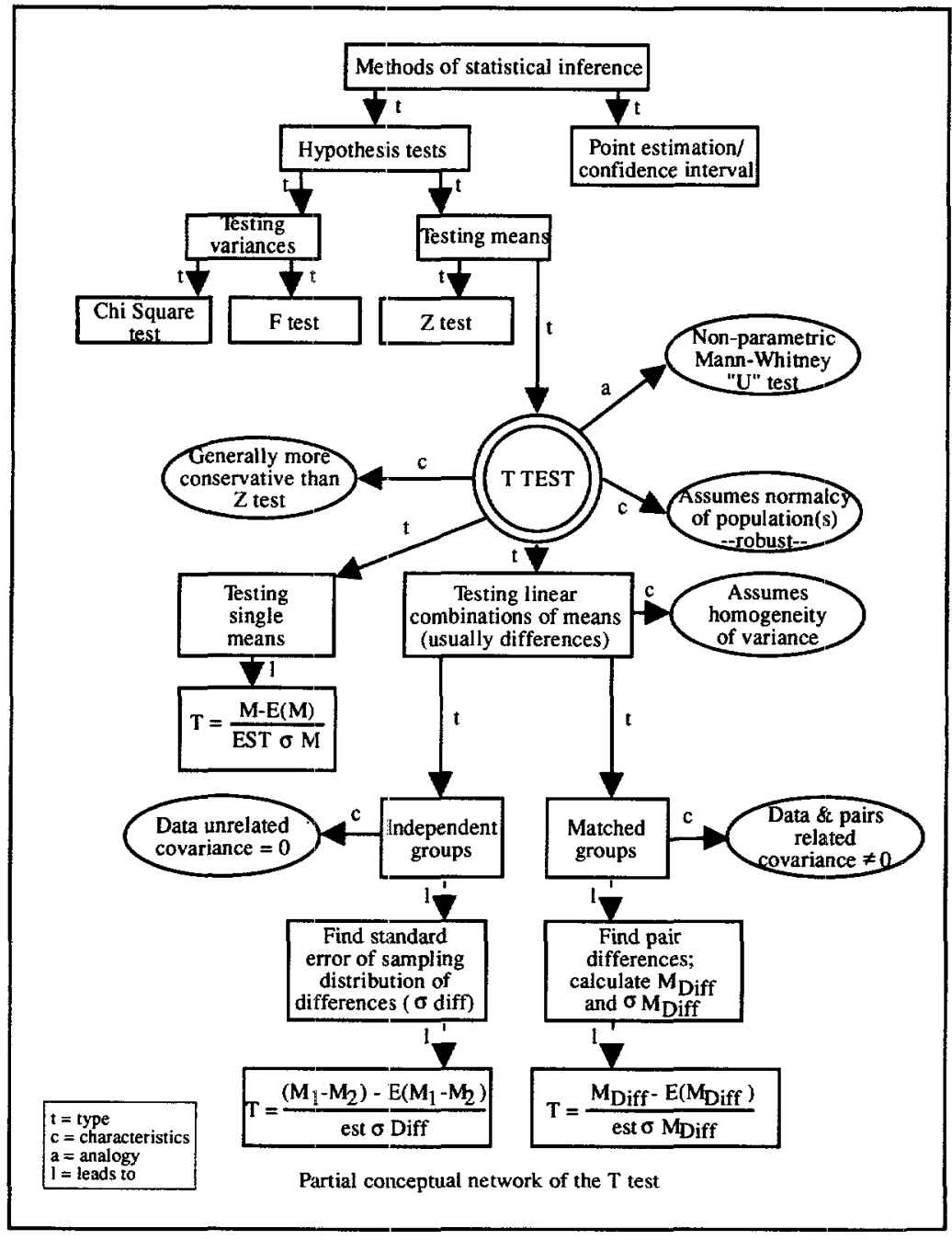

Dansereau, 1987

$\mathrm{ksr} / \mathrm{w45818d}$ 
Figure 19: Link types and structures for concept maps

\begin{tabular}{|c|c|c|c|}
\hline STRUCTURE & LINK & DESCRIPTION & KEY WORDS \\
\hline \multirow[b]{2}{*}{ HIERARCHY } & Pant (of) & $\begin{array}{l}\text { The comtent in a lower node } \\
\text { is part of the object, idea, } \\
\text { process, or concept contained } \\
\text { in a higher node. }\end{array}$ & $\begin{array}{l}\text { part of } \\
\text { segment of } \\
\text { portion of }\end{array}$ \\
\hline & (of) & $\begin{array}{l}\text { The content in a lower node } \\
\text { is a member of the class oo } \\
\text { processes, ideas, concepts, or } \\
\text { objects contained in a higher node. }\end{array}$ & $\begin{array}{l}\text { type of } \\
\text { calegory } \\
\text { kind of }\end{array}$ \\
\hline CHAIN & Is 10 & $\begin{array}{l}\text { The object, process, conceph, } \\
\text { or idea in one node leads to } \\
\text { or results in the object, } \\
\text { process, idea, or concept } \\
\text { in another node. }\end{array}$ & $\begin{array}{l}\text { leads to } \\
\text { results in } \\
\text { causes } \\
\text { produces }\end{array}$ \\
\hline \multirow{5}{*}{ CLUSTER } & $y$ & $\begin{array}{l}\text { The object, idea, process, } \\
\text { or concept in on node is } \\
\text { analogous to, simitar to. } \\
\text { corresponds to, or is like } \\
\text { he object, idea, process, } \\
\text { or concepl in another node. }\end{array}$ & $\begin{array}{l}\text { similar } \\
\text { analagous to } \\
\text { like } \\
\text { corresponds to }\end{array}$ \\
\hline & $c$ & $\begin{array}{l}\text { The object, idea, process, } \\
\text { or concept in one node is a } \\
\text { rrais, aspect, quality. } \\
\text { feature, attribute, detail } \\
\text { or characteristic of he } \\
\text { object, process, concept, } \\
\text { or idea in another node. }\end{array}$ & $\begin{array}{l}\text { fealure } \\
\text { property } \\
\text { trail } \\
\text { aspect } \\
\text { aturibute }\end{array}$ \\
\hline & init & $\begin{array}{l}\text { The object, idea, process, } \\
\text { or concept in one node is } \\
\text { defined by the content of } \\
\text { the other node. }\end{array}$ & $\begin{array}{l}\text { definition } \\
\text { meaning }\end{array}$ \\
\hline & nple & $\begin{array}{l}\text { The content of one node represents } \\
\text { a specific example of the object, } \\
\text { idea, process, or concept contained } \\
\text { in the other node. }\end{array}$ & $\begin{array}{l}\text { example } \\
\text { exemplar } \\
\text { prototype }\end{array}$ \\
\hline & & Link types and structures & \\
\hline
\end{tabular}




\section{Metacognitive Strategies Facilitate Broad Transfer of Learning}

Knowing what strategies to use and how to use them facilitates their use. Thinking about the overall learning process and its goals, however, may be the most important determinant of success in learning. It is now becoming clear that decisions about why and when to use strategies are a result of a person's understanding of how his/her mind processes information (called metacognition; Bransford and others 1986).

Activities that help people reflect on their learning and articulate unstated beliefs about their strategies facilitate transference of comprehension skills to new material. In the final analysis, the ammunition that learners can take with them when they go to conquer new cognitive territory consists of questions like the following:

- What do I know about this subject?

- How much time do I need to learn this?

- What is a good plan of attack to solve this problem?

- How can I predict or estimate the outcome of this task?

- How will I revise my procedures?

- How can I check myself to catch any errors? (Slavin 1986)

\section{Why Information Is Not Accessed When Needed}

Considerable research interest has recently been directed to the area of metacognitive skills (Bransford and others 1986; Pressley and others 1987). Findings promise advances in making already known information accessible for thinking, problem solving, and broad transfer of learning. It is well understood now that people mainly access knowledge that includes information about the conditions and constraints of its use. Learning activities that let people (a) experience problems and then (b) experience the usefulness of information for solving those problems make it more likely that similar information will be looked for in subsequent situations (Sherwood 1985, cited in Bransford and others 1986). Blind training, on the other hand, the learning of material for the sake of learning, results in inert information that people cannot use to solve problems even though they know it well (Brown, Campione, and Day, 1981; see example in annex $\mathrm{H})$. Useful techniques to teach accessible knowledge are still in the process of evolution and research.

For all the reasons discussed thus far, it must now be obvious why theoretical and practical knowledge do not necessarily connect. The following excerpt from a specialized text (Cormier and Hagman 1987) pithily summarizes what is known about transfer of learning. Does it incite you to take action?

Salient common components of either a surface or structural nature, causally or functionally related in outcomes or goal attainment, will increase the likelihood that a problem solver will relate the two situations to each other.

If not, consider how familiar words are given unfamiliar meanings in the use of jargon. Instead, material is much more likely to be utilized in work situations not only if (a) participants have schemata that are detailed enough to register its important points, but also if (b) the schemata that receive the presentation materials have extensive connections with the schemata that contain work procedures (Slavin 1986). 
A speaker who assumes that listeners have more detailed schemata about a subject than they actually do talks "above their heads"; the speaker is written off as "theoretical," and the concepts are deemed inapplicable. Use of professional jargon has that effect, since a term summarizes a list of features that only specialists may have in their cognitive networks under that heading. "Practical" knowledge is more likely to be imparted when a speaker bypasses high-level, superordinate categories that listeners may not possess (for example, macroeconomic stabilization) and connects with the low-level schemata that are attached to many networks (for example, my business; Brooks and Dansereau 1987). This is why "plain language" is so useful. Although its advantages are well understood by trainers, some presenters may choose to show erudition rather than make the transfer of learning easier.

\section{The Future of Cognitive Strategies: Patterns of Learning}

Through its recent attention to metacognitive strategies, cognitive psychology has started moving away from the study of single bits of information to the study of integrated concepts. In the process, it is integrating the thus far dominant issue of how the mind processes information into a more global model of how the mind thinks and uses information. As we are moving away from piecemeal knowledge, the wisdom of experts emerges as a pattern. To become an expert in an area, one must understand and learn to discern the patterns of information that are important in that area. Interactive videotapes may be helpful (Bransford, Sherwood, and Hasselbring 1985) in teaching perceptual learning and pattern recognition so that patterns in the "real world" can be diagnosed (for example, how to "read" the state of the economy).

High-level seminars are essentially concerned with making available knowledge accessible for decisionmaking. Therefore, senior policy seminars must encourage the use of metacognitive strategies, which facilitate use of information for problem solving. Acquiring information is only the first step. The important thing is to package it as a tool available for future manipulation of problems. 


\section{Annex F \\ Deep and Shallow Elaboration? Back to Bloom's Taxonomy}

Much cognitive research (Craik and Tulving 1975) has demonstrated that disjointed facts are candidates for oblivion, while information that is elaborated in connection with existing schernata (for example, is applied, analyzed, or synthesized) is much more likely to be retained. Teaching at any academic level should, therefore, be directed toward integration of facts in existing schemata that grow and get rearranged in the process, rather than toward the acquisition of a list of facts. This is what Benjamin Bloom taught 30 years ago, and his domains of learning are part of basic educational theory in the developed and developing world.

In an effort to help teachers bring about specific educational outcomes, Bloom (1956) classified learning in terms of the (a) cognitive domain (academic knowledge), (b) affective domain (feelings and values about the knowledge), (c) psychomotor domain (motor skills, such as writing), and attempted to specify what instructional activities would realize objectives in specific domains and categories (Bloom, Hastings, and Madaus 1971). Bloom thought that students should not merely show that they have learned facts, but they should also demonstrate comprehension, application, analysis, synthesis, and evaluation of concepts. Fact learning is now understood as shallow elaboration, whereas analytic and synthetic skills are now understood as deeper, meaning-related elaboration. In addition, the often neglected affective domain reflects levels of processing through emotional involvement: merely paying attention denotes the shallowest level of processing and emotional involvement, while being characterized by a set of values is the deepest.

Following is Bloom's taxonomy for the cognitive and affective domains (Bloom and others 1971), this always parsimonious method of describing the "depth" of learning.

- Knowledge: involves the recall of specifics and universals, the recall of methods and processes, or the recall of a pattern, structure, or setting; knowledge can be

- specifics (knowledge of terminology, specific facts);

- ways and means of dealing with specifics (knowledge of conventions, trends and sequences, classifications and categories, criteria, methodology);

- universals and abstractions in a field (knowledge of generalizations, theories, and structure).

- Comprehension: represents the lowest level of understanding. It can be

- translation;

- interpretation;

- extrapolation.

- Application: the use of abstractions in particular and concrete situations.

- Analysis: the breakdown of information into its constituent elements or parts such that the relative hierarchy of idea is made clear and/or the relations between the ideas expressed are made explicit. It can be

- analysis of elements; 
- analysis of relationships;

- analysis of organizational principals.

- Synthesis: the putting together of elements and parts so as to form a whole. It can be

- production of a unique communication;

- production of a plan or proposed set of operations;

- derivation of a set of abstract relations.

- Evaluation: judgments about the value of material and methods for given purposes. It can be

- judgments about the material and methods for given purposes;

- judgments in terms of internal evidence;

- judgments in terms of external criteria.

The affective domain includes (Bloom and others 1971)

- Receiving (attending)

- awareness;

- willingness to receive;

- controlled or selective attention.

- Responding

- accepting to respond;

- willingness in responding;

- satisfaction in responding.

- Valuing

- acceptance of a value;

- preference for a value;

- commitment.

- Organization

- conceptualization of a value;

- organization of a value system;

- Characterization by a value or value system

- consistent response to the world according to the value system;

- individual is characterized by the value system.

Just as behavioral objectives outline what a learner will be able to do at the end of an instructional unit, cognitive objectives can outline the depth to which a concept will be elaborated by participants during a seminar. Bloom's taxonomy for the cognitive and affective domains can be a very useful roadmap to work toward the achievement of deep levels of elaboration. 


\section{Annex G Higher Cognitive Processes}

\section{Reasoning}

We usually assume that people make rational decisions. But do they? A rational decision (Lee 1971, cited in Leahey and Harris 1985) should

- rationally rank-order its priorities: If a government considers primary education more important than vocational education and vocational education more important than higher education, then, given the opportunity, it should prefer to invest in primary education instead of higher education.

- be chosen from a set of all possible alternatives. If a highly desirable or likely choice is not considered, then the final choice may not be the best. A government sensitive about trade union problems, for instance, may exclude from consideration viable alternatives that can anger trade unions rather than weigh their pros and cons along with the rest.

- obtain maximum utility that can be expected, that is, the value of a particular consequence for the decisionmaker. For example, a $\$ 50,000$ contract might have high utility for a small consulting firm but low utility for a multimillion dollar firm.

- be made on the basis of relevant, not irrelevant information. Cost recovery in higher education, for example, has met considerable resistance from journalists who point out that it is not consistent with socialist philosophy.

\section{Cognitive "Frrors"}

The above characteristics of rational decisionmaking are frequently violated. For reasons that are partly understood, decisions are often frequently not rational, a characteristic that has generated considerable research on judgment and decisionmaking. Some of the more frequent errors are described below.

Tendency to confirm a likely hypothesis. The rational decisionmaking procedure would be to examine possible solutions and eliminate all but the best. Instead of searching through possible alternatives for the best one, however, people seem to choose the first alternative that is "good enough" and try to prove it right, ignoring other solutions until the first one is disconfirmed (Solso 1988; Leahey and Harris 1985; Krech and others 1982). Possibly as a result of encoding specificity and the resulting inertness of much knowledge, a lot of the information relevant to a decision is not readily available or is too cumbersome to obtain and use for the split seconds it is often needed. As a result, many not easily available solutions may be left unexamined, such as those dealing with long-term consequences. The most common reasoning problems that result from this tendency are listed below.

Functional fixedness (Duncker 1945). Solving a number of problems by one approach tends to trap the person into using the same method of attack on later 
problems, even though quicker and more obvious methods become appropriate (Krech and others 1982). Furthermore, the greater the initial investment in deriving a certain problem-solving principle, the more people are likely to use it subsequently (Knight 1963). This is a frequent and powerful phenomenon (Reynolds and Flagg 1983), which blocks creativity and results in repeated use of the same set of solutions (for example, price controls) in many countries. One reason why outside consultants are useful is that they may provide a "fresh" view, less encumbered by the brand of functional fixedness dominant in the country.

"Cognitive algebra" and its peculiarities. Our thought processes tend to follow simple algebraic rules that we are not aware of. We frequently make decisions by mentally creating weighted averages of the pros and cons (Anderson 1979). In the equation, however, negative features tend to weigh more than positive ones, and the initial impression gets more attention and weighs more than subsequent ones (Krech and others 1982; see figure 20). The bias toward initial and negative impressions can create considerable obstacles for competent professionals (also see below).

Cognitive shortcuts. Heuristics are practical strategies that people use to shorten their reasoning process (Krech and others 1982). They consist of hunches, educated guesses, and perception of the patterns of a discipline that enable an expert to focus on specific features of a problem. Knowledge of English spelling, for example, helps eliminate a large number of potential solutions for solving anagrams. Heuristics are often useful, but they may also lead to biases by giving prominence to stereotypes, initial impressions, or superstitions. Some of the errors based on them are:

- Availability of knowledge. We estimate the likelihood or frequency of occurrence of some event based on the ease with which its instances and frequency can be brought to mind (Kahneman and Tversky 1982), but we may interpret our own experiences as being more typical than they really are. People refuse to become alarmed, for example, by reports of ozone layer or underground water depletion, because such a thing has never happened before and sounds incredulous.

- Anchoring-adjustment. We make an initial first impression and later revise the estimate upward or downward according to the new information. But we often do not adjust the initial estimate sufficiently and become overly biased by our original estimation. This heuristic is frequently seen in initial low estimates and subsequent revisions of civil works costs.

- Hindsight. People are overly biased by hindsight. The mind's tendency to impose order, structure, and interpretation organizes information in ways that can distort it. After an unfortunate event occurs, people are unable to ignore their after-the-fact knowledge of the outcome, overestimate the probability of its occurrence, and believe they should have foreseen the event. Often people in responsible positions receive the blame after such events occur (Leahey and Harris 1985).

- Representativeness. People tend to predict the outcomes that appear most representative of the evidence. The more consistent the evidence, the more representative the predicted outcome and the greater the confidence in that prediction. People, for example, will predict an overall academic B average with greater confidence on the basis of B grades than on the basis of A's and C's. Consistency, however, often correlates negatively with prediction 
Figure 20: The effects of cognitive algebra on decisionmaking

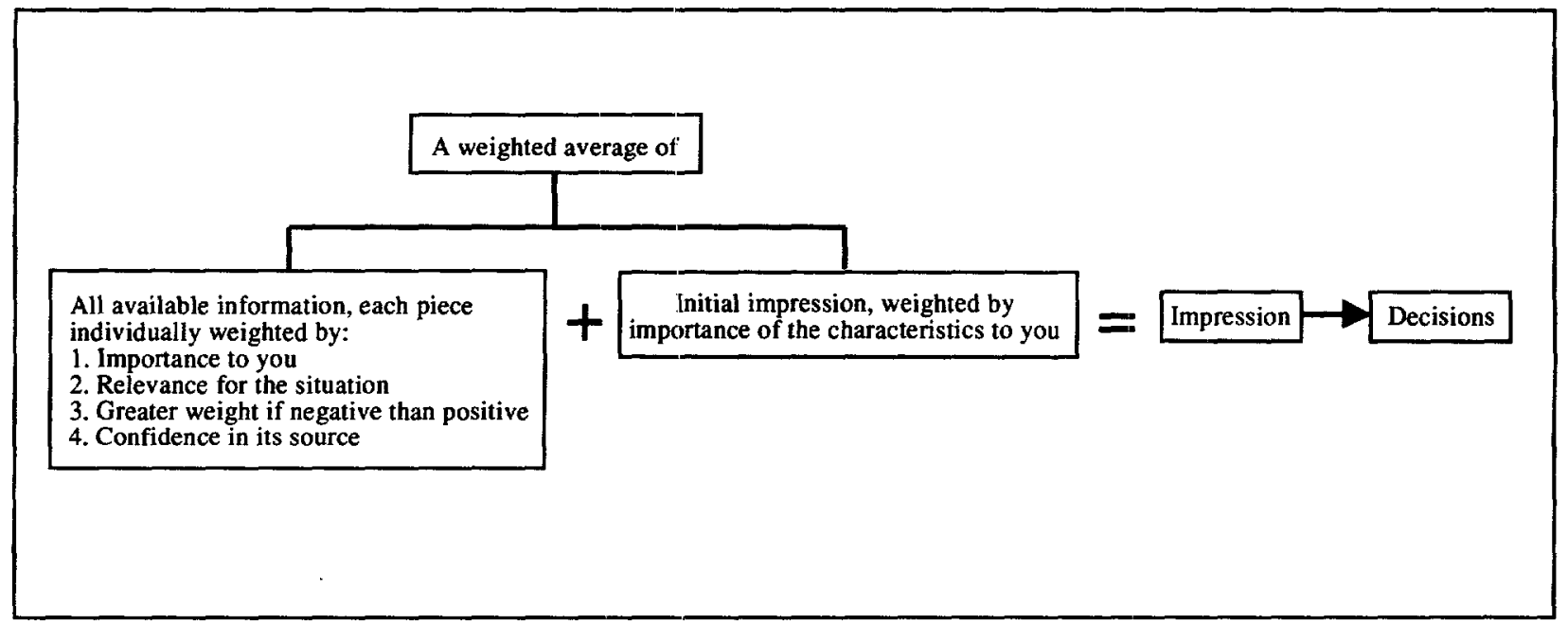

ksr/w45818f 
accuracy, disregards the reliability of the evidence, and the sense of validity is illusory (Kahneman and Slovic 1982).

\section{Arriving at Rational Decisions}

Even educated people have difficulty in evaluating data to make sensible decisions. Training for improved decisionmaking has been the subject of considerable interest and research, and there are several programs and methods that inform people about reasoning pitfalls and train them to recognize these traps and overcome them. One technique that has been found easy to use by political decisionmakers is illustrated below. It utilizes cognitive algebra for adding up the pros and cons as a systematic decisionmaking tool called Multi-Attribute Utility analysis.

To make a rational choice, a person can put in a formula the principles of rational thought, as follows:

- list all realistic alternatives or outcomes;

- identify all factors that can influence a decision;

- estimate subjectively how much each factor weighs in the decision; express its value in terms of a percentage; the values of all factors should sum to 100 percent;

- rate subjectively how much each factor is satisfied by each alternative (through a scale 1-9: 1=bad, low; $9=$ good, high);

- for each factor under each alternative multiply weight by rating; add the products for each alternative separately;

- the most rational decision with the data at hand will be the alternative with the highest total score.

Example. A poor country with high population growth and an educational system of low instructional quality is faced with a prolonged strike of badly paid teachers demanding double pay. The government could (a) give a negotiated salary raise, (b) allow the strike to run its course until teachers' resources are exhausted, or (c) order an end to the strike and fire disobeying teachers'. Which alternative should it follow?

\begin{tabular}{|c|c|c|c|c|c|c|c|}
\hline Factors & $\begin{array}{c}\text { Weight } \\
0.100\end{array}$ & $\begin{array}{c}\text { Raise salari } \\
\text { rating } \\
1.9\end{array}$ & Product & $\begin{array}{c}\text { Wait } \\
\text { rating } \\
1.9 \\
\end{array}$ & Product & $\begin{array}{l}\text { ler teach } \\
\text { conside } \\
\text { rating } \\
1-9\end{array}$ & $\begin{array}{l}\text { hers } \\
\text { ler } \\
\quad \text { Product } \\
\end{array}$ \\
\hline $\begin{array}{l}\text { Political } \\
\text { repercussions }\end{array}$ & 35 & 9 & $35 \times 9=315$ & 5 & $35 \times 5=175$ & 1 & $35 \times 1=35$ \\
\hline $\begin{array}{l}\text { Financial cost } \\
\text { to country }\end{array}$ & 35 & 1 & $35 \times 1=35$ & 9 & $35 \times 9=315$ & 7 & $35 \times 7=245$ \\
\hline $\begin{array}{l}\text { Children's } \\
\text { education }\end{array}$ & 30 & 4 & $10 \times 4=40$ & 1 & $30 \times 1=30$ & 5 & $30 \times 5=150$ \\
\hline Totals & 100 & & 390 & & 490 & & 430 \\
\hline
\end{tabular}


In the example given, the most rational decision would be for the government to wait until teachers decide to stop the strike. Children's education is important, but so are political and financial stability. Anyhow, the striking teachers' classroom performance is not rated highly and children may not miss much by staying out of school.

\section{Problem Solving}

Actually, examining a large number of hypotheses is time consuming and not the best way to proceed if patierns can be used to zero in on what is important. Successful scientists are characterized by a tendency to select a solution and stick to it in spite of some disconfirming evidence (Leahey and Harris 1985). Still, the ability to transcend functional fixedness heuristic traps, to consider all possible solutions if a finite number exists, and to become aware of false premises plays an important role in successful problem solving.

The more different kinds of problems people solve in a learning situation, and the more they have to think to solve them, the greater the chance that they will be able to transfer their skills to the "real world" (Slavin 1986). Problem-solving skills can be taught (Covington and others 1974), and their reinforcement could increase seminar effectiveness. Of assistance are:

- Means-ends analysis: understanding the problem; deciding what is going on and what needs to be done; "What is the difference between where I am now and where I want to be? How can I reduce the difference?" (Newell and Simon 1972). Often people see a problem as an entity that must be solved in one stroke rather than as a series of subproblems that, if resolved, create steady progress toward a goal.

- Extraction of relevant information: clearing away the extra information to get to the important facts (for example, political pressure from vocal groups). That involves weeding out invalid assumptions of which people are often unaware (Leahey and Harris 1985); for example, "public" is better than "private."

- Representation of the problem: making a graph or design, to facilitate the mind that comprehends interacting pictures much more easily than words (Paivio 1971). Even a list of pros and cons is helpful (Leahey and Harris 1985).

To escape functional fixedness and obtain creative, unusual solutions to problems, it helps if one can do the following (Slavin 1986):

- Allow time for incubation in order to suspend the tendency to settle early on a likely solution. Instead, one would pause and reflect on several alternatives before choosing a course of action. Dealing with other tasks for a while may bring out alternatives that were not initially considered because other schemata are brought into play.

- Suspend judgment and consider all possible solutions, no matter how ridiculous. The effect of brainstorming is to avoid focusing on one solution too early and disregard better ways to proceed.

- Work in a relaxed atmosphere. Pressure creates emotional arousal that may interfere with the performance of difficult tasks (Zajonc 1964, cited in Smith and others 1982). Arousal, which prepares the body to fight or flee physical dangers, also tends to bring out the best-learned, survival- 
facilitating responses in people. These are usually the best-known solutions rather than novel, creative ones (Smith and others 1982).

A great deal of theoretical research work has been undertaken in the areas of concept formation, logic, decisionmaking, artificial intelligence, and creativity that are beyond the scope of this document. Though much of this research is still basic, applications on instructional improvement already exist, and future educational innovations to some extent depend on it. 


\section{Annex H \\ How Adults Learn}

Several academic journals and many books are devoted to this field and provide theoretical and practical guidance on training adults. (Samples of significant writings are Srinivasan 1977; Tough 1971; Margolis and Bell 1984.) Following are a number of theories that attempt to outline and justify differences in the learning needs and styles between children and adults. The basic conclusion is that adults pursue different goals through learning, and that they should be given much guidance but little pressure in their learning activities.

\section{Why Should Adults Be Trained Differently Than Children?}

Rogers (1951), a widely cited psychologist who proposed that children should be free to learn at their own pace, formulated a student-centered theory of personality and behavior, which is applicable to adult education. Its most inportant hypotheses are as follows:

- We cannot teach people directly; we can only facilitate their learning.

- A person learns well only those things that he or she perceives as being involved in the maintenance of, or enhancement of, the structure of self.

- Experience that, if assimilated, would involve a change in the organization of self (that is, modify some central beliefs) tends to be resisted through denial or distortion of symbolization.

- The structure and organization of self appear to become more rigid under threat, and more relaxed when free from threat. Experience that is perceived as inconsistent with the self can only be assimilated if the current organization of self is relaxed and expanded to include it.

- The training atmosphere that most effectively promotes significant learning is one in which (a) threat to the self of the learner is reduced to a minimum; and (b) individualized perception of the field is facilitated to suit the adult's needs.

Rogers' popularity in psychotherapy during the 1960s gave a lot of impetus and credibility to his theory, though it has been subjected to very little experimental verification. This theoretical background gave rise to andragogy (Knowles 1973), the philosophy of educating self-directed men as opposed to other-directed children (pedagogy). This theory assumes that as individuals mature, their learning skills differ from those of children. The differences are due to to the following:

- Changes in self-concept: the self concept moves from total dependency to increasing self-directedness. An adult has a need to know and the means to find the knowledge.

- Role of experience: an expanding reservoir of experience causes an adult to become an increasingly rich resource for learning, which can be used by trainers and trainees alike.

- Readiness to learn comes less from academic pressure and more from the requirements of evolving social roles (from staff to manager, from housewife to career woman, and so on). 
- Orientation to learning: children learn the domains of knowledge assigned to them (for example, must study English), while adults learn in order to solve problems (for example, must learn how to read financial statements). Adults are, therefore, concerned with the immediacy of application.

Adults seek further training for pleasure, self-esteem, and knowledge to cope with life changes. Adult learning is a frequent activity in the United States (Tough 1971). It is common for people who engage in it to spend 700 hours a year at learning projects, of which 70 percent are planned by learners themselves. They typically anticipate several desired outcomes and benefits to result, some immediate, others long-term: satisfying a curiosity, enjoying practicing the skill, enjoying the activity of learning, producing something, teaching others, predicting what will happen in some future situation, learning to cope with marriage, divorce, a new job, managerial responsibilities, and so on (Zemke and Zemke 1984). Adult educators have described adult learner orientations in various, frequently overlapping categories, such as (a) goal-orientation-use of education for accomplishing fairly clear-cut objectives; (b) activity-orientation-participation for the sake of having an activity; and (c) learning-orientation-seeking knowledge for its own sake (Houle 1972).

\section{Training Implications for Adults}

Since adults are self-directed, they can only be given facilitation, not taught. In facilitating adult learning, it is important to establish a climate conducive to learning where a two-way transmission of knowledge takes place rather than the one-way transmission of children's classrooms (Knowles 1984). There should be an atmosphere of mutual respect, supportiveness, collaboration rather than competition, openness, and learning- rather than performance-oriented goals. Needs of learning should be diagnosed, and planning should be undertaken jointly. The climate is important because adults are usually not obliged to be in a learning situation. Unless they find the content and mode of presentation appealing, they will either leave or tune the presenter out.

\section{Learning Relationships}

Self-directed learners are able to plan, initiate, and evaluate their own learning experience. Therefore, they may benefit from learning relationships, such as working with mentors and learning partners, or entering into learning contracts (Kelly 1986; Robinson and Saberton 1985; Bova and Phillips 1984). The sparse systematic research that exists in this area suggests that expectations are not always confirmed (Caffarella and Caffarella 1986).

\section{Instructional Preferences}

Adults tend to be application oriented and therefore, less interested in survey courses (Zemke and Zemke, 1984). They prefer single-concept, single-theory training with emphasis on how-to. They also tend to take fewer risks and prefer tried-and-true solutions and learning strategies (Zemke and Zemke 1984). Flexibility to adapt to trainee needs is, therefore, important for adult trainers (Johnson 1985). "Unfreezing," unexpected experiences built into an early phase of a 
course or workshop, can make adults look at themselves more objectively and free their minds from preconceptions (Knowles 1973).

\section{Teacher Perceptions and Practices}

In one of the few research tests of adult education philosophy, teachers agreed that adults do indeed show more intellectual curiosity, concern with applications, motivation to learn, willingness to work hard and to take responsibility for learning, clarity about what they want to learn, less dependence on the teacher, but also more resistance to new ideas. Teachers, however, did not interact with adults in the more facilitative, student-centered fashion prescribed by adult education theories, even when they were well informed about them (Gorham 1984; Conti 1985). Apparently, exhortations to be facilitative do not amount to concrete suggestions on what behaviors trainers must change.

Considerable thought has been given to the adult learning process, and several models have been generated in hopes of guiding curriculum design. One example is the experiential learning model, according to which optimal learning is a cyclical event that includes four basic modes (Williams 1984; Kolb 1976):

- Concrete experience: a person must be able to become involved fully, openly, and without bias in new experiences (for example, trainees observe a film demonstrating various managerial techniques).

- Reflective observation: a person must able to reflect on and observe these experiences from many perspectives (for example, discussion occurs during observations).

- Abstract conceptualization: A person must be able to create concepts that integrate these observations into logically sound theories (for example, lecture and required reading on various aspects of developing managerial skills add depth.)

- Active experimentation: A person must be able to use these theories to make decisions and solve problems (for example, trainee takes part in a mock employer/employee session demonstrating previously learned skills).

\section{The Utility of Adult Education Theories}

The theories presented in this section make a lot of intuitive sense, and this may be one reason why their adherents have not been compelled to test them experimentally. This problem is complicated by the apparent ignorance or disregard of cognitive research shown by many authors. Many phenomena considered characteristic of adults actually characterize all learners (for example, benefits of audiovisual aids, interference of details in the acquisition of main ideas; Zemke and Zemke 1984). Rigorous research in this field would resolve many questions, among them: (a) precisely which instructional variables are more effective in creating long-term retention of material by adults, (b) what components of instructors' behavior toward adult learners are most effective in developing the open climate considered necessary for training mature learners, and (c) how various modes of presentation compare in imparting usable knowledge. Thus far, there has been practically no research on the instructional or social variables that operate in seminar settings. Lacking concrete findings, 
seminar managers can only share empirical advice and generalize from research on children.

\section{The Search for Optimal Methods of Training: Cognitive Learning Styles}

People differ in what they look for in a learning situation and how they plan their actions. For example, some may work better in groups, while others may work better alone. Cognitive styles describe the process through which individuals organize and transform information in a decisionmaking situation. Educators have hypothesized that if the cognitive style of a learner is identified and material is presented in a compatible method, learning will be facilitated.

The concept has gained popularity, and multitudes of vague and overlapping cognitive styles have been generated. Examples are as follows:

- Idealistic (thinker and reasoner), versus Pragmatic (application-oriented), versus Realistic (direct and efficient), versus Existentialistic (no best method exists); (Ward 1982, cited in Sataka 1984)

- Independent (thinks for himself/herself), versus Dependent (learns only what is required), versus Collaborative (shares ideas), versus Competitive (learns material to perform better), versus Participant (takes responsibility for learning), versus Avoidant (not interested in course content) (Reichmann and Grasha 1974, cited in Ash 1986)

- Converger (abstract conceputalizer and active experimenter), versus Diverger (imaginative and emotional), versus Assimilator (abstract conceptualizer and reflective observer), versus Accommodator (becomes involved in new experiences) (Kolb 1976).

- Other styles: Field dependence versus independence, scanning, breadth of categorizing, conceptualizing styles, cognitive complexity versus simplicity, reflectiveness versus impulsivity, leveling versus sharpening, constricted versus flexible control, tolerance versus intolerance (Messick 1970, in Ash 1986).

- Perceptual learning styles: visual, interactive, aural, haptic, kinesthetic, print (that is, reading), olfactory (James and Galbraith, 1985); the most common style is visual.

The best-known cognitive style that has also received some attention from psychologists is field dependence, a trait that can be reliably diagnosed through a test of finding embedded figures in complex designs. Field-dependent people are attentive to external cues and look to the environment for aid in solving problems. They are, therefore, less able to focus on a figure or main idea and more prone to be confused by the complexity of the environment (Witkin and Goodenough 1977). Women tend to be field-dependent more often than men. Field independent students are more likely to favor mathematics and the sciences, subjects that clearly require cognitive restructuring skills. Field-dependent college students tend to favor elementary education, speech therapy, and nursing (Smith and others 1982). According to anecdotal observations, field dependence may be more common among students in developing countries. 


\section{Utility of Cognitive Styles}

Designing training after the cognitive styles of learners have been identified has been fraught with problems. Lacking a firm theoretical basis in cognitive research, different writers have generated multiple overlapping and conflicting lists. Diagnosis of a learning style (assuming a person consistently uses one) is conducted through questionnaires that ask people how they like to learn (for example, Multimodal Paired Associates Learning, Grasha-Reichmann Student Learning Scales). Habits are then transformed into learning styles.

Although this area has some devoted followers, learning styles, as used today, have little utility for most trainers. Training prescriptions (for example, debate, computer-assisted instruction, case study, goal setting, lecture, role) are not sufficiently differentiated among learning styles, nor have recommendations been frequently subjected to experimental verification. Furthermore, taking time to diagnose learning styles is impractical in a brief seminar setting. If consistent styles exist, they probably occur at random, and trainers of adults cannot have in practice a bag of methods to accornmodate all. (How do you teach a person with an olfactory perceptual style?) The greatest use of cognitive styles may lie in making learners aware of their own preferences and in making trainers tolerant toward unusual learning habits. 


\section{Annex I Social Factors That Influence Seminar Participants}

\section{The Behavior of Seminar Participants in the Social Group}

The hope of a good self-concept influences learning. The extent to which people choose to engage in learning activities is a product of many constructs that have not yet been researched enough to provide guidance: self-image as a learner, selfefficacy, self-regulation, cognitive styles (Annex $H$ ), social competence, evaluation anxiety, beliefs as to whether intelligence is fixed or malleable (Snow 1986).

The presence of a group has powerful effects on individuals' behavior, some constructive and some not so constructive. People do not want to act inappropriately and appear foolish in front of everyone. As a result, participants who do not have detailed knowledge of the material may deny that they have not understood a presentation, or ask secondary questions that conceal their ignorance. But participants who know a subject well often find that the presence of others makes them perform better than they otherwise would and they welcome the presence of a group (Smith and others 1982).

Inevitably, concern for the opinion of others has been found to influence the extent to which people will seek challenge and persist in the face of obstacles. If the goal of a training institution is to impart learning and evaluations are hidden (as in computer-assisted instruction), participants are more likely to risk displays of ignorance in order to acquire skills and knowledge. If the goal is performance and evaluations are public, people may sacrifice learning opportunities for opportunities to look smart or "save face" (Dweck 1986). Highly intelligent women are more prone to choose the latter strategy than men (Licht and Dweck 1984) and as a result, tend to choose not very challenging activities.

\section{The Effects of a Crowd}

Widely publicized research (Latané and Nida 1981) has shown that people are much more likely to help a person in need if they think that they are the only available helper. Responsibility is diffused among people in a crowd, and multiple bystanders have repeatedly done nothing to prevent a murder because they thought that someone else was surely getting help. The same phenomenon, called social loafing, has been found to operate in some training situations. In a group, effort and also responsibility are diffused among many individuals who then do not work as hard to attain a goal as they would if the outcome depended only on them (Latane and others 1979). The larger the group, the greater the diffusion of responsibility. For instance, people in a group of three are more likely to pay attention, offer opinions, and debate with a speaker than the same people in a group of 30 . A speaker talking to three people is also more likely to persuade them than if he or she addressed the same people in a group of 30 . Sitting in the back row or far 
from the speaker during a seminar probably encourages social loafing because people feel that someone else is providing audience response to a presenter, and they may be less likely to pay attention. The relative lack of involvement of people in large audiences may inhibit the elaboration process necessary to retain and use material in the long run.

This phenomenon underscores the effectiveness of small group size on learning. Social loafing can be effectively combatted by singling people out and assigning specific responsibilities to them. Making eye contact, moving toward participants, and asking questions probably gives people the impression that the speaker is addressing them directly and can increase the likelihood that they will become involved in the issues. 


\section{Annex J \\ People's Beliefs and Attitude Change}

What are the conditions that promote attitude change? Diplomats, politicians, and advertisers alike want answers to this question. Extensive experimental data exist, but specific answers are hard to give because of the large number of variables that interact and determine the outcome. In order to present the complex answers provided by social psychologists, a brief description of the underlying issues of attitudes and beliefs follows.

\section{How Attitudes Develop}

An attitude is a relatively long-lasting set of feelings, behaviors, and beliefs directed at a person, object, or situation. Attitudes, have, therefore, an emotional component, a behavioral component, and a cognitive component (Smith and others 1982). The cognitive component, beliefs, has been the object of considerable interest. Research to find out how attitudes change has invariably focused on beliefs that are hypothesized to influence emotional responses and behavior. Beliefs may consist of factual arguments, but also of prejudices, or even basic assumptions of which people are unaware (for example, "women are too emotional to be good professionals"; Krech and others 1982).

The tendency people have to settle on a hypothesis that is good enough and then to hold on to it until it is falsified (annex $G$ on reasoning) makes it possible to form a belief from a single, vivid piece of confirming evidence about an issue (for example, newspaper articles about career welfare women; Leahey and Harris 1985). Once a belief is formed in this haphazard fashion, it is self-perpetuating. Schemata in the cognitive networks store information about it and make new information about the object of the belief meaningful and easily learned. As a result, confirming evidence, no matter how isolated and unusual, tends to be integrated into the schemata while disconfirming evidence is dismissed as incredulous. This happens even when balanced arguments are presented, which are supposed to reduce differences between holders of opposing opinions (Lord, Ross, and Lepper, cited in Leahey and Harris 1985).

\section{How Easily Can People Change their Beliefs?}

It is obviously easier to change opinions about the best brand of motor oil than to change religion. This happens because some beliefs provide a foundation for others, and to change those would imply a great deal of changes and reconciliations in the belief schemata that are undesirable. Efforts to understand how resistant beliefs are and what can be done to change them are illustrated by the scheme in figure 21 (Rokeach 1968; Krech and others 1982). Accordingly, beliefs can be classified as follows:

- Type A: deep-seated beliefs recognized by everyone "My name is X"; "I am an Indian"). They are learned very early in life by direct encounters with 
Figure 21: Types of beliefs

\begin{tabular}{|c|c|c|c|}
\hline Type and Definition & Examples & How Maintained & How Changed \\
\hline $\begin{array}{l}\text { Type A } \\
\text { Deep-seated, } \\
\text { primitive beliefs } \\
100 \% \text { consensus }\end{array}$ & $\begin{array}{l}\text { "My name is } \\
\text { "This is a book" } \\
\text { "I am a Buddhist" }\end{array}$ & $\begin{array}{l}\text { Consensus, } \\
\text { consistent } \\
\text { and } \\
\text { continuous } \\
\text { reinforcement }\end{array}$ & $\begin{array}{l}\text { Psychoses, } \\
\text { brainwashing, } \\
\text { religious } \\
\text { conversions }\end{array}$ \\
\hline $\begin{array}{l}\text { Type B } \\
\text { Deep-seated, } \\
\text { primitive beliefs } \\
\text { no consensus }\end{array}$ & $\begin{array}{l}\text { "I am a good person" } \\
\text { "Women are inferior" }\end{array}$ & $\begin{array}{l}\text { Self-support } \\
\text { as a matter of } \\
\text { faith }\end{array}$ & $\begin{array}{l}\text { Possibly through } \\
\text { psychotherapy }\end{array}$ \\
\hline $\begin{array}{l}\text { Type } C \\
\text { Convictions about } \\
\text { who is an authority }\end{array}$ & $\begin{array}{l}\text { "Holy Book x gives } \\
\text { best way to live" } \\
\text { "According to Marx..." } \\
\text { "Scientists are } \\
\text { experts on Z" }\end{array}$ & $\begin{array}{l}\text { Self-support } \\
\text { as a matter of } \\
\text { faith } \\
\text { Social support } \\
\text { via peer groups }\end{array}$ & $\begin{array}{l}\text { Criticize the } \\
\text { social group } \\
\text { Limit authority's } \\
\text { area of expertise } \\
\text { Discredit the } \\
\text { authority }\end{array}$ \\
\hline $\begin{array}{l}\text { Type D } \\
\text { Belifs derived } \\
\text { from the credibility } \\
\text { of an authority }\end{array}$ & $\begin{array}{l}\text { "Free market economy } \\
\text { is best" } \\
\text { "Third world clebt } \\
\text { should by erased" }\end{array}$ & $\begin{array}{l}\text { Self-support with } \\
\text { reference to } \\
\text { authority beliefs } \\
\text { Social support } \\
\text { via social groups } \\
\text { Support based on } \\
\text { premises and } \\
\text { logical argument }\end{array}$ & $\begin{array}{l}\text { Criticize the } \\
\text { social group } \\
\text { Limit authority's } \\
\text { area of expertise } \\
\text { Discredit the } \\
\text { authority }\end{array}$ \\
\hline $\begin{array}{l}\text { Type E } \\
\text { Inconsequential } \\
\text { beliefs }\end{array}$ & $\begin{array}{l}\text { "Instant coffee } \\
\text { tastes terrible" } \\
\text { "WordPerfect is } \\
\text { better } \\
\text { than Mass-11" }\end{array}$ & $\begin{array}{l}\text { Social support via } \\
\text { peer groups } \\
\text { By examples of } \\
\text { personal experience }\end{array}$ & $\begin{array}{l}\text { Easy to change, } \\
\text { usually by } \\
\text { presenting new and } \\
\text { contradictory } \\
\text { evidence or examples }\end{array}$ \\
\hline
\end{tabular}


the object of belief. They are central to an individual and support other beliefs, such as who the enemies of a country are.

- Type B: deep-seated, private beliefs ("God wants me to do X"; "I can't stand socialists"). They are identical to type A, except that they are not shared by everyone.

- Type C: convictions that someone is an authority on something. Notable examples are science and religion authorities. They are not as central as types $\mathrm{A}$ and $\mathrm{B}$, and can therefore be changed through (a) criticizing the group of authorities the person believes in, (b) pointing out the areas in which the authorities have no expertise, and (c) discrediting the authorities. Attempting to change them, however, may produce resistance and hostility.

- Type D: beliefs derived from faith in authorities, bolstered by logical arguments. They are more easily changed than type $\mathrm{C}$, but may have many arguments supporting them, making change difficult.

- Type E: inconsequential beliefs about small things (for example, "Swissair is a great airline to fly") that do not have many connections with other beliefs and can easily be changed.

Seminars routinely challenge type D and type $E$ beliefs. Beliefs in which people have vested interests, however, are probably type B or C, by definition more central to their well-being than logical arguments about the validity of authorities and, therefore, much more difficult to change.

How to change people's attitudes depends on how their beliefs were acquired in the first place. People can form beliefs (Petty, Ostrom, and Brock 1981) for the following reasons:

- People believe something because it serves a function. If supporting a certain political philosophy gives seminar participants economic and social power, presenting them with facts about the consequences of that philosophy will not change their attitude. A trade union leader receiving a salary and a reputation from the union is not likely to be converted by facts that weaken the union's position.

- People must be consistent. For reasons that are unclear, people do not feel right if they have to hold inconsistent beliefs (for example, admire a politician and also believe that he or she compromises national interests for personal gain). If that happens, the less important belief is changed to become consistent with the more important one (Krech and others 1982). This process of reconciliation often involves rationalization, discrediting sources of information, or even forgetting what is inconvenient to remember. People's beliefs change even if they are in some way "tripped" into acting in an inconsistent manner. They may then prefer to change their initial attitudes and rationalize their actions rather than admit that they have been inconsistent. (This phenomenon is called cognitive dissonance.) Seminars routinely create inconsistencies in people's beliefs, and people resolve them by either rejecting previously held attitudes or by rejecting seminar communications (as biased, right-wing, and so on).

- People interpret messages by taking into account the characteristics of the communicator. The same statement attributed to Thomas Jefferson or to Lenin will persuade different groups of people. Considerable research (for example, Ash 1948, cited in Smith and others 1982) has shown that an effective, attitude-changing communicator must be considered by listeners (a) expert on the subject, (b) trustworthy, and (c) unbiased. A widely known African minister of finance, therefore, would be more likely to convince 
Africans of the merits of structural adjustment than a German International Monetary Fund staff member. Unbiased communicators present both sides of the argument, and are more effective in persuading educated audiences, even if people do not agree with the arguments themselves.

- People process information cognitively and, therefore, learn their beliefs. This is currently believed to be the most important factor that creates beliefs (Petty 1981). This hypothesis implies, therefore, that people will change their attitudes if they are given information that in some ways modifies their information processing. Such tactics include the following:

- Inoculation: Presenting a weak attack on a position the communicator wants to reinforce and then refuting it motivates people to develop stronger arguments that will resist later refutation (McGuire and Papageorgis 1961, in Petty and others 1981). Presenting and refuting weak arguments against macroeconomic adjustment policies, for example, might induce seminar participants to form stronger arguments for it.

- Disruption of thoughts: It is hypothesized that when people hear a message they disagree with, they repeat in their minds arguments against it. If attention to an external problem makes them abandon their thoughts for a while, they become more vulnerable to persuasion by the message (Petty and Brock 1981). For instance, if there is noise in a seminar room while an argument is presented, disagreeing participants might stop their thought processes in order to pay attention and, therefore, find the message more persuasive than they would if there were no noise.

- Opinions during discussions can be polarized and become more extreme under certain circumstances. Though groups usually have a dampening effect on many participants, extreme attitudes might be encouraged if a group is like-minded and cohesive. This phenomenon is sometimes referred to as groupthink and can result in unanimous extreme decisions that are agreed upon by group members who are pressured to go along with the tide (Smith and others 1982; Janis and Mann 1977).

- A person who is asked in a debate to argue in favor of positions he or she disagrees with makes opposing arguments seem more convincing and reasonable (Smith and others 1982). Several studies show that when people deliver speeches advocating positions opposite to their own, their attitudes actually shift in the direction of the speech they have given. This strategy can be nonthreatening and very useful in creating attitude changes between representatives of opposing interests in a seminar. Role-playing is a similar strategy that creates empathy by allowing participants to experience what it is like to be someone else (for example, what it is like for women to obtain credit in some countries). Case studies are often very effective in putting participants in someone else's shoes.

- Cooperation with people who hold opposing ideas allows opponents to concentrate on nonthreatening tasks together and has been found to result in some attitude change about the opposing group (Petty and others 1981). This is another useful strategy for seminars that include participants with vested interests. Grouping for various activities should include members of both sides, even though they may tend to avoid each other if allowed to choose sides. 
- Small groups discourage social loafing, and speakers have more influence on their listeners when few people are present (annex I).

- Scare tactics are effective in changing attitudes only under certain circumstances. The message should not be too frightening, and it should include guidelines on what to do to reduce the fear. Otherwise, the subjects may reduce their anxiety by denying the message or the credibility to the communicator.

To conclude, attitude-change strategies that appear constructive in seminars are:

- Expert, credible, trustworthy presenters who present both sides of an argument and who are seen as similar to participants (or could be participants themselves). This is another argument in favor of asking selected participants to chair sessions.

- Asking people to argue in favor of beliefs they are opposed to. Playing of opposing roles in simulations or case studies.

- Cooperative activities with holders of opposing opinions on neutral issues. 



\section{Glossary}

Advance organizers: General statements given before instruction that relate new information to existing knowledge.

Andragogy: The process of facilitating adults to acquire the knowledge they need.

Chunking: One way of organizing material by grouping it into larger units that are meaningful.

Cognitive dissonance: The state of tension that results if an individual experiences two beliefs that are psychologically inconsistent. In order to reduce the tension, the individual will change one of the beliefs to resolve the inconsistency.

Cognitive networks: Intricate, interconnected networks of superordinate and subordinate categories that form the organizational basis of long-term memory.

Cognitive psychology: Discipline that focuses on how knowledge is processed by the human organism, that is, acquired, modified, manipulated, stored, and used.

Cognitive strategies: Methods that learners use to commit material to memory.

Concept: A category under which specific elements may be grouped.

Concept maps (or knowledge maps): Outlines that graphically display relationships among concepts in a topic.

Educational psychology: The branch of psychology concerned with all aspects of the educational process, including learning, classroom instruction, vocational counseling, and the testing of abilities and attitudes.

Encoding: The process of transforming material into a form acceptable for storage in memory.

Encoding specificity principle: (a) Items are stored in memory the way they are first perceived; (b) the particular manner of encoding determines which retrieval cues will permit access to the stored information; and (c) the closer coding and retrieval cues match each other, the better we can expect recall to be (Wingfield and Byrnes 1981).

Episodic memory: The record or personal life experiences.

Functional fixedness: Solving a number of problems by one approach tends to trap the person into using the same method of attack on later problems, even though quicker and more obvious methods have become appropriate.

Heuristics: problem-solving methods characterized by quick and easy search procedures. They can be used to approximate questions to answers.

Information retrieval: Recovery of stored information used to guide behaviors needed in a particular situation.

Interference: The presumed disruptive influence upon a response of the tendency to make other responses that were learned either before or after the correct response was learned.

Learning: A relatively permanent change in behavior resulting from experience and practice (that is, not mere maturation).

Long-term memory: The system with an extremely large capacity and complex organization that is assumed to account for relatively enduring memories for periods ranging from over a minute to many years. 
Maintenance rehearsal: The process of maintaining an item in short term memory by repetition.

Metacognitive strategies: Skills that increase retention by making learners more aware of how they process information.

Mind: The thinking aspect of the brain. Psychology focuses on observable behavior and eschews vague terms, but cognition, which cannot be directly observed, is forced to use some metaphysical-sounding terms.

Perception: Interpretation of sensory information according to experience.

Proposition: The hypothetical smallest unit of knowledge about which it makes sense to make a true or a false statement.

Schema (plural is schemata): A network of connected ideas or relationships.

Semantic memory: The organized knowledge people have of rules and procedures, meaning of concepts, relationships among them, and rules for manipulating them.

Sensation: Initial experience of elementary forms of stimulation.

Sensory register: The assumed memory system that stores stimulus information directly for a duration of less than a second.

Short-term memory: A system that is presumed to receive information from the sensory input or sensory memory, usually maintaining this input for only a minute or so. Its capacity is quite limited and an auditory or articulatory code is often used.

Social loafing: The tendency of group members in some situations to reduce their own individual efforts in expectation that someone else will accomplish what is needed.

Storage: The state of memory in which information is maintained over a period of time.

Thinking: A process by which a new mental representation is formed through the transformation of information by complex interaction of the mental attributes of judging, abstracting, reasoning, imagining, and problem solving.

Tip-of-the-tongue phenomenon: The situation in which one can almost remember something previously learned. One can often accurately state something about the sought-after material, such as the length of the word and so on.

Transfer of learning: The general term for the effect (positive or negative) of other learning on current learning or memory. 


\section{References}

Altman, J. Autoradiographic examination of behaviorally induced changes in the protein and nucleic acid metabolism of the brain. In J. Gaito, ed. Macromolecules and Behavior, 2d ed. New York: Appleton, 1972.

Anderson, J. R., and Bower, G. H. Human Associative Memory. Washington, D. C.: Winston, 1973.

Anderson, N. H. Algebraic rules in psychological measurement. American Scientist, 1979, 67, 555-563.

Ash, B. F. Identifying Learning Styles and Matching Strategies for Teaching and Learning. 1986 (ERIC Document Reproduction Service No. ED 270 142).

Atkinson, R. C., and Shiffrin, R. M. Human memory: A proposed system and its control processes. In K. W. Spence and J. T. Spence, eds., The Psychology of Learning and Motivation: Advances in Research and Theory (vol. 2) New York: Academic Press, 1968.

Ausubel, D. P. The Psychology of Meaningful Verbal Learning. New York: Grune and Stratton, 1963.

Bartlett, F. C. Remembering: A Study in Experimental and Social Psychology. Cambridge: Cambridge University Press, 1932.

Bloom, B. S., ed. Taxonomy of Educational Objectives. Handbook I: Cognitive Domain. New York: McKay, 1956.

Bloom, B. S., Hastings, J. T., and Madaus, G. F. Handbook on Formative and Summative Evaluation of Student Learning. New York: McGraw-Hill, 1971.

Bova, B. M., and Phillips, R. R. Mentoring as a learning experience for adults. Journal of Teacher Education, 1984, 35, 16-20.

Bower, G. H. Mood and memory. American Psychologist, 1981, 36, 129-148.

Bransford, J. D., Sherwood, R. D., and Hasselbring, T. S. Computers, videodisks, and the teaching of thinking. Paper presented in the Conference on Computers and Complex Thinking, Washington, D. C.: 1985.

Bransford. K., Sherwood, R., Vye, N., and Rieser, J. Teaching, thinking and problem solving. American Psychologist, 1986, 41, 1078-89.

Brooks, L. W., and Dansereau, D. F. Transfer of information: An instructional perspective. In S.M. Cormier, and J.D Hagman, eds. Transfer of Learning: Contemporary Research and Applications. New York: Academic Press, 1987.

Brown, A. L., and Campione, J.C. Psychological theory and the study of learning disabilities. American Psychologist, 1986, 41, 1059-1068.

Caffarella, R. S., and Caffarella, E. P. Self-directedness and learning contracts in adult education. Adult Education Quarterly, 1986, 36, 226-234.

Campbell, B., and Spear, N. Ontogeny of memory. Psychological Review, 1972, 79, 215-237.

Carey, S. Cognitive science and science education. American Psychologist, 1986, $41,1123-1130$.

Casse, P. Training for the Cross-Cultural Mind (2nd ed.) Washington, DC: The Society for Intercultural Education, Training and Research, 1981. 
Chall, J.S., and Peterson, R.W. The influence of neuroscience upon educational practice. In S.L. Friedman, K. A. Klivington, and R. W. Peterson, eds. The Brain, Cognition, and Education. New York: Academic Press, 1986.

Charrow, R. P., and Charrow, V. R. Making legal language understandable: A psycholinguistic study of jury instruction. Columbia Law Review, 1979, 79, 1306-1374.

Check, J. F. Teaching learning preferences of the adult learner. Education. 1984, $105,107-112$.

Cherry, E. C. Some experiments on the recognition of speech with one and with two years. Journal of the Acoustical Society of America, 1953, 25, 975-979.

Clifford, M. M. Thoughts on a theory of constructive failure. Educational Psychologist, 1984, 19, 108-120.

Collins, A. M., and Loftus, E. E. A spreading activation theory of semantic processing. Psychological Review, 1975, 82, 407-428.

Collins, A. M. and Quillian, M. R. Retrieval time from semantic memory. Journal of Verbal Learning and Verbal Behavior, 1969, 8, 240-249.

Conti, G. The relationship between teaching style and adult student learning. Adult Education Quarterly, 1985, 35, 220-228.

Cormier, S.M., and Hagman, J.D., eds. Transfer of Learning: Contemporary Research and Applications. New York: Academic Press, 1987.

Covington, V. M., Cruchfield, R. S., Davies, L and Olton, R. M. The Productive Thinking Program: A Course in Learning to Think. Columbus, Ohio: Merrill, 1974.

Craik, F. I. M. Age difference in human memory. In J. E. Birren and $K$. W.Schaie, eds. Handbook of the Psychology of Aging. New York: Van Nostrand Reinhold, 1977.

Craik, F. I. M., and Lockhart, R. S. Levels of processing: A framework for memory research. Journal of Verbal Learning and Verbal Behavior, 1972, $11,671-684$.

Craik, F. I. M., and Simon, E. Age differences in memory: The roles of attention and depth of processing. In L. W. Poon, J. L. Fozard, L.S. Cermak, D. Arenberg, and L. W. Thompson, eds. New Directions in Memory and Aging: Proceedings of the George Talland Memorial Conference. Hillsdale, N. J.: Lawrence Eirlbaum Associates, 1980.

Craik F. I. M., and Tulving, E. Depth processing and the retention of words in episodic memory. Journal of Experimental Psychology: General, 1975, 104, 268-294.

Craik, F.I.M., and Watkins, M.J. The role of rehearsal in short-term memory. Journal of Verbal Learning and Verbal Behavior, 1973, 12, 599-607.

Dansereau, D. F. Knowledge Maps: An Analysis of Spatial/Nerbal Processing. Unpublished report, Texas Christian University, 1987.

Dansereau, D. F., McDonald, B. A., Collins, K.W., Gerland, J., Holley, C. D., Diekhoff, G. M., and Evans, S. H. Evaluation of a learning strategy system. Cognitive and Affective Learning Strategies. New York: Academic Press, 1979.

Denney, N. W. Classification abilities in the elderly. Journal of Gerontology, 1974, 29, 309-314.

- Free classification in preschool children. Child Development, 1972, 43, 1161-1170. 
Doherty, S. Case Writing for Instructors in Project Planning. Bradford, England: Project Planning Centre for Developing Countries, University of Bradford, 1982.

Duncker, K. On problem solving. Psychological Monographs, 1945, 58 (entire No. 270).

Dweck, C. S. Motivational processes affecting learning. American Psychologist, $1986,41,1040-1048$.

Eagle, M., and Ortoff, E. The effect of level of attention upon "phonetic" recognition errors. Journal of Verbal Learning and Verbal Behavior, 1967, 6, 226-231.

Ebbinghaus, H. Ueber das Gedachtnis: Untersuchungen zur Experimentellen Psychologie. Leipzig: Dunker and Bumbolt, 1885. Translated by H. A. Ruger and C. E. Bussenius, 1913, and reissued by Dover Publications, 1964.

Farrell, J. Senior Policy Seminars: An Evaluation of Two Examples. Unpublished manuscript, Washington, D.C.: Economic Development Institute of the World Bank, 1986.

Fox, S. S., and O'Brien, J. C. Duplication of evoked potential waveform by curve of probability of firing of a single cell. Science, 1965, 147, 888-890.

Garrity, L.I. An electromyographical study of subvocal speech and recall in preschool children. Developmental Psychology, 1975, 11, 274-281.

Gay, J., and Cole, M. The New Mathematics and an Old Culture. New York: Holt, Rinehart, and Winston, 1967.

Gladwin, T. East is a Big Bird. Navigation and Logic on Puluwat Atoll. Cambridge: Harvard University Press, 1970.

Glynn, S. M. A contextual view of adult learning and memory. Paper presented at the American Psychological Association Meeting, Montreal, Quebec, 1980.

Gorham, J. Differences between teaching adults and pre-adults: A closer look. Adult Education Quarterly, 1985, 4, 194-209.

Guilford, J. P. General Psychology. New York: Van Nostrand, 1939.

Halff, H. M., Hollan, J.D., and Hutchins, E. L. Cognitive science and military training. American Psychologist, 1986, 41, 1131-1139.

Harris, R. J. The use of student journals in teaching psychology, 1982 (ERIC Document Reproduction Service No. ED 206 223.)

Hartley J., and Davies, I. K Preinstructional strategies: The role of pretests, behavioral objectives, overview, and advance organizers. Review of Educational Research, 1976, 46, 239-266.

Heerman, B. Personal computers and the adult learner. In B. Heerman, ed. New Directions for Continuing Education, No. 28. San Francisco: Josey-Bass, 1986.

Heyneman, S. P., and Etienne, B. Higher Education in Developing Countries: What, How, and When. Washington, D.C.: Economic Development Institute of the World Bank, 1988.

Horn, G. Memory, Imprinting, and the Brain. Oxford: Clarendon Press, 1985.

Houle, C. O. The Design of Education. San Francisco: Josey-Bass, 1972.

Howe, M. J. A. Using students' notes to examine the role of the individual learner in acquiring meaningful subject matter. Journal of Educational Research, $1970,64,61-63$.

James, W. B., and Galbraith, M. W. Perceptual learning styles: Implications and techniques for the practitioner. Lifelong Learning, 1985, 4, 20-23.

Janis, I. L., and Mann, I. Decision-Making. New York: Free Press, 1977.

Johnson, S. E. Faculty perspectives on outreach teaching. Lifelong Learning, 1985, 9, 11-27. 
Kahneman, D., and Tversky, A. The simulation heuristic. In Kahneman, D., Slovic, P., and Tversky, A. eds. Judgment Under Uncertainty: Heuristics and Biases. Cambridge, U.K.: Cambridge University Press, 1982.

Kasamatsu, A., and Hirai, T. An electroencephalographic study on the Zen Meditation (Zazen). Folio, Psychiatria and Neurologia Japonica, 1966, 20, 315-316.

Kaye, L. W., Stuen, C., and Monk, A. The learning and retention of teaching skills by older adults: A time series analysis. Educational Gerontology, $1985,11,113-125$.

Kelly, D. Adult Learners: Implications for Faculty. Graduate seminar paper, Claremont Graduate School, 1986 (ERIC Document Reproduction Service No. ED 277 442).

Klausmeier, H. J., Jeter, J. T., Quilling, M. R., Frayer, D. A., and Allen, P. S. Individually Gained Motivation. Madison, Wis.: Research and Development Center for Cognitive Learning, 1975.

Klein, R., and Lasky, R. Early determinants of human development: Nutritional factors. Paper presented at the Annual Meeting of the American Association for the Advancement of Science, Washington, D.C.: 1982.

Knight, K. E. Effect of effort on behavioral rigidity in a Luchins Water Jar task. Journal of Abnormal and Social Psychology, 1963, 66, 190-192.

Knowles, M. S. The Adult Learner: A Neglected Species. Houston: Gulf Company, 1973.

- Adult learning theory and practice. In L. Nadler, ed. Handbook of Human Resource Development. New York: John Wiley, 1984.

Kolb, J. Learning Style Inventory Technical Manual. Boston: McBer and Co., 1976.

Krech, D., Crutchfield, R.S., Livson, N., Wilson, W.R., and Parducci, A. Elements of Psychology, 4th ed. New York: Alfred Knopf, 1982.

Laboratory of Comparative Hurnan Cognition. Contribution of cross-cultural research to educational science. American Psychologist, 1986, 41, 1049-1058.

Lachman, J. L., Lachman, R., and Thronesbery, C. Metamemory through the adult life span. Developmental Psychology, 1979, 15, 543-551.

Lashley, K.S. Brain Mechanisms and Intelligence: A Quantitative Study of Injuries to the Brain. Chicago: University of Chicago Press, 1929.

Latané, B., and Nida, S. Ten years of research on group size and helping. Psychological Bulletin, 1981, 89, 308-334.

Latané, B., Williams, K. D., and Harkins, S. G. Many hands make light the work? The causes and consequences of social loafing. Journal of Personality and Social Psychology, 1979, 37, 822-832.

Lawton, J. T., and Wanska, S. K. Advance organizers as a teaching strategy: A reply to Barnes and Lawson. Review of Educational Research, 1977, 47, 233244.

Leahey, T. H., and Harris, R. J. Human Learning. Englewood Cliffs, N.J.: Prentice-Hall, 1985.

Licht, B. G., and Dweck, C. S. Determinants of achievement orientations: The interaction of children's achievement orientations with skill area. Developmental Psychology, 1984, 20, 628-636.

Loftus, E. F. Eyewitness Testimony. Cambridge: Harvard University Press, 1979.

Margolis, F. H., and Bell, C. R. Managing the Learning Process, Minneapolis, Minn.: Lakewood Publications, 1984. 
Mayer, R. E. Can advance organizers influence meaningful learning? Review of Educational Research, 1979, 49, 371-383.

Mishkin, M. A memory system in the monkey. Philosophical Transactions of the Royal Society of London, Series B, 1982, 298, 85-95.

- Memory in monkeys severely impaired by combined but not separate removal of amygdala and hippocampus. Nature, 1978, 273, 297-298.

Morris, C. D., Bransford, J. D., and Franks, J. L. Levels of processing versus transfer appropriate processing. Journal of Verbal Learning and Verbal Behavior, 1977, 16, 519-533.

Morton, J. The logogen model and orthographic structure. In U. Frith, ed. Cognitive Processes in Spelling. London: Academic Press, 1980.

Newell, A., and Simon, H. Human Problem Solving. Englewood Cliffs, N. J.: Prentice-Hall, 1972.

O'Neil, H.F., and Spielberger, C.D., eds. Cognitive and Affective Learning Strategies. New York: Academic Press, 1979.

Owens, R. D. Effects of age, education, and attitudes on learning by older adults from a documentary program. Journal of Educational Television 1987, 13, 95-113.

Paivio, A. Imagery and Verbal Processes. New York: Holt, Rinehart, and Winston, 1971.

Pearson, D., and Shaw, S. Life Extension. New York: Warner Bros., 1982.

Peper, R. J., and Mayer, R. E. Note taking as a generative activity. Journal of Educational Psychology, 1978, 70, 514-522.

Perfetto, G. A., Bransford, J. D., and Franks, J. J. Constraints on access in a problem solving context. Memory and Cognition, 1983, 11, 24-31.

Petty, R. E., and Brock, T. C. Thought disruption and persuasion: Assessing the validity of attitude change experiments. In R. E. Petty, T. M. Ostrom, and T. C. Brock, eds. Cognitive Responses in Persuasion. Hillsdale, N. J.: Lawrence Erlbaum Associates, 1981.

Petty, R. E., Ostrom, T. M., and Brock, T. C. Historic foundations of the cognitive response. Approach to attitudes and persuasion. In R. E. Petty, T. M. Ostrom, and T. C. Brock eds. Cognitive Responses in Persuasion. Hillsdale, N. J.: Lawrence Erlbaum Associates, 1981.

Picton, T.W., Stuss, D.T., Marshall, K.C. Attention and the brain. In S.L. Friedman, K. A. Klivington, and R. W. Peterson eds. The Brain, Cognition, and Education. New York: Academic Press, 1986.

Posner, M.I. and Friedrich, F.J. Attention and the control of cognition. In S.L. Friedman, K. A. Klivington, and R. W. Peterson, eds. The Brain, Cognition, and Education. New York: Academic Press, 1986.

Pressley, M., Snyder, B. L., Cariglia-Bull, T. How can good strategy use be taught to children? In S.M. Cormier, and J.D. Hagman, eds. Transfer of Learning: Contemporary Research and Applications. New York: Academic Press, 1987.

Quinton, E. E. and Kramarcy, R. N. Memory impairment correlated clearly with cycloheximide dose and degree of inhibition of protein synthesis. Brain Research, 1977, 278, 184-190.

Reynolds, A. G., and Flagg, P. W. Cognitive Psychology 2d ed. Boston: Little, Brown, and Co., 1983.

Rips, L. J., Shoben, K. J., and Smith, E. E. Semantic distance and the verification of semantic relations. Journal of Verbal Learning and Verbal Behavior, $1973,12,1-20$. 
Robinson, J., and Saberton, S. Learning Partnerships: Interdependent Learning in Adult Education. Toronto: Ontario Institute for Studies in Education, 1985 (ERIC Document Reproduction Service No. ED 259 170).

Rogers, T. B. Client-Centered Therapy. Boston: Houghton-Mifflin, 1951.

Rogers, T. B., Kulper, N. A., and Kirker, W. S. Self-reference and the encoding of personal information. Journal of Personality and Social Psychology, 1977, $35,677-688$.

Rohwer, W. D., Jr., and Thomas, J. W. The role of mnemonic strategies in study effectiveness. In M. A. IMcDaniel and M. Pressley, eds. Imagery and Related Mnemonic Processes: Theories and Applications. New York: Springer-Verlag, 1986.

Rokeach, M. Beliefs, Attitudes, and Values. San Francisco: Josey-Bass, 1968.

Rosch, E. Principles of categorization. In E. Rosch and B. Lloyd, eds. Cognition and Categorization. Hillsdale, N. J.: Earlbaum and Associates, 1978.

Rosenzweig, M. R. Multiple models of memory. In S.L. Friedman, K. A. Klivington, and R. W. Peterson, eds. The Brain, Cognition, and Education. New York: Academic Press, 1986.

- Evidence for anatomical and chemical chains in the brain during primary learning. In K. H. Pribram, and D. E. Broadbent, eds. Biology of Memory. New York: Academic Press, 1970.

Rumelhart, D. E. Schemata: The building blocks of human cognition. In R. Spiro, B. C. Bruce, and W. F. Brewer eds. Theoretical Issues in Reading Comprehension. Hillsdale, N.J.: Lawrence Erlbaum, 1980.

Sataka, R. T. Adult Education Theory and Practice. Outreach Series Paper no. 2. Chapel Hill: University of North Carolina, 1984 (ERIC Document Reproduction Service No. ED 254633 ).

Schaie, K. W. and Gribbin, K. Adult development and aging. Annual Review of Psychology, 1975, 26, 65-96.

Schoffield, A. Simulations in Management Training: A Review. (A. Dowsett, ed.), Washington, D.C.: Education and Training Design Division, Economic Development Institute of the World Bank, 1986.

Shashua, V. E. Brain metabolism and the acquisition of new behaviors, III. Evidence for secretion of two proteins into the brain extracellular fluid after training. Brain Research, 1979, 278, 349-358.

Sheckley, B. G. Microcomputers and adult learning: Maximizing potentials. In B. Heerman, ed. New Directions for Continuing Education, No.29. San Francisco: Josey-Bass, 1986.

Simon, H. The role of attention in cognition. In S.L. Friedman, K. A. Klivington, and R. W. Peterson, eds. The Brain, Cognition, and Education. New York: Academic Press, 1986.

Slaughnessy, M. F., and Reif, L. An investigation of differential encoding and retrieval in older adult college students. Paper presented at the Rocky Mountain Psychological Association Conference, Las Vegas, Nevada, 1985 (ERIC Document Reproduction Service No. ED 255 692).

Slavin R.E. Educational Psychology. Englewood Cliffs, N.J.: Prentice-Hall, 1986.

Smith, R. E., Sarason, I. G., and Sarason B. R. Psychology: The Frontiers of Behavior. 2d ed. Cambridge, Mass.: Harper and Row, 1982.

Snow, R.E. Individual differences and the design of educational programs. American Psychologist, 1986, 41, 1029-39.

Solso, R.L. Cognitive Psychology 2d ed. Boston: Allyn and Bacon, 1988. 
Sperling, G. The information available in brief visual presentations. Psychological Monographs, 1960, 74, (whole no. 11).

Squire, L. Memory and the brain. In S.L. Friedman, K. A. Klivington, and R. W. Peterson eds. The Brain, Cognition, and Education. New York: Academic Press, 1986.

Srinivasan, L. Perspectives on Nonformal Adult Learning. New York: World Education, 1977.

Stein, B.S. Depth of processing reexamined: The effects of the precision of encoding and test appropriateness. Journal of Verbal Learning and Verbal Behavior, $1978,17,165-174$.

Stice, C. A., and Alvarez, M. Hierarchical Concept Mapping: Young Children Learning How to Learn (A Viable Heuristic for the Primary Grades). Center of Excellence and Basic Skills for the Disadvantaged, ReadingWriting Component Report No. 5, 1986 (ERIC Document Reproduction Service No. ED 274 948).

Sulin, R. A., and Dooling, J. D. Intrusions of a thematic idea in retention of prose. Journal of Experimental Psychology, 1974, 103, 255-262.

Thomas, J. W., and Rohwer, W. D., Jr. Academic studying. The role of learning strategies. Educational Psychology, 1986, 21, 19-41.

Thompson, R. Introduction to Physiological Psychology. New York: Harper and Row, 1975.

Thorndike, E. L., and Woodworth, R. S. The influence of improvement in one mental function upon the efficiency of other functions. Psychological Review, 1901, 8, 247-261.

Tough, A. The Adult's Learning Projects. Toronto: Ontario Institute for Studies in Education, 1971.

Treisman, A. M. Selective attention in man. British Medical Bulletin, 1964, 20, $12-16$.

Tulving, E. Episodic and semantic memory. In E. Tulving and W. Donaldson, eds. Organization of Memory. New York: Academic Press, 1972.

Tversky, A., and Kahneman, D. Judgment under uncertainty. Heuristics and biases. Science, 1974, 185, 1124-1131.

Ward 1982. Adult Education theory and practice. See Sataka 1984.

Williams, C. W. Designing learning activities for adults: A practical approach. Community Services Catalyst, 1984, 14, 8-12.

Wilson, E. O. Visual system: pulvinar-extrastriate cortex. In R. B. Masterton, ed. Handbook of Behavioral Neurobiology. Vol 1. Sensory Integration. New York: Plenum Press, 1978.

Wingfield, A., and Byrnes, D. The Psychology of Human Memory. New York: Academic Press, 1981.

Witkin, H. A., and Goodenough, D. R. Field dependence and interpersonal behavior. Psychological Bulletin, 1977, 84, 661-684.

Wollen, K. A., Weber, A., and Lowry, D. H. Bizarreness versus interaction of mental images as determinants of learning. Cognitive Psychology, 1972, 3, 518-523.

Youker, R., and Dowsett, A. Readings for Training Trainers. Washington, D.C.: Economic Development Institute of the World Bank, 1983.

Zemke, R. and Zemke, S. 30 things we know for sure about adult learning. Innovation Abstracts, 1984, 6, n. 8 (ERIC Document Reproduction Service No. ED 248 920). 




\section{The World Bank}

EDI Seminar Papers are designed for use in EDI courses and seminars. They discuss issues in economic development policy and lessons from experience in a way that can be understood by persons lacking extensive background knowledge or technical expertise. They will be of particular interest to readers concerned with public affairs.

\section{World Bank Publications of Related Interest}

Pathways to Change: Improving the Quality of Education in Developing Countries.

Adriaan Verspoor. World Bank Discussion Paper 53.

Textbooks in the Developing World: Economic and Educational Choices. Joseph P. Farrell and Stephen P. Heyneman, editors. EDI Seminar Series.

Education in Sub-Saharan Africa: Policies for Adjustment, Revitalization, and Expansion.

A World Bank Policy Study. In English and French.

Educating Managers for Business and Government: A Review of International Experience.

Samuel Paul, John C. Ickis, and Jacob Levitsky. World Bank Discussion Paper 54.

Education for Development: An Analysis of Investment Choices.

George Psacharopoulos and Maureen Woodhall. Oxford University Press. In English, French, and Spanish.

Training for Public Administration and Management in Developing Countries: A Review.

Samuel Paul. World Bank Staff Working Paper 584.

Education and Its Relation to Economic Growth, Poverty, and Income

Distribution: Past Evidence and Further Analysis.

Jandhyala B. G. Tilak. World Bank Discussion Paper 46. 